\title{
DIFFERENTIAL DIAGNOSIS BETWEEN CONSTITUTIONAL DELAY OF GROWTH AND PUBERTY, IDIOPATHIC GROWTH HORMONE DEFICIENCY AND CONGENITAL HYPOGONADOTROPIC HYPOGONADISM: A CLINICAL CHALLENGE FOR THE PEDIATRIC ENDOCRINOLOGIST
}

Journal: Minerva Endocrinologica

Paper code: Minerva Endocrinol-3228

Submission date: April 29, 2020

Article type: Review Article

Files:

1. Reply letter to comments on the manuscript Version: 2

Description: Letters to the reviewers and final version of the paper after minor modifications with highlighted corrections

File format: application/vnd.openxmlformats-officedocument.wordprocessingml.document

2. Manuscript

Version: 4

Description: Orginal article_Galazzi\&Persani after minor revisions without corrections

File format: application/vnd.openxmlformats-officedocument.wordprocessingml.document

3. Figures 1

Version: 3

Description: Figure 1 after minor revisions

File format: image/jpeg

4. Figures 2

Version: 1

Description: Figure 2.

File format: image/jpeg

5. Figures 3

Version: 1

Description: Figure 3

File format: image/jpeg 
Minerva Endocrinologica

EDIZIONI MINERVA MEDICA 
Replay to the reviewers and the Editors

Dear Editor of Minerva Endocrinologica and dear Reviewers, thank you for accepting our paper "DIFFERENTIAL DIAGNOSIS BETWEEN CONSTITUTIONAL DELAY OF GROWTH AND PUBERTY, IDIOPATHIC GROWTH HORMONE DEFICIENCY AND CONGENITAL HYPOGONADOTROPIC HYPOGONADISM: A CLINICAL CHALLENGE FOR THE PEDIATRIC ENDOCRINOLOGIST", code number 3228.

We had performed minor modifications to the paper according to your suggestions, that we are explaining here below, point by point, in red line:

\section{Comment 1}

General comment (originality, scientific accuracy, strengths andi/or weaknesses)

The present review by Galazzi and Persanil is a very well written revision of the current literature about the challenging topic of differentiai diagnosis between $\mathrm{cHH}, \mathrm{CDGP}$ and IGHD, especially in the peri-pubertal period.

\section{Major corrections (main criticisms)}

I have no major corrections

Minor corrections (page, paragraph, line where the author must make the corrections)

I have only the foliowing suggestions.

1. CDGP Endoerine workur, parg 9 line 4: priming is still a controversial issue; I would rather menition not oniy the Guidelines of 2016 but also the statements absut sex priming found in the last ones by Collet-Solberg et al. $\rightarrow$ We had added the citation accordingly, thank you

2. CDGP Genetic tests, pag 13, line 1: authors should better specify what they mean with "shared causes with GHD". A possible role of GHSR mutation has been reported (Pugliese-Pires PN et al. Eur J Endocrinol. 2011. See also a recent report by the group of Latronico AC in Neuroendocrinology 2019). $\rightarrow$ We had specified the phenotype of POU1F1 mutation and added the GHSR mutation in the text and in Figure 1 as well, together with the reference of the paper by Pugliese-Pires PN et al, thank you for these suggestions.

3. CDGP Final outcomes and therapeutic options, pag 14, line 9: a recent report by Chioma and coll suggests also the use of testosterone gel in CDGP patients (Chioma $L$ et al. Use of testosterone gel compared to intramuscular formulation for puberty induction in males with constitutional delay of growth and puberty: a preliminary study. J Endocrinol Invest. 2018). $\rightarrow$ We have added the reference 
by Chioma et al, thank you

4. IGHD Endocrine Workup, pag 16: does it seem that sex steroid priming can be more useful in some tests than others (arginine vs glucagon)? $\rightarrow$ Very few papers are actually available in literature exploring the use of a primed vs unprimed growth hormone stimulation tests, especially in the form of randomized controlled trials. The utility of priming before arginine test has been associated with conflicting results in GHD (GH peaks seems to increase in the paper by Molina S, Paoli M, Camacho N, Arata-Bellabarba G, Lanes R. "Is Testosterone and Estrogen Priming Prior to Clonidine Useful in the Evaluation of the Growth Hormone Status of Short Peripubertal Children? "-J Pediatr EndockinolMetab. 2008 J;21(3) 257-66, but not in the paper written by Martínez AS, Domené HM, Ropelato MG, Jasper HG, Pennisi PA, Escobar ME, et al. "Estrogen Priming Effect on Growth Hormone (GH) Provocative Test: A Usefut Tool tor the Diagnosis of GH Deficiency." J Clin Endocrinol Metab. 2000;85(11):4168-72). Indeed, to our knowledge, there are no papers investigating the benefits of primed vs unprimed glucagone tests.

5. IGHD Endocrine Workup, pag 17, line 4: the latest Guidelines by CollettSolberg et al report: "the majority of delegates suggested that the threshold be revised to $7 \mathrm{ng} / \mathrm{mL}$ " though the previous cut-off (already ai $10 \mathrm{mcg} / \mathrm{dL}$ ) has not been revised yet. Also in Italy, it seems thai the cut-cfi of $8 \mathrm{mcg} / \mathrm{dL}$ will be confirmed in the forthcoming revision of nota AIFA. 39. $\rightarrow$ I had added your sentence with these specifications, thank you

6. IGHD Endocrine workup, pag 17, line 21: "abnormal auxological clinical examination", please explain better--> I had better defined the auxological features warrenting endocrine workup for evalutation of $\mathrm{GH}$ reserve, thank you.

Commento ?

General comment (originality, scientific accuracy, strengths and/or weaknesses)

Overall, the authors have complied a very much needed narrative review of the evidence related to constitutional delay of growth and puberty (CDGP), partial growth hormone deficiency ( $\mathrm{GHH}$ ), and congenital hypogonadotropic hypogonadism $(\mathrm{cHH})$. They have clearly organised the evidence and provided clear figures. My only hesitation is regarding the study design. In fact, it is a narrative review - although the author refers to it as a 'Personal revision'. I would recommend that it be re-positioned as a narrative review.

\section{Major corrections (main criticisms)}

This manuscript is a narrative review of the literature on constitutional delay of growth and puberty (CDGP), partial growth hormone deficiency (pGHD), and 
congenital hypogonadotropic hypogonadism (cHH). It may also be important to know some of the historical debates in this area. Also what are the consequences of incorrect diagnosis.

$\rightarrow$ We had modified the paper as a narrative review, thank you. We had also added a short introductive chapter at the end of the introduction, explaining the increasing interest in the topic over years as well as the consequences of a failed diagnosis of $\mathrm{GHD}$ or $\mathrm{cHH}$.

\section{Minor corrections (page, paragraph, line where the author must make the corrections)}

Page 2 line 9. the abbreviation capitolization is incorrect. $\mathrm{CH} H \mathrm{H}$ should be $\mathrm{cHH}$

$\rightarrow$ Modified accordingly, sorry about that.

Page 15 line 12. The statement regarding the prevalence of GHD is inaccurate. It is estimated at approximately 1:4,000 to $1: 10,000$. Please provide more detail to the geographical differences in the worldi.

$\rightarrow$ We had modified the prevalence of GHB for tertiary centers, and we also had added a wider estimation of the prevalence around the world, which seems very much influenced by diagnostic criterias

Page 22 line 25. prevalence of $\mathrm{CH}$ iH. again please provide more more detail to the geographical differences in the world

$\rightarrow$ We have added a wider estimation of the prevalence around the world, which seems very much influenced by referrat bias. Thank you for the suggestion.

\section{Scheda di revisione editoviale}

\section{Bibliografia.}

Flease, modify References following these examples:

JOURNALS:

Liu H, Li J, Du L, Yang M, Yang D, Li J, et al. Short-term effects of core stability training on the balance and ambulation function of individuals with chronic spinal cord injury: a pilot randomized controlled trial. Minerva Med 2019;110:216-23.

\section{HOMEPAGE:}

AMA: helping doctors help patients. Chicago: American Medical Association; (C1995-2007 [Internet]. Available from: http://www.ama-assn.org/ [cited 2007, Feb 22].

You have mixed both styles, so please adjust References. 
$\rightarrow$ Done, thank you. Sorry about that.

Tabelle:

Please, add references in the tables. $\rightarrow$ Done, thank you.

\section{Figure:}

Please, mention Figure 3 in the text. $\rightarrow$ We had mentioned Figure 3 in the evidence synthesis, thank you. 
DIFFERENTIAL DIAGNOSIS BETWEEN CONSTITUTIONAL DELAY OF GROWTH AND PUBERTY, IDIOPATHIC GROWTH HORMONE DEFICIENCY AND CONGENITAL HYPOGONADOTROPIC HYPOGONADISM: A CLINICAL CHALLENGE FOR THE PEDIATRIC ENDOCRINOLOGIST.

Elena GALAZZI ${ }^{1}$ *, Luca G. PERSANI ${ }^{1,2}$

${ }^{1}$ Department of Endocrine and Metabolic Diseases, Istituto Auxologico Italiano IRCCS, 20149 Milan, Italy; ${ }^{2}$ Department of Clinical Sciences and Community Health, Dniversity of Milan, 20122 Milan, Italy.

*Corresponding author: Elena Galazzi, Department of Endocrine and Metabolic Diseases, Istitutô Auxologico Ialliano, 20149 Milan, Italy; E-mail: e.galazzi@auxologico.it 


\section{ABSTRACT}

INTRODUCTION: Differential diagnosis between constitutional delay of growth and puberty (CDGP), partial growth hormone deficiency (pGHD), and congenital hypogonadotropic hypogonadism (EHH $\mathrm{cHH})$ may be difficult. All these conditions usually present with poor growth in pre- or peri-pubertal age and they may recur within one familial setting, constituting a highly variable, but somehow common, spectrum of pubertal delay.

EVIDENCE ACQUISITION: Personal-Narrative review of the most relevant English papers published between 1981 and march 2020 using the following search terms "constitutional delay of growth and puberty", “central hypogonadism”, "priming”, "grovth hormone deffciency”, "pituitary”, “pituitary Magnetic Resonance Imaging”, with a special regard to the latesfogeientific acquisitions.

EVIDENCE SYNTHESIS: CDGP is by far the most prevalent enitity in boys and recurs within families. pGHD is a rare, often idiopathic and transient condition, where hypostaturism presents more severely. Specificity of pGHD diagnosis is increased by priming children before growth hormone stimulation test (GHST); pituitary MRI and geneticanalysis are recommended to personalize future follow-up. Diagnosing chitrmay be obvious, when anosmia and eunuchoid proportions concomitate. However, cHH can either overlap withpe $\mathrm{HD}$ in forms of multiple pituitary hormone deficiencies (MPHD) or syndromic cønditions either with CDGP in family pedigrees, so endocrine workup and genetic investigations are necessary. The use of growth charts, bone age, predictors of adult height, primed GHST and low dose sex steroids (LDSS) treatment are recommended.

CONCLUSIONS: Only a step-by-step diagnostic process based on appropriate endocrine and genetic markers together with LDSS treatment can help achieving the correct diagnosis and optimizing outcomes.

\section{Key words:}

puberty, short stature, central hypogonadism, growth retardation, pituitary 


\section{TEXT}

Growth hormone $(\mathrm{GH})$ is the most abundant hormone in the adult pituitary gland. Somatotrophs, located predominantly in the lateral wings of the anterior pituitary, represent the most abundant cell population in the pituitary (35-45\% of total). GH action is crucial in mediating growth and metabolic functions in human tissues and, for this reason, is finely regulated. Neuropeptides, neurotransmitters and opiates impinge on the hypothalamus modulating the release of either GHRH, which induces GH gene transcription and hormone release, or somatostatin (also called sontatotropin release-inhibiting factor, SRIF), which suppresses both basal and GHRH-stimulated GH pulse amplitude and frequency. Stimulating effects have been described from $\alpha$-adrenergic pathway (morepinephrine, insuline induced hypoglicemia, clonidine, arginine, and Ldopa, apomorphine), endorphins/enkephalins (released after physical stress and extreme excercise), from slow-wave sleep, orexigenic hormones (ghrelin and synthetic hexapeptides through-growth hormone secretagogue receptor), cholinergic and serotoninergic neurons, gut neuropeptides (neurotensin. VIP, motilin, cholecystokinin, glucagone), acute glucocorticoid administration and sex steroids. Inhibiting effects have instead been described from $\beta$-adrenergic pathway, anorexigenighormones (leptine), high circulating fat free acids levels, acute hyperglysemia, hypothyroidism, chronic glicocorticoid exposure, and IGF-1, this last one as part of the hypoynalanic-pituitary peripheral regulatory feedback system. The integrated interactions between these influences elicit the classical episodic GH peaks right inside a specific 24-h circadian rythm. (1)

Gonadotropins (LH and FSH) comprise only 10-15\% of the anterior pituitary cell population but their role is crucial for gonadal stimulation and reproduction. Hypothalamic GnRH pulse amplitude and frequency determines the physiologic pattern of LH and FSH secretion. Kisspeptin neurons undergo a dynamic process of prenatal-postnatal maturation that enables them to establish connections to GnRH neurons early in development. KNDy neurons located in the arcuate nucleus of the hypothalamus and co-expressing Kisspeptin, neurokinin B and dynorphin represent the GnRH pulse 
generator in both sexes, which then in turn stimulate gonadotroph cells in the pituitary, triggering puberty induction and progression. After a first period of action in utero and in the first months of life (the so-called mini-puberty), this axis is switched off during childhood and reawakens itself in the peripubertal period. Many neurotrasmitters from the limbic system, the brain stem and from other hypothalamic nuclei stimulate (glutammate, norepinephrine, kisspeptin) or inhibit (GABA, endogenous opioid, dynorphin) the hypothalamus-pituitary-gonadal (HPG) axis. Other influences may derive from glial cells, periferic steroids milieu and gonadic peripheric production of activin/inhibin. Leptin, a product of peripheral adipose tissue, is also a positive regulator of the hypothalamic-pituitary-gonadal axis, signaling energy availabiiity to the central nervous system. (2) (3)

Gonadal steroids then reciprocally have a wide influence on GAS secretion and action. Testosterone stimulates central GH secretion mainly through its aromatization to estrogen: in fact, anti-estrogen tamoxifen is able to significanty reduce in norma, and in hypogonadal men on testosterone replacement therapy, the 24-h mean serum GHconcentrations, the mean GH pulse amplitudes, and the serum IGF-1 levels. (4) As further proof, the administration of a non-aromatizable androgen (dihydrotestosterone) is ngtable to elicit GH secretion. (5) Testosterone additionally acts peripherally, amplifying GH-mediated secretion of IGF-1, sodium retention, substrate metabolism and protein anabolism. Exogenous estrogens are instead able to stimulate GH secretion when given orally, due to their first-pass hepathic inibition of IGF-1 production. This effect can be avoided using transdermal routes, at least if physiological doses of estrogens are given. (6)

Instead it is still unresolved whether, in females pituitaries, estrogens have a central direct stimulatory role on somatotrophs, since stimulated $\mathrm{GH}$ secretion proved to be similar between women with premature ovarian failure (either assuming or not hormonal replacement therapy) and aged-matched controls with normal ovarian cycles. (7) 
Animal models studies proved the importance of the sex steroids impingement on fetal pituitary somato-mammotrophs cells store, which will subsequently determine the GH reserve in childhood and adulthood. (8) (9) Similarly, human studies have also demonstrated that, physiologically, during puberty the activation of the hypothalamic-pituitary-gonadal axis leads to a large increase in the circulating sex steroids concentration, which then enhance the pulse amplitude of $\mathrm{GH}$ secretion, increase IGF-I concentrations and the anterior pituitary size. (5) (10)

Many association studies in normal children have also proved a physiological threefold increase in GH secretion following the increase in gonadal steroid concentrations during puberty. (11)

GH secretion has also proved to be reduced in hypogonadal children (12) bat increased in precocious puberty, whose successful therapy is able to normalize GH secretion. (13)

Because of these multiple interconnections between $\mathrm{GH}$-and HPG axis, itis not infrequent that a child in peripubertal age may present to a pediatric endocrinologist with shert stature and/or reduced growth velocity with associated delayed puberty. [Table I]. For the same reasons, subnormal GH peaks to physiological or pharmacological stimuli are frequenty found in normal prepubertal children, but they have proven to fully normalize when theswili achieve stages 4 or 5 of Tanner maturation or after estrogen administration. (14)

While constitutional deiay of growih and puberty (CDGP) may be the most probable diagnosis in a child presenting with short stature and pubertal delay, especially for males, growth hormone deficiency and congenital hypogonadotropic hypogonadism must at the same time be ruled out. Otherwise, in children with true GHD or $\mathrm{cHH}$ left untreated, adult height and pubertal maturation will lack to fully develop normally, resulting in important psycho-social discomfort as well as long term medical sequelae in these children (permanent short stature in GHD, cryptorchidism and risk of testicular cancers/lack of fertility in $\mathrm{cHH}$, osteoporosis and alteration of body composition in both conditions). As growth is a good indicator of a child's health, the increasing attention on children wellness and well-being especially in the more developed countries has been a matter of medical 
Page 10 of 120

1 attention over years. Moreover, as the child grows into adulthood, fertility potential becomes an

2

3 4

5

6

7

8

9

10

11

12

13

14

15

16

17

18

19

20

21

22

23

24

25

26

27

28

29

30

31

32

33

34

35

36

37

38

39

40

41

42

43

44

45

46

47

48

49

50

51

52

53

54

55 important issue, which is also a major concern for parents. 


\section{EVIDENCE ACQUISITION}

\section{Constitutional delay of growth and puberty (CDGP)}

\section{A Definition}

The term CDGP describes children who have a normal variant of maturation tempo characterized by short stature with relatively normal growth rate during infanicy, but showing deceleration during peribubertal period possibly due to to the lack of growth spurt physiologicalin driven by the sex hormones rise. According to the pubertal status, 3 different "categories? of CDGP children may be defined:

- CDGP type 1: Prepubertal children (Tanner stage of for boys $\geq 14$ yo or B1 for girls $\geq 13$ yo), as reported by the $200 \%$ ESPE classification. (15) usually associated by slow growth rate, delayed bone age (delay of 1 year or more compared to chronological age) and a positive family history of delayed puberty

- CDGP type 2: Pubertal chiduren but displaying slow or stuttering progression of sexual caracteristics, with a genital Tanner stage less than - 2 SDS compared to normal age-matched peers, defined by the use of puberty nomograms (16)

- Possible CDGP type 3, according to Stalman et al: if before 14 (for boys) or 13 (for girls) years old if, during his/her growth, three out of four conditions are met: i) Tanner stage $<-1$ SDS defined with the use of puberty nomograms; ii) bone age delay $>1$ year compared to chronological age; iii) being short for target height (TH); and iv) positive family history of pubertal delay (menarche in the mother > 15 yo; late paternal growth spurt and shaving). (17)

\section{B Prevalence}


CDGP is a relative common condition, affecting $2-2.5 \%$ of the population. (18) This alteration is extremely common in boys, and less in girls. It is estimated that up to $80 \%$ of boys and around $33 \%$ of girls displaying delayed puberty have a self-limited condition. (19) However, prevalence in CDGP females ranges widely : in a large Georgean cohort of female adolescents with delayed puberty, for example, the prevalence of CDGP in girls is accounted to be lower and around 10\%, against the great majority of the female cohort displaying organic diseases (premature ovarian failaretabsence of uterus or vagina). (20) Because in family series reports males and females are described to be equally affected (19), a gender selection bias seeking medical attention has been postulated. (21)

\section{C Clinical presentation}

Children displaying CDGP may frequentry seek for medical attention for short stature, which is usually not severe (>-2.5 SDS) and for reduced growth veloeity $(<-2$ SDS) together with a prepubertal stage of sex maturation. Although growth yelocity (sy) may be reduced compared to normal pubertal children, it is frequently found to be $>3.6 \mathrm{~cm} / \mathrm{year}$ in boys. On the other hand, GV seems not discriminative at best for different etiologies of delayed puberty in girls. (22)

Because CDGP patients are sometimes poor eaters (23) and need higher caloric intake compared to age-matched controls (24), BMI is often found to be at lower range, which is an important concern for parents and contributes possibly indipendently to the reduced growth. Of interest, nearly $25 \%$ of boys with CDGP come with the diagnosis of attention deficit with hyperactivity disorder (24). Even though adrenarche/pubarche derive from adrenal rather than HPG axis activation, delayed puberty in these patients consists of a delayed gonadarche together with absence of pubarche/adrenarche. (25)

Looking at growth charts may be useful. CDGP boys are born with normal length, have a decreased growth pattern compared to target percentile until 2 years old, then tend to level till 5 years old, 
Page 13 of 120

starting from when a height SDS loss is already detectable, reaching its maximum at pubertal age. (26)

For a complete auxological workup, a sistematic assessment of bone age is warrented, either using Greulich-Pyle or Tanner Whitehouse methods (referring to its second edition of 1983 TW2, or its third revised edition of 2001 TW3) or informatic programs that are rising into attention for the more accurate bone age assessment in non-american non-caucasian etnicities. (27) In CDGP subjects bone age is frequently found to be delayed by at least 2 years compared to chronological age, even though it can range from 1 to 3 years less, so that if we bring the child back on his biological age the growth percentile may be adequate for the family target. (28)

The prediction of adult height based on bone age (PAH $=$ predicted adult height) may also be very useful because it frequently suggest that a child with CDGP willay within the lower range of his/her target height (29). To this regard it is worth explaining that different methods for final height prediction based on bone age exist and according to the method used there may be some overestimations or undestimations of the predigted final height. (Table II) In the matter of question, the most used Bayley and Pinneaud system has been proved to overestimate boy's final height, raising doubts of the possibility of truly reîy on this method for adult height prediction. (29) For this reasons, new models of bøne age prediction in CDGP patients have been recently established. (30)

Clinical hystory and examination of the child should point out the so called "red flags" i.e. cues orienting the clinician towards specific diagnostic subgroups (Fig. 2). To this extent it is worth noticing that in CDGP patients cryptorchidism may be found in a low percentage of cases (2\%) mostly as a unilateral finding. (18) Up to $80 \%$ of children diagnosed as CDGPs have at least one family member in which self-limited delayed puberty has occured, which can be also taken as an important diagnostic tool; however, a family history of CDGP does not exclude cHH given the incomplete penetrance and variable expressivity of $\mathrm{cHH}$ phenotype within pedigrees (of which delayed puberty, 
subfertility and hypo-anosmia can also be enriched). (2) (3) A new observation of our group introduced into this complex clinical picture also TBX3 mutations accounting for Ulnar Mammary Syndrome (UMS), and several reports of UMS families describe the variable association of either CDGP, more frequently, either of true cHH defects and GHD, in a minority of cases (31). (Figure 2)

\section{D Endocrine workup and the role of sex steroid priming before growth hormone stimulation} tests

Priming refers to the administration of sex steroids to prepubertal or early puberal children prior to GHST. The evidence to support this practice is low, however suggested by the 2016 International Guidelines for growth hormone deficiency and idiopathic short statureAccording to these guidelines, priming is suggested for prepubertal boys older than 11 or prepubertal girls older than 10 years with adult height prognosis within -2 SD of the peference population mean in order to prevent unnecessary rhGH treatment of children with a more probable diagnosis of constitutional delay of growth and puberty. (32) (33)

The studies supporting this approach are however of limited evidence, considering the small group of patients of the studies analyzed, yet sometimes conflicting. Marin et al showed a 95\% rate of normalization in 11 normal children after administration of ethinylestradiol (EE) $40 \mu \mathrm{g} / \mathrm{m} 2$ in 3 divided doses with meals for 2 days and, compared to placebo, a rise in both GH peak from $7.6 \pm 4.4$ on placebo to $18.7 \pm 9.2 \mu \mathrm{g} / \mathrm{L}$ on $\mathrm{EE}$ and of the lower limit of the $95^{\circ}$ confidence interval from 1.7 to $7.2 \mu \mathrm{g} / \mathrm{L}$. (14) Martinez et al, similarly, showed in a randomized control study a significant increase in $\mathrm{GH}$ peaks under a sequential arginine-clonidine test when 44 short normal children were primed with estradiol valerate (E2) orally ( 1 or $2 \mathrm{mg}$ depending on the weight $<$ or $>$ of $20 \mathrm{~kg}$, respectively) in three consecutive days before testing, compared to placebo: in these children GH mean peak 
increased from $17.8 \pm 10.9$ on placebo to $27.9 \pm 14.5 \mu \mathrm{g} / \mathrm{L}$ on $\mathrm{E} 2$, increasing diagnostic accuracy of GHST form $90 \%$ to $95 \%$. (34) Analogously, Molina et al proved that 39 children primed with either $100 \mathrm{mg}$ i.m. of testosterone enanthate for 5-8 days (in boys) or with $1 \mathrm{mg}$ estradiol valerate daily for 3 days (in girls) were able to significantly increase GH mean peaks under clonidine stimulation test, either if diagnosed as CDGP (from $5.83 \pm 2.67$ to $17.42 \pm 8.46 \mathrm{ug} / \mathrm{l}$ ) or as GHD (from $3.68 \pm 2.34$ to $5.95 \pm 2.76 \mathrm{ug} / \mathrm{l}) .(35)$ Muller et al showed a normalization $(\mathrm{GH}$ peak $>10 \mathrm{ug} / \mathrm{l}$ ) after arginine test in $77 \%$ of 26 peripubertal boys primed with $100 \mathrm{mg}$ of testosterone enanthate $3-10$ days before the stimulation. (36) Taken together, these studies led to the suggestion that estrogen priming may reduce the number of false positive children (i.e. false non responders to a GHST) avoiding unnecessary rhGH treatment in a high proportion of children under assessment for short stature.

Other studies have however shown opposite results. Soliman et al proved that in children above 9 years of age under investigation for short stature with a clonidine stimulation test, the proportion of patients displaying GH peaks $>10 \mu \mathrm{g} / \mathrm{L}$ did not/differ between the primed group (pre-treated with 25 $\mathrm{mg}$ of intramuscular testosterone depot $7-10$ days before the test for boys or with $1,25 \mathrm{mg}$ of oral conjugated estrogens for 3 days before the test for girls) compared to the unprimed group (52\% vs 47\% respectively, N.S) (37) Most importantly, only one follow-up study on 50 boys was able to prove that avoiding treatment in children with subnormal unprimed but normal primed GH peaks under GHST does not result in an impaired final height compared to their midparental target (-1.27 vs -1.38 SDS, respectively). (38)

Larger follow-up studies considering both males and females and looking at final height of children undergoing primed GHST are lacking. However, taken together, these studies evoke the idea that priming before GHST may reduce the false positive diagnosis of growth hormone deficiency, avoiding unnecessary rhGH treatment in many children under investigation for short stature. It is however estimated that only $30-40 \%$ of pediatric endocrinologists prime peripubertal children prior to $\mathrm{GH}$ stimulation testing in routine clinical practice. The limited diagnostic application is justified 
Page 16 of 120

by some experts based on considerations of priming as an artificial stimulus generating false transient normal GH peaks under GHST. (39)

Beyond GHST, no endocrine marker can be fully reliable in the diagnosis of CDGP. Nevertheless, in males, measurable levels of Inhibin B (> $35 \mathrm{ng} / \mathrm{mL}$ ) have been proposed to fairly correlate with the maturation of Sertoli cells in the gonads, hence indirectly proving that, in the first menths of life, mini-puberty has occurred, pointing out a CDGP rather than $\mathrm{cHH}$ diagnosis. (40) $\mathrm{AMH}$ has also proved to be slightly higher in prepubertal CDGP compared to $\mathrm{cHH}$, however not discriminative for peripubertal CDGP (Tanner stage 2) where it is found to be lower, thus not giving advantages compared to inhibin B alone. (40) (41) In prepubertal CDGP the combination OPrnhibin B at a cutoff $\geq 28.5 \mathrm{ng} / \mathrm{L}$ with $\mathrm{AMH}$ at a cut-off of $\geq 20 \mathrm{ng} / \mathrm{mL}$ has however proved to increase the specificity of CDGP diagnosis up to 83\%. (41) Other markers of testicular (INSL3), and adrenal (DHEAS) activity have not proved to be discriminative for the differential diagnosis between CDGP and $\mathrm{cHH}$.

The restriction of most of the studies to the malecohorts does not allow to use these endocrine markers for girls. At the same time, in females Inhibin B levels are less useful as they are lower and a less significant rise is seen at puberty. (42)

Basal gonadotropin levels are not discriminative as they are supposed to be low either in prepubertal CDGP or in $\mathrm{CHH}$ cohorts. If in CDGP children puberty is in a very initial stage, basal gonadotropins levels may be found to be more than $0.2 \mathrm{UI} / \mathrm{L}$ in both genders with the use of immunochemiluminometric assays, which could be a simple and useful marker against a severe $\mathrm{cHH}$ form. (43) Moreover, HPG axis stimulation upon GnRH test or following a GnRH agonist (GnRHa) has also been proposed (22) (42) (43), however up to $30 \%$ of children diagnosed as either CDGP or cHH overlap their LH peaks under stimulation. (44) Despite some promises for longer GnRH test protocols (up to 36 hours), these tests have suggested to be helpful only in a few studies but without 
high diagnostic accuracy. Similarly, the use of GnRHa (Naferelin, Leuprolide, Triptorelin, Buserelin) has proved to elicit higher LH peaks but the low sample size of these studies, the presence of overlapping results with $\mathrm{cHH}$ cohorts and the absence of a clear diagnostic threshold limit their diagnostic utility. (44)

HCG test has also been postulated as a useful diagnostic tool for the differential diagnosis between CDGP and cHH (see below section 3.D). (45) (46).

Kisspeptine boluses have also proved to heterogeneously increase LHiesponses in CDGP patients (47) in research settings, but this approach is not yet routinely performed in clinical practice.

Another important tool that can be taken into account to differentiate CDGPfrom other cohorts is the evidence of a self progressing pubertal development after a 3-6 months treatment trial with low dose sex steroids (LDSS). (3) (48) After LDSS withdra wal, an Inhisin B > $94.7 \mathrm{ng} / \mathrm{mL}$ and LH peak after GnRHa > 14.7 U/L have been also provein to discriminate at best CDGP upon cHH. (49)

\section{E GENETIC TESTS}

Genetic basis of CDGP are supposed to be different from those of $\mathrm{cHH}$. Even though, heterozygous variants in cHH putative genes have been found in up to $7 \%$ of the CDGP cohorts (18), the current scientific literature tends to consider the hereditary basis of CDGP as a different, yet mainly still unknown, genetic field. Observational studies have demonstrated that several different inheritance patterns can occur in CDGP, including autosomal dominant pattern (in the majority of the cases, with or without complete penetrance), autosomal recessive, bilinear (both parents affected) or X-linked. De novo mutations can also occur. (19) 
Page 18 of 120

Four genes clusters have been demonstrated in CDGP cohorts by Howard et al. with exome sequencing in Finnish CDGP index patients: (3)

1) Fat Mass and Obesity-associated (FTO) gene (in three of 67 families)

2) Heparan Sulfate 6-O-Sulfotransferase 1 (HS6ST1) gene (in one in 67 families)

3) Enhanced At Puberty 1 (EAP1) gene (in two in 67 families)

4) IGSF10 rare sequence variants in up to $16.4 \%$ of the CDGP cohorts, a gene which encodes a protein that belongs to the immunoglobulin superfamily. However, the role of IGFS10 in delayed puberty remains open, as in a follow-up study, IGSF10 mutations were not reported to be enriched in CDGP patients when compared to controls.

Mutations in the pituitary trascription factor POLF1 (PIT1) involved in pituitary thyrotrophs and lacto-somatotrophs cells development and hormonal expression may present with pubrrtal delay or with absent or delayed adrenarche, resembling delayed puberty (50). Mutations in GHSR, a growth hormone secretagogue receptor gene whose endogenous ligand ghrelin produced from gastric cells increases GH pituitary secretion, have been found to be mutated in both GHD and CDGP patients.

Some known syndromic conditions may present with either CDGP, GHD or cHH within family pedigrees (Prader Willy Syndrome or CHARGE syndrome). Moreover, as already mentioned, TBX3 mutations accounting for Ulnar Mammary Syndrome (UMS) have been described in litterature also linked to all of these scenarios including CDGP in many family pedigrees. (31).

The genetic basis of CDGP and shared causes with GHD and cHH are illustrated in Figure 1.

\section{F FINAL OUTCOMES AND THERAPEUTIC OPTIONS}

Given that CDGP is a self-limiting condition, reassurance and watchful waiting are reasonable approaches to treatment. On the other hand, however, new evidences towards long-term sequelae 
Page 19 of 120

associated with delayed puberty are rising into clinician's attention, from the possibility of early menopause and low bone density to a worse psychosocial well-being and peer's relationships (19). Moreover, association studies investigating earlier or later timing in puberty in both genders have been linked with a wide range of adverse health outcomes, including cancers, cardiometabolic, gastrointestinal, musculoskeletal and neurological pathologies. (52)

Additionally, because in CDGPs the magnitude of the growth spurt may be blunted as the child gets older, not infrequently these children will not be able to reach their full growth potential. (53) To this regard, final height in CDGP patients has been widely investigated in boys and many studies have proven that untreated CDGP patients are prone to become shorter either cornpared to their mid parental targets and/or their peers displaying normal timing of puberty, wereas if a treatment with LDSS is given to the child for a short period a time, FH has proved to become similar or better compared to those left untreated. (54) (55) (56) (57). (Table III) This effect may expire if higher doses of testosterone are used. (58) Testosterone therapy (in the form of testosterone esters/undecanoate, given either intramuscularly, transdermal gel, or orally) in this group of patients appears a safe and well tolerated approach thatcan favor a prompt recovery of hypothalamus-pituitary axis after discontinuation of treatment in vow doses are given. (59) The treatment schedules are quite variable, and the efficacy of the treatment is clearly an under-investigated area in adolescent medicine with very few randomised trials available. Letrozole treatment has also been proven to give benefits in CDGP boys compared to testosterone in terms of pubertal progression, even by eliciting different HPG axis responses (increasing gonadotropins and Inhibin B, leading to larger testis size). (22) Both therapies (testosterone $1 \mathrm{mg} / \mathrm{kg} / \mathrm{month}$ or letrozole $2.5 \mathrm{mg} /$ day) had anyway proven to elicit changes in Sertoli cells markers (i.e. decrease in $\mathrm{AMH}$ ), reassuring about safety in developing mature seminiferous epithelium with both approaches. (60) Other therapies such as oxandrolone have also been suggested for treatment of CDGP, but long term data are lacking. (61) (62) 
Very few follow-up studies are instead available for CDGP girls, and data on treatment with low dose estradiol are almost lacking. (57) (63) (Table III) This is possibly due to the lower rate of presentation to medical attention of girls with pubertal delay compared to boys (26). For girls, natural and transdermal estradiol preparations are preferred.

A reasonable therapeutic approach for CDGP children may be made either with $50 \mathrm{mg}$ testosterone enanthate intramuscolary monthly for 3-6 months either with $10 \mathrm{mg}$ testosterone gel $2 \%$ daily for 3 months for boys, or with $1 / 4$ of a $25 \mu \mathrm{g}$ patch of $17-\beta$ estradiol once or twice weekly for 6 months for girls. (3) (64) (65)

Taken together we believe that CDGPs should not be considered as a para-physiological variant of maturation-tempo but, perhaps more appropriately, as a condition charactented by a significant delay of pubertal timing needing treatment with LDSS for a short perigd of time in order to normalize their growth pattern and achieve full growth potential and limit psychosocial and medical issues associated with delayed puberty.

\section{Idiopathic growth hormone dericiency}

\section{A DEFINITION:}

Growth hormone deficiency is a complex yet rare diagnosis in a child, that should be based on the whole thing of auxological, anatomic and laboratory's findings. (33) This condition can be challenging to differentiate from CDGP as in both settings there is a height SDS deflection and relatively low height velocity compared with cross-sectional population references. Moreover, GHD may also overlap with $\mathrm{cHH}$ clinically, especially when multiple pituitary hormone deficiencies (MPHD) or shared genetic mutations with the condition occurs. 


\section{B PREVALENCE}

The prevalence of GHD is around 1 child every 4.000-10.000 It is therefore a rare condition and mainly a diagnosis of exclusion upon other possible causes of poor growth (malnutrition, chronic liver and renal diseases, pulmonary diseases, syndromic conditions, iron overload, hypothyroidism, diabetes, skeletal dysplasias, inborn errors of metabolism, and CDGP).

Prevalence of GHD worldwide may ranges widely due to the lack of standard diagnostic criterias (for example, it has been overestimated as up as 1:1800 in Sri Lanka probabily due to more liberal diagnostic standards) and also due to referral bias. Even thought there are no apparent racial differences in the incidence of GHD, The National Cooperative Growth Stridy (NCGS), Genentech's study on North American database, revealed that $85 \%$ of patients receiving GH treatment for idiopathic GHD were white, $6 \%$ were black, and 2\% were Asian and similar distributions were seen with patients with other forms of short stature. Additionally, pacients with GHD from organic causes such as tumors and radiation, may be nuch more prevalent in more industrialized countries, where medical intervention on population is deepened. (66).

\section{C CLINICAL PRESENTATION}

Children with GHD may display serere armonic short stature, a reduced height compared to the target height (T4) and/or a poor growth rate. The past medical history may help the clinician if neonatal hypoglycernias, midline defects, prolonged jaundice or MPHDs are present. (67)

In growth charts of boys with congenital GHD a continuous decrease in height SDS from birth on occurs without any levelling (68). Moreover, an increase in fat mass has been described in patients left untreated giving them a "cherubic appearance", which can also be taken as an important diagnostic tool against a presumptive CDGP diagnosis, where BMI is classically found to be low. 
Bone age, either assessed with Greulich \&Pyle or Tanner-Whitehouse methods, is again found to be delayed due to the low GH-IGF-1 levels modelling bone maturation. However, there may be three possible confounding scenarios in which bone age may not be delayed: (i) recently acquired GHD, (ii) obesity, which is tipically associated with advanced bone age, and (iii) concomitant precocious puberty, a scenario where sex hormones can trigger bone maturation. (33)

PAH based on bone age will clearly show an adult height well below the genetic potential of the child. As already mentioned, many methods for PAH preditions exist (Table II): target height, which is the most used method of height prediction in clinical practice, has anyway been associated with a higher prediction error compared to the less used Roche-Weiner-Thissen method (RPT) in a cohort of severe GHD. (69) Therefore, this method might be superior for the prediction of adult height in a child with short stature. It is however clear that CDGP can come into differential diagnosis mainly with cases of recently acquired GHD or, more frequently, partial idiopathic GHD (pGHD).

\section{D ENDOCRINE WORKUP, role of sex steroid priming before GHST and pituitary MRI}

Serum IGF-1 levels are fiequently low in GHD compared to pubertal aged-matched peers and its determination in peripubertal children should be assessed within adjusted reference ranges for actual pubertal status. (70) An IGF-1 level > 0 SDS for gender and age specific range makes the GHD diagnosis highly unlikely (71) and it can be used as a screening tool for GHD. However, when IGF1 is found to be low, a series of other conditions need to be excluded (such as malnutrition, chronic diseases, hepatic diseases).

However, IGF-1 levels may be influenced by a series of other conditions, therefore an evaluation of $\mathrm{GH}$ reserve in the majority of cases is warranted. 
Page 23 of 120

Regarding growth hormone stimulation tests, in the absence of a "gold standard", it is impossible to precisely define the sensitivity and the specificity of any test for GHD. Insulin tolerance test (ITT) may be considered the gold standard for the evaluation of GH reserve, but its intrinsic risks hamper the definition of normal responses thresholds. Some information in specificity can be learned by comparing the results obtained in normal children. It is well known that within normal children and/or children with idiopatic short stature 10 to $25 \%$ will show a GH peak $<7 \mu \mathrm{g} / \mathrm{L}$ and up to $23-49 \%$ will have a peak < $10 \mu \mathrm{g} / \mathrm{L}$. (72) This may suggest that every individual stimulus may incorrectly classify almost half of the children as false positive GHD, if higher cut-offs are assumed. To this regard, the definition of normal $\mathrm{GH}$ peak under stimuli has been changed and progressively reduced over years and a further reduction of the diagnostic cut off of $\mathrm{GH}$ peak by 7 $4 \mathrm{~g} / \mathrm{L}$ has been recently proposed by the latest Growth Hormone Research Society Guidelmesthe definition - f normal GH peak under stimuli an attempt of progressively reducing the diagnostic cut-off of GH peak by $7 \mu \mathrm{g} / \mathrm{L}$ has been recently proposed by the latest Growth Hormone Research Society Guidelines (33), although the previous cut-off (at $10 \mathrm{mcg} / \mathrm{dL}$ ) has not been revised yet. Also in Italy, the cut-off of $8 \mathrm{mcg} / \mathrm{dL}$ has just been confirmed in the latest revision of notafifA 39.

Sensitivity of GHST, can hence be deduced by comparing one positive test to the positive response of another investigation, for example correlating low IGF-1 concentrations to the failed results on GHST. However sometimes the tests can be discrepant and in this scenario it is difficult to determine whether this is due to the poor sensitivity of the IGF-1 test or to the poor specificity of the GHSTs themselves.

To increase GHST specificity, sex steroids priming preparation should be performed before testing. However, in contrast with CDGP cohorts, sex steroid priming before growth hormone stimulation testing has been associated with conflicting benefits in the GHD cohorts in litterature. Even though in the already cited study of Molina primed GHD children were able to significantly increase GH mean peaks under clonidine stimulation test from $3.68 \pm 2.34$ to $5.95 \pm 2.76 \mathrm{ug} / \mathrm{l}$. (35), in the study 
performed by Martinez et al, GHD children did not significantly increase GH mean peaks under sequential arginine-clonidine test after estrogen priming ( $\mathrm{GH}$ peak $3.1 \pm 2.4$ on placebo and $4.5 \pm 2.7$ $\mu \mathrm{g} / \mathrm{L}$ on E2, NS), suggesting that the effect of priming is irrelevant in those patients with more severe forms of GHD, thus displaying lower GH peaks under stimuli. (34)

Because of the poor specificity and the low reproducibility of the GHST, the cardinal tool for a correct diagnosis is again an abnormal auxological clinical examination, considered to be the gold standard. a pathological short stature and/or growth deceleration (i.e. height $<-2$ SDS, difference from target height $<-1.5$ SDS, growth velocity $<-2$ SDS) highlighted by clinical examnation, considered to be the undeniable starting point. Pathological auxological criterias are in fact thought of increase the pretest probability of GHD in children under investigation, expecially in thoses without any other risk factor (i.e. pathology including ectopic posterion pituitary and/or abnormality of the pituitary stalk, irradiation, at least other pituitary hormone deficiency or carrying a pathogenic genetic mutation), and in these patients two abnormal tests are frequently needed before GHD is diagnosed. (32) Instead, in a patient with pathologic auxological criteria, a nornal GH peak in one test rules out GHD in most of the cases. However, as in seme conditions (cranial irradiation, optic nerve hypoplasia, traumatic brain injury, or knøwn genetic conditionsy GHD may evolve over time, a second GHST is frequently suggested at a later time point. (33)

A Magnetic Resonance Imaging (MRI) of the hypothalamus and pituitary glands should be performed in all patients diagnosed with GHD in order to rule out anatomical defects of the hypothalamicpituitary region or tumoral brain lesions. This is important for predicting the likelihood of other pituitary deficiencies, the utility of genetic testing and the probability of persistent GHD after attainment of final height. (33) In around $15 \%$ of cases an anatomic malformation of the hypothalamus-pituitary axis is found, but in the majority of the children, no cause can be identified and this group of patients are often referred as having idiopathic growth hormone deficiency (IGHD). (73) These children diagnosed as IGHD frequently carry transient forms of growth hormone 
Page 25 of 120

Galazzi \& Persani, 25

deficiency during childhood and the rate of normal retesting has been found to be as high as $80 \%$ in many papers (see later). (74) (75) (76) (77)

Major anatomical abnormalities (including thin or interrupted hypophyseal stalk, suprasellar or intrasellar tumors invading the hypothalamus-pituitary anatomy) are known risk factors for multiple pituitary hormonal deficiencies (MPHDs) and of persistent GHD in adulthood. (74) (75) (78) Ectopic posterior pituitary with an otherwise normal anterior pituitary gland is also consider to increase by $26 \%$ the probability of adult persistent GHD (79). A small anterior pituitary, defined as a gland $<-2$ SDS of normal size using the few available standards for normal population categorized for age and gender (80) (81) (82), may incidentally be found on MRI. A hypoplastic anterigropituitary gland by itself is not sufficient to diagnose GHD, but may indicate the need for a more extensive evaluation of the anterior pituitary function. (33) Pituitary sise should be interpreted in the context of pubertal status. It is in fact well established in normal subjects that the plituitary gland increases its size during puberty (a phenomenon even more pronounced in femates, reaching a plateau at approximately 20 years old, and a physiologic decline thereafter. (83)

Many Authors studying pituitary MRI of IGHAD children have indeed found a significantly low volume of the pituitary gland compared io age-matched peers, speculating that there could be an association between anatomic and functional abnormalities, meaning that those patients with smaller pituitary glands may have a smaller somatotrophs volume thus secreting less growth hormone. (84) (85)

\section{E GENETIC TESTS}

The majority of patients with growth hormone deficiency is considered of idiopathic origin. Some isolated growth hormone deficiency are secondary to a genetic mutation within the GH gene locus named GH1 (IGHD type IA or IB ) or in its introns (IGHD type II), or may be transmitted as an Xlinked trait together with hypogammaglobulinemia (IGHD type III) (73). 
An exome or a genome wide approach is nowadays thought to be the best diagnostic option, yet sometimes not available in clinical settings. A panel-oriented gene analysis for the most frequent genes associated with GHD could be a reasonable approach. Some features are associated with a high pre-test probability of a genetic mutation: severe short stature at presentation $(<-3$ SDS from population or from target height), multiple pituitary hormonal deficiencies, anatomic alteration of the CNS, familial segregation with an autosomal dominant or recessive pattern or with a history of consanguinity. (33) Genes associated with GHD and shared with CDGP and $\mathrm{cHH}$ are illustrated in Figure 2.

\section{F FINAL OUTCOMES AND THERAPEUTIC OPYIONS}

Even though growth hormone therapy has been given since 1958 starting with extracted GH from human pituitary glands, and then from 1980 s with the use of the recombinant human GH (rhGH) technology, little is still known about its effect on adult height and conflicting data exist on long-term studies, with some showing failure to reach the geretic mid-parental target height but others, by contrary, showing successful target height achievements. It is clear from reports that individual height response may vary consyderably even with individualized treatment regimens, mainly depending on the chronologieal age at the start of therapy, on the severity of the GH deficiency after stimulation tests and on the stage of pubertal development. (86) (87) (88) (89) (90) (Table IV).

In fact, as a result of the lack of a uniformed cut-off limit for GHD, of the heterogeneity of the GHST used, and the fact that sex steroid priming is frequently not performed, it is not infrequent that a lot of these studies on IGHD children erroneously include also CDGP patients, who may present with short stature and pubertal delay. For this reason, outcomes reported in papers on final height of patients receiving rhGH treatment may vary widely and in some cases an overlap in terms of FH outcomes is seen with CDGP cohorts, expecially for CDGP girls or for CDGP boys treated with 
LDSS. (Tables III and IV). If very low growth outcomes are achieved after treatment with rhGH (SDS FH-IH around +1.2 only), possible other causes of short stature should be considered. (91)

Roughly, a standard substitutive dose of rhGH should be $25-35 \mu \mathrm{g} / \mathrm{kg} / \mathrm{die}$ but the dose of rhGH should then be individualized according to $\mathrm{GH}$ responsiveness aiming for the lowest dose able to induce a response in height velocity, possibly using prediction models. (92)

Retesting GH status at end of growth is currently recommended by the European Society for Pediatric Endocrinology guidelines for all patients with GHD except for those children with multiple $(\geq 3)$ pituitary hormone deficiencies regardless of the etiology, for GHD with a documented causal genetic mutation or specific pituitary/ hypothalamic structural defect. (32) To this extent, small pituitary glands are not considered as anatomic defects, since a 1 ijgh proportion of hormalization at retesting in children with this condition has been demonstrated (74)

Guidelines differ on suggested cut-offs for GHD diagnosis during transition under ITT test, with American guidelines using lower cut offs (5 $1 \mathrm{~kg} / \mathrm{L})$ (93), European Society for Pediatric Endocrinology guidelines suggesting a cut-off of $5.6 \mu \mathrm{g} / \mathrm{L}$ (94) for immunometric assays, and GH Research Society guidelines suggesting a cut-off of $6 \mathrm{mg} / \mathrm{L}$. (33)

Studies using standard cut-offs have confirmed that around two thirds of patients diagnosed as GHD during childhood-puberty, proved to have transient form of GHD. Tauber et al reported a $67 \%$ rate of normalization at retesting in IGHD patients, which was increased up to $71 \%$ in children previously diagnosed as partial GHD (GH peak at diagnosis between 5-10 $\mu \mathrm{g} / \mathrm{L})$. (76) Moreover, a proportion of normalization of GH secretion in adulthood has been demonstrated as high as $87 \%$ for children with isolated IGHD of childhood onset. (75)

Additionally, early retesting of children diagnosed as idiopathic GHD with a normal MRI has turned out to normalize in up to $85 \%$ in 1-6 months after diagnosis (95), and has been recommended. (96) 
Page 28 of 120

The reasons for the high proportion of patients who are apparently increasing their GH secretion at retesting are however likely to be multifactorial. Long-term exposure to sex steroids may increase pituitary size and GH secretion, some children may have had a form of transient GHD and, eventually, some others may have been incorrectly diagnosed as GHD, given the problems associated with biochemical testing outlined previously.

\section{Congenital Hypogonadotropic Hypogonadism}

\section{A DEFINITION}

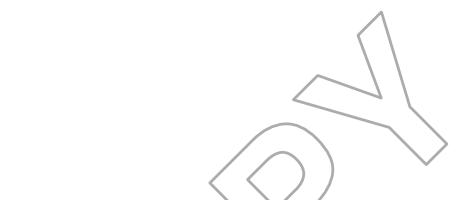

\section{A DEFINITION}

Congenital Hypogonadotropic Hypogonadism ( $\mathrm{c}(\mathrm{HH})$ is an organic and heterogeneous disease due to abnormal secretion or action of GnRH. It may be characteristically associated with an olfactory defect such as anosmia/hyposmia, the so called Kallmann syndrome (KS), or may occur in the context of normal olfaction, also known as normesmic HH (njh). (2) The possible association with olfactory defects is related to the eommon embryonic origins of the GnHR-secreting and olfactory neurons, which both migrate from the olfactory placode to their final location in the brain through the cribriform plate of the ethmoid bone.

$\mathrm{cHH}$ is defined by the criteria of a prepubertal state at the age of $>14$ years and by a testicular volume not reaching a value of $\geq 5 \mathrm{~mL}$ during a 24-month follow-up despite a short trial with testosterone. A final differential diagnosis between CDGP is made if spontaneous puberty does not occur by the age of 18 years old. (44) However, the wait-and see approach is clearly not recommended because of the known psychosocial and medical issues associated with a pubertal delay already cited above.

\section{B PREVALENCE}


Page 29 of 120

$\mathrm{cHH}$ is a rare disease with a frequency of 1:4000-6000 males with a 3-5:1 male:female sex ratio in tertiary centers. (97) The prevalence worldwide is difficult to determin, but it has been reported spanning from 1:10.000 to around 1: 86.0000 , but when interpreting these findings methodological limitations of case ascertainment by medical record review should be kept in mind. (98) cHH may be familial or sporadic.

\section{C CLINICAL PRESENTATION}

A wide spectrum of phenotypes have been described.

- Complete cHH starting form foetal/neonatal life

- Complete $\mathrm{cHH}$ starting from the peripubertal period

- Partial cHH with an initial spontaneous drive or pubertal development but a subsequent sudden arrest (one third of the cases)

- Same as above with a reversal of GnRH secretion during aduithood (almost 10\% of the cases)

- Adult onset $\mathrm{cHH}$

The phenotype may vary accordingly. In bos the presence of microphallus, mild hypospadias and/or (bilateral) cryptorehidism may indicate a complete defect of foetal/neonatal origin, whereas the absence of these signs but the lack of puberty to start or to progress till Tanner 5 may indicate either a complete peripuberatal form or a partial form of $\mathrm{cHH}$, respectively, which may be difficult to differentiate from self-limiting costitutional delay. In females the scenario is even less well-defined, since the foetal/neonatal phenotype of $\mathrm{cHH}$ females is still unknown and possibly indistinguishable from other phenotypes. Clinical features of $\mathrm{cHH}$ of peripubertal onset or of partial forms in females are again the absence/ the incomplete self progressing puberty and primary amenorrhea, both overlapping with CDGP females, and the presence of eunuchoid proportions. (97) Interestingly, in both sexes, gonadarche alone is found to be absent, whereas adrenarche and pubarche may be present. 
It is therefore clear that a complete physical examination considering limbs' asymmetry (ratio arm span/standing height $>1$, arm span $>6 \mathrm{~cm}$ of standing heightand for eunuchoid proportions, sitting height/leg lenght ratio $<0.8-1)$ may orient clinicians towards $\mathrm{cHH}$ when disproportionateness is clinically detectable, taking available clinical chart for normal children as a reference. (99)

Short stature at pubertal age in $\mathrm{cHH}$ accounts for $40 \%$ of the cases, further rising complexity to the picture, however, an accurate analysis of the patient's growth chart may help in the diagnosis. In boys with $\mathrm{cHH}$, in fact, height SDS does not differ to that of target potential till the first 5 years of life but a typical decreases at puberty occurs, with an inverse correlation with BMI, which is frequently found to be in the higher part of normal range. (30) Similar data on growth charts arg however lacking in literature for $\mathrm{cHH}$ girls.

Apart from these specific endocrine phenotypes, other specific features, both neurological and extraneurological, may be present. Associated neurological phenotypes, include a defective smell sensation, sensorineural hearing loss, color blindiness (daltonism), nystagmus and bimanual synkinesis (mirror movements). Hypo-Anosmia that can be found in $50 \%$ of the patients, is also a patognomonic sign of Kallunam syndrome and may help in the diagnostic process. (2) The olfactory competence can be quantitatively tested with specific tests e.g. the University of Pennsylvania Smell Identification test (UPSIT) or the Brief-Smell Identification test (B-SIT). This evaluation is critical since many patients with $\mathrm{cHH}$ and hypo-anosmia are not aware of their defective sense of smell.

Other non-neurological signs are also described, such as midline defects (cleft lip/palate; arched palate), dental abnormalities, renal agenesis/dysgenesis, syndactyly, polydactyly, camptodactyly, and metacarpal shortness. All of these features have to be carefully elicited during the physical examination of these patients and need to be considered all together because some of them can concomitate in GHD patients (Figure 2). 
Moreover, a deep clinical examination must rule out syndromic conditions associated with hypogonadotropic hypogonadism. For example, the presence of morbid obesity and mental retardation should suggest Prader Willy Syndrome or Bardet-Biedl syndrome. The combination of coloboma, heart malformations, choanal atresia, growth retardation, genital anomalies should point out a diagnosis of CHARGE syndrome. The presence of $46 \mathrm{XY}$ sex reversal and primary adrenal insufficiency should suggest adrenal hypoplasia congenita secondary to NROB1 mutation. The presence of other pituitary deficiencies and midline defects should suggest Septo Optic Dysplasia, or the rare Hartsfield syndrome or Gordon Holmes syndrome. (19) (97) The presence of ulnar forearm abnormalities, absence/hypoplasia of mammary and apocrine glands eventually associated with midline defects (i.e. hypoplastic anterior pituitary) or renal matformations in the proband or in a family member may suggest UMS. (31) (Figure 2)

\section{D ENDOCRINE WORKUP}

Basal gonadotropins levels are in the majority of the cases not discriminative. For this reason, other basal endocrine markers hac been investigated. Inhibin B, a protein derived from gonadal tissues through FSH stimalation (seminiferaus tubules of the testis or cortical layer of the ovaries), are thought to be lowe in chH than in other conditions because of the absence of minipuberty in these patients able to trigger the differentiation either of Sertoli cells in males either of Granulosa cells in females. In males, a low Inhibin B level $(<35 \mathrm{pg} / \mathrm{mL})(40)$, or the combination of low Inhibin B levels $(10-49 \mathrm{pg} / \mathrm{mL})$ together with low testis volume $(<1 \mathrm{~mL})(22)$, seems to discriminate at best $(100 \%$ sensitivity and specificity) cHH patients. Moreover, the combination of a low basal LH $(<0.3$ IU/L) and a low basal Inhibin B $(<111 \mathrm{pg} / \mathrm{ml})$ has been proven to provide $100 \%$ sensitivity and $98 \%$ specificity for the $\mathrm{cHH}$ diagnosis, giving a valid and reliable alternative to dynamic and more invasive stimulations. (100) In females with $\mathrm{cHH}$, Inhibin B levels are however reported to be either low or normal compared to age-matched controls, therefore not discriminative. (42) 
Page 32 of 120

\begin{abstract}
Stimulation test may also be helpful in the diagnostic process. GnRHa Triptorelin proved to have an excellent accuracy for the diagnosis of $\mathrm{cHH}$ if $\mathrm{LH}$ peaks prove to be lower than 5.3 U/L after 4 hours of pharmacological stimulation (100\% sensibility and specificity). (100)
\end{abstract}

The hCG stimulation test has also been used for many years, primarily to assess the presence of functioning testicular tissue and to investigate defects of testosterone biosynthesis and action. It is based on the ability of hCG to increase androgen production in Leydig cells via stimulation of the $\mathrm{LH}$ receptor. Therefore, a blunted testosterone response to hCG stimulation test has been supposed as evidence towards a cHH diagnosis. However, many protocols have been used and large studies are lacking. Promising results have been assumed with longer protocols (19 days of stimulation proving to perform better than 3 days) (45) or higher doses (subsequent injections of, 500 UI of hCG in three consecutive days) (46). Combining the results of GnRH test stimulatin and hCG test has also proved to differentiate $\mathrm{cHH}$ from CDGP with a sensibility and a specificity of $100 \%$ if LH peaks under LHRH test are $<2.8 \mathrm{U} / \mathrm{L}$, testosterone levels after 3 day hCG test are $<3.6 \mathrm{nmol} / \mathrm{L}$ and testosterone levels after 19 days of hCG test are < $9.5 \mathrm{nmel} / \mathrm{L}$. (45)

\title{
3.E GENETIC TESTING
}

The pathogenesis of $\mathrm{cHH}$, with or without hypo/anosmia, is a wide area of current research in endocrinology. A genetic basis of $\mathrm{cHH}$ can be defined in almost 50\% of the cases. (97) The genetic heterogeneity of $\mathrm{cHH}$ is due to the fact that all modes of inheritance can occur: X-linked, autosomal recessive and autosomal dominant. Rising complexity to the picture, the traditional Mendelian view of inheritance has been revised following identification of oligogenic forms of $\mathrm{cHH}$ in at least $20 \%$ of the cases. (2) Moreover, a specific genotype-phenotype correlation is frequently lacking, as the penetrance is incomplete and the expressivity extremely variable, again possibly due to the oligogenic fashion of inheritance, although an involvement of environmental factors cannot be excluded. Many 
Page 33 of 120

mutations in genes known to cause aberrations of the hypothalamic-pituitary-gonadal axis have been described. The mutations can be classified as either affecting $\mathrm{GnRH}$ action, $\mathrm{GnRH}$ secretion, $\mathrm{GnRH}$ neurons development and migration or GnRH neurons specification and/or activation, and many of them are shared with CDGP cohorts. Moreover, some mutation in genes responsible for hereditable forms of MPHD or syndromic conditions have also been associated with both cHH and GHD. (97) The genetic basis of cHH and shared causes with CDGP or GHD cohort are illustrated in Figure 1.

\section{F FINAL OUTCOMES}

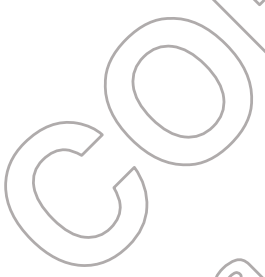

For males, treatment is based on the use of testosterone esters given either by intramuscular or transdermal routes with subsequent gradual dose increasê every 6 monthe until reaching, in around 36 months, the adult scheme. The use of testosterone, either injectable or transdermal, leads to good virilization but has little-no effect on testicular growth. Treatment for females with hypogonadism is based on the initial use of estrogens in the form of 1.7P-estradiol (preferably), either trans dermally (fancied) or orally, or in the form of oral EE. Estrogen therapy must also be integrated with progestin therapy after at least 2 years (or earlier in the case of more than one significant bleeding episode) in order to avoid endometrial hypertrophy. The natural (i.e. micronized) over the synthetic forms of progestins are preferred. A complete explanation of therapeutic protocols and doses is beyond the scope of this review but can be found in the recent review published by Raivio T. et al. (3) While testosterone replacement only causes virilization, treatment with recombinant FSH associated with hCG has been shown to induce testes growth, increase Inhibin B levels and stimulate spermatogenesis in adolescent males with $\mathrm{cHH}$. Moreover, an early treatment with gonadotropins has been suggested to have a positive effect on future fertility. (44) Also, as already mentioned, the observation of a self limiting pubertal progression at discontinuation of sex steroids therapy may point out a $\mathrm{cHH}$ rather than CDGP diagnosis. (3) 


\section{EVIDENCE SYNTHESIS}

In every child referred for a suspected growth disorder, anthropometric measurements, medical history (with special attention to the so called "red flag", see Figure 2), full physical examination with special attention to dysmorphisms and disproportions, pubertal development and bone age assessment must be evaluated by the pediatric endocrinologist.

Regarding auxological measurements standing height, arm span, sitting height and leglength must be measured at every examination, with the use of a proper stadiometer and a tape-measure. At the same time pubertal stage must be evaluated by the use of Tanner charts, with the use of a proper orchidometer for boys. At this regard it is worth remembering that, even though in both sexes hair growth in the pubic area depends on adrenal secretion, glinically, a deived gonadarche together with a delayed adrenarche and pubarche orients towards a CDGP diagrosis, whereas delayed gonadal development alone is a more peculiar presentation of $\mathrm{cHH}$ patients. (25)

Bone age is another important diagnostic tool. To exp is extent it is worth remembering that in every child, TW3 method and G\&P method may overestimate and underestimate bone age, respectively. (28) Moreover, because G\&P standards and TW standards were derived from white children living in the United States and predominantly of North European ancestry, the use of new automated methods is recommended for the assessment of children of other ethnicity groups. (27) Bone age is usually found to be delayed in relation to chronological age in all three CDGP, GHD and cHH patients. Even if many endocrine (hypothyroidism, rickets, Cushing disease, panhypopituitarism) and non-endocrine conditions (malnutrition, prematurity, cardiac, liver or kidney diseases, systemic inflammations or infections) may present with a delayed bone age, this assessment is considered a non-invasive and cost-effective method able to select those patients in which further testing are recommended. In fact, a great proportion of patients with non-endocrine short stature (familial short stature, skeletal dysplasia, idiopathic short stature) may be excluded from further testing because 
displaying a bone age equal or sometimes advanced compared to chronological age, or because manifesting straightforward signs of skeletal dysplasia on X-rays. Moreover, usually, a failure of spontaneous pubertal development at the bone age maturation of 12 and 13 years, in females and males respectively, may be indicative of an organic cause rather than CDGP. (28)

Bone age is also a useful starting point to predict FH outcomes. (Table II) PAH may be helpful for the differential diagnosis, as it will end up laying in the lower end of target height for CDGP patients, be far way lower than TH in GHD children, hence higher than TH in cHH patients. (Table I).

Taken as a whole, self-limited delayed puberty is the most common cause of short stature and delayed puberty in both sexes in clinical practice, and the higher number of males that present to medical attention is thought to be a consequence of referral bias. According to the literature, we can expect to find an underlying secondary medical cause of poor grewth/delaved puberty in up to $27 \%$ of boys and $57 \%$ of girls presenting to medical attention. (3) Chronic systemic illnesses and malnutrition (the so called "functional causes" of delayed puberty) and other causes of poor growth must be ruled out by baseline blood exams including full blood count, liver function test, creatinine, celiac screen, thyroid function tests, IGF-1, PRI, LH/FSH, testosterone/estradiol levels. (25) At the same time, the evidence of syndromic stigmata may evoke a specific syndromic phenotype or a contiguous gene syndrome. The targeted genome analysis and/or a standard karyotype together with an array-CGH may be useful investigations in these situations. When all these confounding phenotypes are ruled out, the diagnosis must be carried out through a step-by-step approach (Figure 3).

Useful information can firstly be taken from growth charts from infancy, at least in boys. CDGP boys soon after birth are known to display poor growth until 2 years old, then tend to level till 5 years old, starting from when a height SDS loss starts to be detectable reaching their nadir at puberty (26) and BMI is found to be concordantly low. (30) By contrast, in boys with GHD a continuous decrease in height SDS without any levelling is found from birth on and a severe short stature is frequently 
detected (68), together with an increase in fat mass (in patients left untreated). (30) In boys with $\mathrm{cHH}$, instead, height SDS does not differ to that of target potential in the first 5 years of life but a typical decreases at puberty occurs, with an inverse correlation with BMI. (30) Special considerations must then be taken for girls, in which GV does not discriminate at best the different etiologies of delayed puberty. (22)

If cHH presents with pathognomonic "red flags" (e.g. anosmia, eunuchoid habitus, pituitary lesions, ulnar-mammary malformations) this should help in the diagnostic process, however many features seem to overlap with GHD cohorts, further mistakening the diagnosis (Figure 2).

Anyway, not all peripubertal children with pathological causes of growth fâinure present to medical attention with short stature. If insufficient clues for a disturbed growth arefound at the first screening, the patient can be put on watchful waiting. If clues for disturbed growth are highlighted, additional further investigations must be performed. A combination of short stature (SDS H $<-2.5$ ), severe distance to target height $(\triangle$ SDS $/$ SDSTH $>-1.6)$ and growth deflection $(>0.5$ SDS/year or $>0.7$ $\mathrm{SDS} / 2$ years or $>1 \mathrm{SDS}$ /undefined time) should be used as practical guideline to decide which child should be screened with a GHST $>$ (17)

An important consideration must betaken for those children in which puberty may be anticipated: in this scenario growth velocity may be falsely reassuring because driven by pubertal hormones, but then a severe deviation from target height becomes evident after puberty completion if growth hormone deficiency concomits. For this reason patients at risk of having GHD (i.e. Cancer Survivors treated with surgery and/or total body radiation and/or chemotherapy) must be investigated with a growth hormone stimulation test regardless of height SDS and GV SDS. (33)

In terms of GHST, hypothalamic stimulation (hypoglycemia tolerance test, clonidine test, arginine test, glucagon test) are preferred rather than combined stimuli (i.e. GHRH+ arginine) in order to rule out possible hypothalamic causes of growth hormone deficiency. Moreover, priming with sex steroids 
before GHST is useful in order to increase diagnostic accuracy of the stimulation and reduce the false positive diagnosis of presumed peripubertal idiopathic GHD, at least for boys $>11$ years old and for girls > 10 years old. (32) To this extent many protocols exist within different centers (39): the use of $100 \mathrm{mg}$ of testosterone enanthate intamuscolary 1 week before the test for boys, and $1-2 \mathrm{mg}(<20 \mathrm{~kg}$ or $>20 \mathrm{~kg}$ respectively) of valerate estradiol orally for girls for the three nights before the test may be considerered a reasonable scheme, even though oral estradiol preparations can also be used for boys if a less invasive route of administration is preferred. If GH peak under GHST is less than 7-8 $\mu \mathrm{g} / \mathrm{L}$ (with immunometric assays), especially under 2 different stimulations, the child is considered as having GHD and a pituitary MRI is warranted. If no tumorai lesions in the brain are found, rhGH therapy can be started at substitutive doses (25-35 $\mu \mathrm{g} / \mathrm{kg} / \mathrm{die})$ and the chid must be followed up periodically in order to verify appropriate catch-up growth after rhGH iscommenced. According to the severity of GHD and to the underlying cause, early retesting of GH secretion may be considered. (95) (96)

It is also worth mentioning that in terms or final height outcomes a lot of different results are described in literature for treated GHD patients, showing $\mathrm{FH}$ SDS spanning between -1.1 to -0.5 and $\triangle \mathrm{SDS}$ $\mathrm{FH}-\mathrm{TH}$ concordantly ranging between $0.6 \mathrm{to}+1.08$. For this reason, it is also very difficult to confirm the diagnosis backwards, as theseresults overlap mostly with those described in some CDGP cohorts (Tables LI and IV). This is possibly due to the low specificity of GHST per se together with the fact that most of these studies were performed without any priming preparation before stimulation, and as a result they might include also some false positive patients that could have possibly displayed normal GH peaks if sex steroids priming would had been performed.

If GH peaks prove instead to be higher than 7-8 $\mu \mathrm{g} / \mathrm{L}$ in at least one GHST, a diagnosis of CDGP or cHH may be expected. The differential diagnosis between these two conditions is however far from being straightforward, especially in the peripubertal age given the heterogeneity of these diseases and the tendency to overlap of one into another clinically, hormonally and genetically. (Figures 1 and 2). 
Page 38 of 120

Basal gonadotropin levels have limited diagnostic specificity as they tend to be low both in CDGP and $\mathrm{cHH}$ cohorts. Even if in some CDGP patients at the very beginning of puberty gonadotropins may be detectable $(\mathrm{LH}>0.2-0.3 \mathrm{U} / \mathrm{L}$ ), this picture again tends to overlap at least with partial forms of cHH. (43)

For this reason, dynamic stimulation of HPG axis has been proposed. A combination of LHRH test and hCG test (3days \& 19 days stimulation) has been proposed in order to increase sensitivity and specificity of cHH diagnosis by $100 \%$. (45)

At least in boys, Sertoli cell markers but not Leydig cells, growth or adrenal markers are considered helpful in establishing whether a boy with delayed puberty will progress spontaneously. (41) Inhibin B may provide a simple first-line test capable of identifying a subset of patients with delayed puberty who are highly likely to have $\mathrm{cHH}$. These test may be performed before a short period of treatment with LDSS, which is considered more indicative and helpfuis fin fact, an increase in growth velocity and in gonadal and breast development after a short comise of 3-6 months of LDSS can be taken as evidence against the presence of GHD or cHH. (3) (64) This treatment may at the same time be helpful for CDGP children in sensibilizating their anterior pituitary glands to sex steroids in order to allow puberty to trigger spontaneously, minimizing psychosocial distress of these patients compared to peers and avoiding the known long term metabolic and bone sequelae associated with delayed puberty. (2)

Finally, it is worth mentioning that as these conditions may overlap mostly in terms of genetic causes, this is not yet a field able to differentiate these conditions, even though some promising studies on specific genes selectively discovered in CDGP families have been recently published. (19) 
Page 39 of 120

Galazzi \& Persani, 39

\section{CONCLUSIONS}

After systemic chronic illnesses or other causes of "functional" delayed growth have been ruled out, CDGP may be the most probable cause of poor growth in a child presenting with short stature and delayed puberty, especially for boys. However the differential diagnosis between CDGP GHD and $\mathrm{cHH}$ is a challenging one for the clinician at the beginning of clinical examination, for many reasons. First, as already mentioned, children may present with the same auxological features (short stature, low growth velocity, delayed puberty, delayed bone age). Secondary, even if PAH may help, it is difficult to reliably trust the predicted adult height given the low aceuracy of different methods, especially if bone age is extremely delayed. Third, although the presence of a positive familial history of delayed puberty may give a cue towards a presumptive CDGP diagnosis, $\mathrm{cHH}$ cannot be excluded giving the high hetherogenity of $\mathrm{cHH}$ presentation within pedigrees. Fourth, because of the lack of sensibilization of the pituitary gland of thesechildren to detectable levels of sex steroids, peripubertal CDGP can display decresed GH/stimulation peaks ander GHST and lower IGF-1 levels compared with their pubertal, age-matched peers pointingout the need of further investigations in order to rule out a low pituitary growth hormene resere. For this reason we recommend the use of priming before GHST in every patient tested for Gith at least from the age of 10 years old (girls) or 11 years old (boys). A. treatment hormonal approach is also recommended afterwords for those patients with normal GH peaks under GHST in order to allow a correct differential diagnosis between CDGP and $\mathrm{cHH}$, being beneficial at the same time for psychosocial wellness, final height outcomes, sexual, bone and metabolic health. 
Page 40 of 120

1
2
3
4
5
6
7
8
9
10
11
12
13
14
15
16
17
18
19
20
21
22
23
24
25
26
27
28
29
30
31
32
33
34
35
55
56
37
37
38
39
40
41
42
43
44
45
47
59

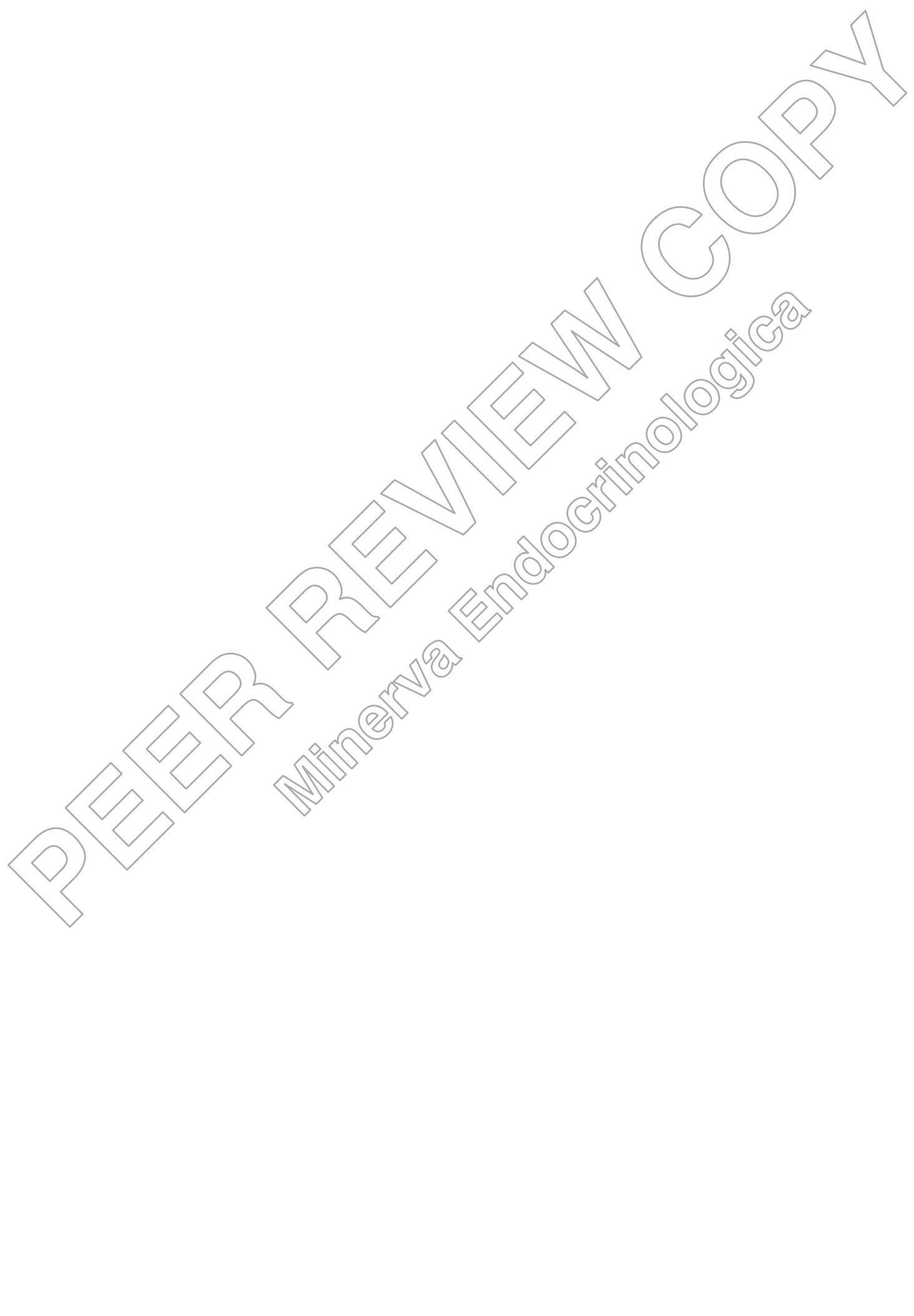




\section{REFERENCES}

1. Barinaga M, Yamonoto G, Rivier C, Vale W, Evans R, Rosenfeld MG. Transcriptional regulation of growth hormone gene expression by growth hormonereleasing factor. Nature 1983; 306(5938): 84-5.

2. Boehm U, Bouloux P-M, Dattani MT, de Roux N, Dodé C, Dunkel 12, et al. Expert consensus document: European Consensus Statement on congenital hypogonadotropic hypogonadism--pathogenesis, diagnosis and treatment. Nat Rev Endocrinol 2015;11(9):547-64.

3. Raivio T, Miettinen PJ. Constitutionai delay of puberty versus congenital hypogonadotropic hypogonadism: Genetics, management and updates. Best Pract Res Clin Endocrinol Metab 2019:33(3):1013:16.

4. Weissberger AJ, HO KK. Activation of the somatotropic axis by testosterone in adult males: evidence for the role of erromatization. J Clin Endocrinol Metab $1993 ; 76(6): 1407-12$.

5. Veldhuis JD, Metzger DL, Martha PM, Mauras N, Kerrigan JR, Keenan B, et al. Estrogen and testosterone, but not a nonaromatizable androgen, direct network integration of the hypothalamo-somatotrope (growth hormone)-insulin-like growth factor I axis in the human: evidence from pubertal pathophysiology and sex-steroid hormone replacement. J Clin Endocrinol Metab 1997;3414-20.

6. Meinhardt UJ, Ho KKY. Modulation of growth hormone action by sex steroids. Clin Endocrinol (Oxf) 2006; 65(4):413-22. 
7. Hartmann BW, Huber JC, Kirchengast S, Söregi, M.D. G, Albrecht AE. Effect of hormone replacement therapy on growth hormone stimulation in women with premature ovarian failure. Fertil Steril 1997; 68(1):103-7.

8. González-Parra S, Argente J, García-Segura LM, Chowen JA. Cellular Cơmposition of the Adult Rat Anterior Pituitary Is Influenced by the Neonatal Sex Steroid Environment. Neuroendocrinology 1998;68(3):152-62.

9. Yan M, Jones MEE, Hernandez M, Liu D, Simpson ER, Chen C. Oestrogen Replacement in vivo Rescues the Dysfunction of Pituitary Somatotropes in Ovariectomised Aromatase Knockout Mice. Neưroendocrinology 2005;81(3):158-66.

10. Mauras N, Rogol AD, Haymond MW, Veldhuis $1 \mathrm{D}$. Sex steroids, growth hormone, insulin-like growth factor-1: neuroendocrine and meiabolic regulation in puberty. Horm Res 1996;45(1-2):74-80.

11. Albertsson-Wikland K, Rosberg S, Libre E, Lundberg LO, Groth T. Growth hormone secretory rates in childiren as estinated by deconvolution analysis of 24-h plasma concentration profiles. Am J Pinysiol Metab. 1989 Dec;257(6):E809-14.

12. Glistira A, Scalvini T, Tassi C, Desenzani P, Poiesi C, Wehrenberg WB, et al. Maturation of the regulation of growth hormone secretion in young males with hypogonadotropic hypogonadism pharmacologically exposed to progressive increments in serum testosterone. J Clin Endocrinol Metab.1997;82(4):1210-9.

13. Mansfield MJ, Rudlin cCR, Crigler JF, Karol KA, Crawford JD, Boepple PA, et al. Changes in Growth and Serum Growth Hormone and Plasma Soipatomedin-C Levels During Suppression of Gonadal Sex Steroid Secretion in Girls with Central Precocious Puberty. J Clin Endocrinol Metab1988 Jan;66(1):3-9. 
14. Marin G, Domené HM, Barnes KM, Blackwell BJ, Cassorla FG, Cutler GB. The effects of estrogen priming and puberty on the growth hormone response to standardized treadmill exercise and arginine-insulin in normal girls and boys. J Clin Endocrinol Metab 1994;79(2):537-41.

15. Wit JM, Ranke MB KC. International Classification of Paediatric Endocrine Diagnoses. Hormon Res. Pediatr. 2016; 86(3): 212-214.

16. Lawaetz JG, Hagen CP, Mieritz MG, Jensen MB, Petersen JH, Juki A. Evaluation of 451 Danish boys with delayed puberty: Diagnostic use of a new puberty nomogram and effects of oral testosterone therapy. J Clin Endocrinol Metab 2095;100(4):137685.

17. Stalman SE, Hellinga I, Wit JM, Hennekam RCM, Karmp GA, Plötz FB. Growth failure in adolescents: etiology, the role of puberiat timing and most useful criteria for diagnostic workup. J Pediair Endocrinol Metab 2016;29(4):465-73.

18. Cassatella D, Howard SR, Acierno IS, Xu C, Papadakis GE, Santoni FA, et al. Congenital hypogonadotropichypogonadism and constitutional delay of growth and puberty have distinct genetic, architectures. Eur J Endocrinol 2018;178(4):377-88.

19. Howard SR. The genetic basis of delayed puberty, Frontiers in Endocrinology. Frontiers Media S.A. 2019; (10): 423.

20. Reindollar RH, Rogers Byrd J, McDonough PG. Delayed sexual development: A study of 252 patients. Am J Obstet Gynecol 1981;140(4):371-80.

21. Grimberg A, Feemster KA, Pati S, Ramos M, Grundmeier R, Cucchiara AJ, et al. Medically underserved girls receive less evaluation for short stature. Pediatrics. 2011;127(4):696-702. 
22. Varimo T, Miettinen PJ, Känsäkoski J, Raivio T HM. Congenital hypogonadotropic hypogonadism, functional hypogonadotropism or constitutional delay of growth and puberty? An analysis of a large patient series from a single tertiary center. Hum Reprod 2017;32(1):147-53.

23. Wudy SA, Hagemann S, Dempfle A, Ringler G, Blum WF, Berthold LD, et al. Children with idiopathic short stature are poor eaters and have decreased body mass index. Pediatrics 2005; 116(1):52-7.

24. Han JC, Balagopal P, Sweeten S, Darmaun D, Mauras N. Cvidence for hypermetabolism in boys with constitutional delay of growth and maturation. J Clin Endocrinol Metab. 2006;91(6):2081-6.

25. Howard SR, Dunkel L. Delayed Puberty-Phenotypic Diversity, Molecular Genetic Mechanisms, and Recent Discoveries. Endocr Rev. 2019;40(5):1285-317.

26. Sedlmeyer IL, Palmert MR. Delayed guberty: analysis of a large case series from an academic center. J Clin Endocrino Metab 2002;87(4):1613-20.

27. Ren X, Li Y, Yang X, Wang S, Ahmad S, Xiang L, et al. Regression Convolutional Neural Network for Automated Pediatric Bone Age Assessment from Hand Radiograph. IEEE J Biomed Heal Informatics 2019;23(5):2030-8.

28. Creo AL, Schwenk WF. Bone age: A handy tool for pediatric providers Pediatrics. American Academy of Pediatrics 2017; Vol. 140

29. Brämswig JH, Fasse M, Holthoff M-L, von Lengerke HJ, von Petrykowski W, Schellong G. Adult height in boys and girls with untreated short stature and constitutional delay of growth and puberty: Accuracy of five different methods of height prediction. J Pediatr 1990;117(6):886-91. 
30. Reinehr T, Hoffmann E, Rothermel J, Lehrian TJ, Brämswig J, Binder G. A New Model of Adult Height Prediction Validated in Boys with Constitutional Delay of Growth and Puberty. Horm Res Paediatr 2019;91(3):186-94.

31. Galazzi E, Duminuco P, Moro M, Guizzardi F, Marazzi N, Sartorio A, et al Hypogonadotropic hypogonadism and pituitary hypoplasia as recurrent features in ulnar-mammary syndrome. Endocr Connect. 2018;7(12) 1432-1441

32. Grimberg A, DiVall SA, Polychronakos C, Allen DB, Cohen LE, Quintos JB, et al. Guidelines for Growth Hormone and Insulin-Like Growth Factor-I Treatment in Children and Adolescents: Growth Hormone Deficiency, Idiopathio Short Stature, and Primary Insulin-Like Growth Factor-I Deficiency. Horm Res, Paediatr. 2017;86(6) 361-97.

33. Collett-Solberg PF, Ambler G, Backeljauw PF, Bijilingmaier M, Biller BMK, Boguszewski MCS, et al. Diagnosis, Genetics, and Therapy of Short Stature in Children: A Growth Hormone Research Society International Perspective. Horm Res Paediatr. 2019;92/(1):1-14.

34. Martínez AS, Domené tiMA, Ropelato MG, Jasper HG, Pennisi PA, Escobar ME, et al. Estrogen Priming Effect on Growth Hormone (GH) Provocative Test: A Useful Too! for the Diagnosis of GH Deficiency. J Clin Endocrinol Metab. 2000:85(11):4168-72.

35. Molina S, Paoli M, Camacho N, Arata-Bellabarba G, Lanes R. Is Testosterone and Estrogen Priming Prior to Clonidine Useful in the Evaluation of the Growth Hormone Status of Short Peripubertal Children? J Pediatr Endocrinol Metab. 2008;21(3) 25766.

36. Müller G, Keller A, Reich A, Hoepffner W, Kratzsch J, Buckler JM, et al. Priming with 
Testosterone Enhances Stimulated Growth Hormone Secretion in Boys with Delayed Puberty. J Pediatr Endocrinol Metab 2004;17(1) 77-83.

37. Soliman A, Adel A, Sabt A, Elbukhari E, Ahmed H, Sanctis V. Does priming with sex steroids improve the diagnosis of normal growth hormone secretion in short children? Indian J Endocrinol Metab 2014;18(7):80-3.

38. Gonc EN, Kandemir N, Ozon A, Alikasifoglu A. Final heights of boys with normal growth hormone responses to provocative tests following priming. J Pediatr Endocrinol Metab 2008;21(10):963-71.

39. Murray PG, Dattani MT, Clayton PE. Controversies in the diagnosis and management of growth hormone deficiency in childhoodand adolescence Archives of Disease in Childhood. 2016;101,96-100.

40. Coutant R, Biette-Demeneix E, Bouvattier $Q$, Bouhours-Nouet N, Gatelais F, Dufresne S, et al. Baseline inhibin B and anti-Mullerian hormone measurements for diagnosis of hyogonadotropic hypogonadism $(\mathrm{HH})$ in boys with delayed puberty. $\mathrm{J}$ Clin Endocrinol Metáb 2010:95(12):5225-32.

41. Rohayern J, Nieschlag E, Kliesch S, Zitzmann M. Inhibin B, AMH, but not INSL3, IGF1 or DHEAS support differentiation between constitutional delay of growth and puberty and hypogonadotropic hypogonadism. Andrology 2015;3(5):882-7.

42. Li HWR, Anderson RA, Yeung WSB, Ho PC, Ng EHY. Evaluation of serum antimullerian hormone and inhibin B concentrations in the differential diagnosis of secondary oligoamenorrhea. Fertil Steril 2011;96(3):774-9.

43. Resende EAMR, Lara BHJ, Reis JD, Ferreira BP, Pereira GA, Borges MF. Assessment of Basal and Gonadotropin-Releasing Hormone-Stimulated 
44. Harrington J, Palmert MR. Clinical review: Distinguishing constitutional delay of growth and puberty from isolated hypogonadotropic hypogonadism: criticail appraisal of available diagnostic tests. J Clin Endocrinol Metab 2012. 97 (9) 3056-6\%.

45. Segal TY, Mehta A, Anazodo A, Hindmarsh PC, Dattani MT. Role of GonadotropinReleasing hormone and human chorionic gonadotropin stimulation tests in differentiating patients with hypogonadotropic hypogonadism from those with constitutional delay of growth and puberty. J Clin ㄷndocrinol Metab Pe? 2009;94(3):780-5.

46. Kauschansky A, Dickerman Z, Phillip M, Weintrob N, Strich D. Use of GnRH agonist and human chorionic gonadotrophin tests for differentiating constitutional delayed puberty from gonadotrophim deficiency in boys Clin Endocrinol (Oxf) 2002. 56(5) 603-7.

47. Chan YM, LippincottMF, Kusa TO, Seminara SB. Divergent responses to kisspeptin in children with delayed pubsty. JCl insight. 2018;3(8) e99109.

48. Dunkel L, Quinton R. Transition in endocrinology: Induction of puberty. Vol. 170, European Journal of Endocrinology. BioScientifica Ltd.; 2014 R229-39.

49. Sukumar SP, Bhansali A, Sachdeva N, Ahuja CK, Gorsi U, Jarial KDS, et al. Diagnostic utility of testosterone priming prior to dynamic tests to differentiate constitutional delay in puberty from isolated hypogonadotropic hypogonadism. Clin Endocrinol (Oxf) 2017;86(5):717-24.

50. Taha D, Mullis PE, Ibáñez L, De Zegher F. Absent or delayed adrenarche in Pit1/ 
POU1F1 deficiency. Horm Res 2005; 64(4):175-9.

51. Pugliese-Pires PN, Fortin JP, Arthur T, Latronico AC, Mendonca BB, Villares SMF, et al. Novel inactivating mutations in the $\mathrm{GH}$ secretagogue receptor gene in patients with constitutional delay of growth and puberty. Eur J Endocrinol 2011;165(2):23341.

52. Day FR, Elks CE, Murray A, Ong KK, Perry JRB. Puberty timing associated with diabetes, cardiovascular disease and also diverse health outcomes in men and women: The UK Biobank study. Sci Rep. 2015;(5):11208.

53. Bourguignon JP. Variations in duration of pubertal growth aneechanism compensating for differences in timing of pubeity and minimizing their effects on final height. Belgian Study Group for Paediatric Endocrinoiogy. Acta Paediatr Scand Suppl 1988;347:16-24.

54. Crowne EC, Shalet SM, Wallace WHEminson DM, Price DA. Final height in boys with untreated constitutional delay in growth and puberty. Arch Dis Child [Internet]. 1990;65(10);1109-12.

55. Poyrażoğlu ș, Günöz H, Darendeliler F, Saka N, Bundak R, Baș F. Constitutional delay of growth and puberty: From presentation to final height. J Pediatr Endocrinol Metab. 2005;18(2):171-9.

56. Couto-Silva AC, Trivin C, Adan L, Lawson-Body E, Souberbielle JC, Brauner R. Management of boys with short stature and delayed puberty. J Pediatr Endocrinol Metab 2005;18(8):807-13.

57. Zucchini S, Wasniewska M, Cisternino M, Salerno M, lughetti L, Maghnie M, et al. Adult height in children with short stature and idiopathic delayed puberty after 
different management. Eur J Pediatr 2008 Jun 24;167(6):677-81.

58. Martin MM, Martin ALA, Mossman KL. Testosterone treatment of constitutional delay in growth and development: effect of dose on predicted versus definitive height. Acta Endocrinol (Copenh) 1986;113(4_Suppl):S147-52.

59. Uruena M, Pantsiotou S, Preece MA, Stanhope R. Is testosterone therapy for boys with constitutional delay of growth and puberty associated with impaired final height and suppression of the hypothalamo-pituitary-gonadal axis? Eur J Pediatr 1992 $\mathrm{J} ; 151(1): 15-8$.

60. Kohva E, Varimo T, Huopio H, Tenhola S, Voutilainen R, Toppari J, et al. AntiMüllerian hormone and letrozole levels in boys yyth consfitutional delay of growth and puberty treated with letrozole or testosterone. furn Reprod 2020;35(2):257-64.

61. Stanhope R, Buchanan GR, Fenn GC, Preece MA. Double blind placebo controlled trial of low dose oxandrolone in the treatment of boys with constitutional delay of growth and puberty. Arch Dis Chiid 1988;63(5):501-5.

62. De Luca $\mathrm{F}$ Argente J, Cavallo L, Crowne E, Delemarre-Van de Waal HA, De Sanctis C, ei al. Management of Puberty in Constitutional Delay of Growth and Puberty. J Pediatr Endocrinol Metab 2001;14(s2):953-7.

63. Crowne EC, Shalet SM, Wallace WH, Eminson DM, Price DA. Final height in girls with untreated constitutional delay in growth and puberty. Eur J Pediatr 1991;150(10):708-12.

64. Kaplowitz PB. Diagnostic value of testosterone therapy in boys with delayed puberty. Am J Dis Child 1989;143(1):116-20. 
65. Chioma L, Papucci G, Fintini D, Cappa M. Use of testosterone gel compared to intramuscular formulation for puberty induction in males with constitutional delay of growth and puberty: a preliminary study. J Endocrinol Invest. 2018 Feb 1;41(2):259_ 63.

66. Overview | Human growth hormone (somatropin) for the treatment of growth failure in children | Guidance | NICE. [Internet]. Available from https://www.nice.org.uk/guidance/TA188 [cited 2020 January/29]

67. Murray PG, Clayton PE. Disorders of Growth Hormone in Childhood. In: Feingold KR, Anawalt B, Boyce A, et al., (Editors) Endotext. South Dartmootho (MA): MDText.com, Inc.; 2000. Available from:ì https://www.ncbi.nlm.nih.gov/books/NBK278971

68. Rothermel J, Lass N, Toschke C, Reinehr T, Progressive decline in height standard deviation scores in the first 5 years of ife distinguished idiopathic growth hormone deficiency from familial short stature and constitutional delay of growth. Horm Res Paediatr. 2016;86(2):117-25.

69. Biczysko-Mokosa A, Petriczko E, Horodnicka-Józwa A, Dawid G, Kedzia A, Lewiński $A$, et al Evaluation of final height prediction and selected parameters in Polish patients with severe and partial growth hormone deficiency. Neuro Endocrinol Lett. $2014 ; 35(3): 242-7$.

70. Inoue-Lima TH, Vasques GA, Scalco RC, Nakaguma M, Mendonca BB, Arnhold IJP, et al. IGF-1 assessed by pubertal status has the best positive predictive power for GH deficiency diagnosis in peripubertal children. J Pediatr Endocrinol Metab. 2019 Feb 1;32(2):173-9.

71. Blum WF, Alherbish A, Alsagheir A, El Awwa A, Kaplan W, Koledova E, et al. The 
growth hormone-insulin-like growth factor-I axis in the diagnosis and treatment of growth disorders. Endocrine Connections. BioScientifica Ltd. 2018;(7):R212-22.

72. Ghigo E, Bellone J, Aimaretti G, Bellone S, Loche S, Cappa M, et al. Reliability of provocative tests to assess growth hormone secretory status. Study in 472 normally growing children. J Clin Endocrinol Metab 1996;81(9):3323-7.

73. Giordano M. Genetic causes of isolated and combined pituitary hormone deficiency. Best Pract Res Clin Endocrinol Metab2016;30(6):679-91.

74. Léger J, Danner S, Simon D, Garel C, Czernichow D. Do all patients with childhoodonset growth hormone deficiency (GHD) and ectopic neuroripyophysis have persistent GHD in adulthood? J Clin Endocringl Metab 2005;90(2):650-6.

75. Quigley CA, Zagar AJ, Liu CC, Brown DM, Huseman C, Levitsky L, et al. United States multicenter study of factors predicting the persistence of $\mathrm{GH}$ deficiency during the transition period between childhood and adulthood. Int J Pediatr Endocrinol 2013;(1):6.

76. Tauber M, Moulin P, Pienkowski C, Jouret B, Rochiccioli P. Growth hormone (GH) retesting and auxological data in $131 \mathrm{GH}$-deficient patients after completion of treatment. J Clin Endocrinol Metab 1997;82(2):352-6.

77. Toogood A, Shalet S. Diagnosis of severe growth hormone (GH) deficiency in young adults who received $\mathrm{GH}$ replacement therapy during childhood. Acta Paediatr 1997;86(S423):117-20.

78. Donaubauer J, Kiess W, Kratzsch J, Nowak T, Steinkamp H, Willgerodt H, et al. Reassessment of growth hormone secretion in young adult patients with childhoodonset growth hormone deficiency. Clin Endocrinol (Oxf) 2003;58(4):456-63. 
79. Murray PG, Hague C, Fafoula O, Gleeson H, Patel L, Banerjee I, et al. Likelihood of persistent $\mathrm{GH}$ deficiency into late adolescence: relationship to the presence of an ectopic or normally sited posterior pituitary gland. Clin Endocrinol (Oxf) 2009;71(2):215-9.

80. Yadav P, Singhal S, Chauhan S, Harit S. MRI evaluation of size and shape of normal pituitary gland: age and sex related changes." J Clin Diagn Res 2017 TC01TC04.

81. Argyropoulou M, Perignon F, Brunelle F, Brauner R, Rappaport R. Height of normal pituitary gland as a function of age evaluated by magnetic resonance imaging in children. Pediatr Radiol 1991;21(4):247-9.

82. Han X, Xiu J, Huang Z, Zhang J, Zhang Z, Dong Y, êl. Three-dimensional magnetic resonance volumetry of the pituitary gland is effective in detecting short stature in children. Exp Ther Med 2014;8(2):551-6.

83. Doraiswamy PM, Potts JM, Axelson DA, Husain MM, Lurie SN, Na C, et al. MR assessment of pituitary gland morphology in healthy volunteers: age- and genderrelated differences. AJNR Am J Neuroradiol;13(5):1295-9.

84. Kessler M, Tenner M, Frey M, Noto R. Pituitary volume in children with growth hormone deficiency, idiopathic short stature and controls. J Pediatr Endocrinol Metab 2016;29(10):1195-200.

85. Maghnie M, Lindberg A, Koltowska-Häggström M, Ranke MB. Magnetic resonance imaging of CNS in 15043 children with GH deficiency in KIGS (Pfizer International Growth Database). Eur J Endocrinol 2013;168(2):211-7.

86. Kriström B, Aronson AS, Dahlgren J, Gustafsson J, Halldin M, Ivarsson SA, et al. 
Growth Hormone (GH) Dosing during Catch-Up Growth Guided by Individual Responsiveness Decreases Growth Response Variability in Prepubertal Children with GH Deficiency or Idiopathic Short Stature. J Clin Endocrinol Metab 2009;94(2):483-90.

87. Reiter EO, Price DA, Wilton P, Albertsson-Wikland K, Ranke MB. Effeet of growth hormone $(\mathrm{GH})$ treatment on the near-final height of 1258 patients withiciopathic $\mathrm{GH}$ deficiency: analysis of a large international database. J Clin E.ndocrinoi Metab 2006;91(6):2047-54.

88. Cutfield W, Lindberg A, Wikland KA, Chatelain P, Ranke M, Wilton Final height in idiopathic growth hormone deficiency: the KIGS experience. ACta Paediatr 1999;88(s428):72-5.

89. Blethen SL, Baptista J, Kuntze J, Foley T, LaFranchi S, Johanson A. Adult Height in Growth Hormone (GH)-Deficient Children Treated with Biosynthetic GH. J Clin Endocrinol Metab 1997;82(2):418-20.

90. Pozzobon G, Partenope C, Mora S, Garbetta G, Weber G, Barera G. Growth hormone therapy in children predictive factors and short-term and long-term response criteria. Endocrine 2019; 66(3):614-621

91. Deodati A, Cianfarani S. Impact of growth hormone therapy on adult height of children with idiopathic short stature: systematic review. BMJ 2011;(342):c7157.

92. Wit JM, Ranke MB, Albertsson-Wikland K, Carrascosa A, Rosenfeld RG, Van Buuren S, et al. Personalized approach to growth hormone treatment: Clinical use of growth prediction models. Vol. 79, Hormone Research in Paediatrics. Horm Res Paediatr; 2013; 257-70. 
93. Yuen KCJ, Biller BMK, Radovick S, Carmichael JD, Jasim S, Pantalone KM, et al. American association of clinical endocrinologists and american college of endocrinology guidelines for management of growth hormone deficiency in adults and patients transitioning from pediatric to adult care. Endocr Pract 2019;25(11):1191-232.

94. Grimberg A, DiVall SA, Polychronakos C, Allen DB, Cohen LE, Quiratos JB, et al. Guidelines for Growth Hormone and Insulin-Like Growth Factor-I Treatment in Children and Adolescents: Growth Hormone Deficiency, Idiopathic Short Stature, and Primary Insulin-Like Growth Factor-I Deficiency. Horm Rês Paediatr 2016;86(6):361-97.

95. Loche S, Bizzarri C, Maghnie M, Faedda A, Tzialla C, Auteili M, et al. Results of early reevaluation of growth hormone secretion in short children with apparent growth hormone deficiency. J Pediati 2002;140(4):445-9.

96. Vuralli D, Gonc EN, Ozon ZA, Alikasifogiu A, Kandemir N. Clinical and laboratory parameters predicting a requiremen for the reevaluation of growth hormone status during growth hormone treatmen: Retesting early in the course of $\mathrm{GH}$ treatment. Growth HormigF Res 20 17:34:31-7.

97. Carigiano B, Swee DS, Quinton R, Bonomi M. Genetics of congenital hypogonadotropic hypogonadism: peculiarities and phenotype of an oligogenic disease. Hum Genet 2020 [Epub ahead of print].

98. Fraietta R, Zylberstejn DS, Esteves SC. Hypogonadotropic Hypogonadism Revisited. Clinics 2013;68(Suppl 1):81.

99. Fredriks AM, Van Buuren S, Van Heel WJM, Dijkman-Neerincx RHM, Verloove- 
Vanhorick SP, Wit JM. Nationwide age references for sitting height, leg length, and sitting height/height ratio, and their diagnostic value for disproportionate growth disorders. Arch Dis Child. 2005 Aug;90(8):807-12.

100. Binder G, Schweizer R, Blumenstock G, Braun R. Inhibin B plus LH vs GriRH agonist test for distinguishing constitutional delay of growth and puberify from isolated hypogonadotropic hypogonadism in boys. Clin Endocrinol (Oxf) 2015 ;82(1):100-5. 
Page 56 of 120

Galazzi \& Persani, 56

1

2

3

\section{NOTES}

Conflicts of interest - The Authors certify that there is no conflict of interest with any financial organization regarding the material discussed in the manuscript.

Funding-This work was supported by Ricerca Corrente funds of Istituto Auxologico Italiano (codes: 05F401_2014 and 02C502_2005).

Authors' contributions - E.G. conducted the literature review and prepared the manuscript.L.P. performed the critical revision of the manuscript. All authors read and approved the submitted version. 
Page 57 of 120

\section{TABLES}

Table I - Clinical differences between CDGP, GHD and cHH at presentation

(2) (3) (15) (16) (17) (18) (25) (26) (29) (30) (33) (44) (67) (68) (97) (99)

\begin{tabular}{|c|c|c|c|}
\hline & CDGP & GHD & $\Delta$ \\
\hline $\begin{array}{l}\text { Initial Height } \\
\text { (SDS) }\end{array}$ & $>-2.5$ & any & $\begin{array}{l}>-2.5 ; 60 \% \text { of the cases has normal } \\
\text { height }\end{array}$ \\
\hline Growth velocity & $\begin{array}{l}\text { Prepubertal, } \\
\text { concordant with } \\
\text { bone age }\end{array}$ & $\begin{array}{l}\text { Extremely } \\
\text { reduced }\end{array}$ & \\
\hline BMI & Reduced & Increased & Normal or increased \\
\hline Bone Age (BA) & $\begin{array}{l}\text { Delayed by 1-3 } \\
\text { years }\end{array}$ & $\begin{array}{l}\text { Frequently } \\
\text { delayed; } \\
\text { possible rare } \\
\text { cases of } \\
\text { normal/adyanced } \\
\text { BA for CA ir } \\
\text { sudden GHD } \\
\text { onset occurs or } \\
\text { precocious } \\
\text { puberty coexists }\end{array}$ & \\
\hline $\begin{array}{l}\text { Predicted Adult } \\
\text { Height (PAH) }\end{array}$ & $\begin{array}{l}\text { Lower limit } \\
\mathrm{TH}\end{array}$ & Th & $>\mathrm{TH}$ \\
\hline $\begin{array}{l}\text { Past history } \\
\text { illness }\end{array}$ & $\begin{array}{l}\text { Sometimes } \\
\text { cryptorchidism } \\
\text { unilateral) or } \\
\text { phimosis }\end{array}$ & $\begin{array}{l}\text { Neonatal } \\
\text { hypoglycemia, } \\
\text { prolonged } \\
\text { jaundice, } \\
\text { micropenis, } \\
\text { midline defects }\end{array}$ & $\begin{array}{l}\text { "Red flags": cryptorchidism } \\
\text { (bilateral), micropenis, } \\
\text { hypospadias, renal anomalies, } \\
\text { midline defects, hypo/anosmia }\end{array}$ \\
\hline Family histery & $\begin{array}{l}\text { positive for } \\
\text { CDGP in } 80 \% \text { of } \\
\text { the cases }\end{array}$ & $\begin{array}{l}\text { Parent's } \\
\text { consanguinity; } \\
\text { one family } \\
\text { member affected } \\
\text { if secondary to a } \\
\text { specific } \\
\text { mutation }\end{array}$ & $\begin{array}{l}\text { One family member affected or } \\
\text { presenting hypo/anosmia or } \\
\text { neurologic diseases or history of } \\
\text { CDGP }\end{array}$ \\
\hline
\end{tabular}

Table note:

$B M I=$ body mass index,$P A H=$ predicted adult height $B A=$ bone age,$C A=$ chronological age, $T H=$ target height. 
Table II- Differences of five methods of adult height prediction (PAH) in terms of overestimation or under-estimation (in cm) compared to actual final height

(27) (28) (29) (30) (69)

\begin{tabular}{|l|l|l|}
\hline Method of PAH & boys & girls \\
\hline Bayley and Pinneau & $+3.1 \mathrm{~cm}$ & $-0.8 \mathrm{~cm}$ \\
\hline Roche-Weiner-Thissen (RWT) & $-0.6 \mathrm{~cm}$ & $+2.3 \mathrm{~cm}$ \\
\hline TH & $+1.7 \mathrm{~cm}$ & $-7.3 \mathrm{~cm}$ \\
\hline $\begin{array}{l}\text { Tanner-Whitehouse Mark I } \\
\text { (TW-MI) }\end{array}$ & $-4.2 \mathrm{~cm}$ \\
\hline $\begin{array}{l}\text { Tanner-Whitehouse Mark II } \\
\text { (TW-MII) }\end{array}$ & & \\
\hline
\end{tabular}


Table III._Final height (FH) in CDGP boys and girls considering their possible treatment with low dose sex steroids

(54) (55) (56) (57) (63)

\begin{tabular}{|c|c|c|c|c|c|}
\hline & $\begin{array}{l}\text { SDS FH } \\
\text { untreated } \\
\text { patients }\end{array}$ & $\begin{array}{l}\text { SDS FH } \\
\text { treated } \\
\text { patients }\end{array}$ & SDS TH & $\begin{array}{l}\Delta \text { SDS } \\
\text { FH -TH }\end{array}$ & $\begin{array}{l}\text { SDS FH } \\
\text { reference } \\
\text { population }\end{array}$ \\
\hline \multicolumn{6}{|c|}{ BOYS } \\
\hline $\begin{array}{l}\text { Crowne et al, } \\
\text { EJP, } 1991 \\
(n=43)\end{array}$ & -1.6 & n. $r$. & -0.6 & -1 & n. $r$. \\
\hline $\begin{array}{l}\text { Poyrazoglu et } \\
\text { al, JPEM } 2005 \\
(\mathrm{n}=30)\end{array}$ & -2.3 & n. $r$. & n. $r$. & & +0.12 \\
\hline $\begin{array}{l}\text { Couto-Silva et } \\
\text { al, JPEM } 2005 \\
(\mathrm{n}=70)\end{array}$ & -0.7 & -1.2 & & n. $r$ & n. $r$. \\
\hline $\begin{array}{l}\text { Zucchini et al, } \\
\text { EJP } 2008 \\
(\mathrm{n}=29)\end{array}$ & -1.02 & -1.39 & $\begin{array}{l}-1.12 \\
\text { untreated } \\
\text { patients } \\
-1.45 \text { trea } \\
\text { patients }\end{array}$ & $\begin{array}{l}+0.1 \\
\text { untreated } \\
\text { patients; } \\
+0.43 \\
\text { treated } \\
\text { patients }\end{array}$ & n. $r$. \\
\hline & & & & & \\
\hline $\begin{array}{l}\text { Crowne et al, } \\
\text { EJP, } 1991 \\
(\mathrm{n}=15)\end{array}$ & & n.r. & -0.8 & -0.7 & n. $r$. \\
\hline $\begin{array}{l}\text { Zucchini et al, } \\
\text { EJP } 2008 \\
(n=16)\end{array}$ & -0.78 & n. $r$. & -0.88 & +0.1 & n. $r$. \\
\hline
\end{tabular}

Table note: $n . r .=$ not reported 
Page 60 of 120

Table IV._Final height (FH) in GHD boys and girls treated with rhGH at substitutive doses.

(86) (87) (88) (89) (90)

\begin{tabular}{|c|c|c|c|}
\hline & FH SDS & $\Delta \mathrm{SDS} F H-\mathrm{IH}$ & $\Delta$ SDS FH -TH \\
\hline $\begin{array}{l}\text { Reiter E.O. et al } \\
(\mathrm{n}=1258)\end{array}$ & $-0.8(\overbrace{}^{\Uparrow}) ;-1(+)$ & n.r. & From -0.6 to +0.2 \\
\hline $\begin{array}{l}\text { Cutfield et al } \\
(\mathrm{n}=369)\end{array}$ & -1.5 & +1.7 & $\nabla$ \\
\hline $\begin{array}{l}\text { Genentech American } \\
\text { group } \\
(\mathrm{n}=121)\end{array}$ & $-0.7 \pm 1.2$ & n.r. & n.r. \\
\hline $\begin{array}{l}\text { Pozzobon et al } \\
(\mathrm{n}=94)\end{array}$ & -1.11 & From +1 & $\begin{array}{l}+0.26 \pm 0.82 \\
+0.00 \text { to }+0.11 \pm 0.80 \text { to }\end{array}$ \\
\hline
\end{tabular}

Table note: $n . r .=$ not reported 
Page 61 of 120

\section{TITLES OF FIGURES}

Figure 1. - Genetic bases of CDGP, GHD and cHH and shared causes.

Figure 2. - Red Flags for cHH. Note that most of these features are shared with GHD and, in a minority of cases, with CDGP.

Figure legend:

ONH = Optic nerve hypoplasia

SOD = Septo optic dysplasia

$H P E=$ holoprosencephaly

$E P P G=$ ectopic posterior pituitary gland

PSIS = pituitary stalk interruption syndrome

MPHD = multiple pituitary hormonal deficiencies

CHARGE = Coloboma, Heart defects, Atresia of choande, Retânotion of growth, Ear abnormalities

Figure 3. -Diagnostic algorithm for the differential diagnosis between CDGP, GHD and cHH

Figure legend

- GHST = growth hormone stimulation test; Criteria for GHST : SDS H<-3 or delta $\triangle S D S$ TH-IH $<1.5 \& \mathrm{GV}<\mathrm{I}$

- LDSS = low dose sex steroials: for example testosterone enanthate im 25-50 mg/monthly for boys for 6 months or oestrudiol patches $12.5 \mu \mathrm{g}$ twice weekly for girls for 6 months

*Example of priming protocol before GHST: Testosterone enanthate $100 \mathrm{mg}$ im 7 days before the test for boys; E2 Valerate 1-2 mg orally (if <20 kg or > $20 \mathrm{~kg}$ respectively) 3 days before the test for girls.

** Supportive endocrine markers (for boys):

- Inhibin B <35 ng/L for Tanner stage 1; <65 ng/L for Tanner stage 2

- $A M H<20 \mathrm{ng} / \mathrm{mL}$

- LH peak under GnRH test or GnRHa < 4-5 UI/L

- Testosterone levels < $3.6 \mathrm{nmol} / \mathrm{L}$ after 3 days or $<9.5 \mathrm{nmol} / \mathrm{L}$ after 19 days of hCG test 
DIFFERENTIAL DIAGNOSIS BETWEEN CONSTITUTIONAL DELAY OF GROWTH AND PUBERTY, IDIOPATHIC GROWTH HORMONE DEFICIENCY AND CONGENITAL HYPOGONADOTROPIC HYPOGONADISM: A CLINICAL CHALLENGE FOR THE PEDIATRIC ENDOCRINOLOGIST.

Elena GALAZZI ${ }^{1}$ *, Luca G. PERSANI $^{1,2}$

${ }^{1}$ Department of Endocrine and Metabolic Diseases, Istituto Auxologico Italiano IRCCS, 20149 Milan, Italy; ${ }^{2}$ Department of Clinical Sciences and Community Health, Dniversity of Milan, 20122 Milan, Italy.

*Corresponding author: Elena Galazzi, Department of Endocrine and Metabolic Diseases, Istitutô Auxologico Ialliano, 20149 Milan, Italy; E-mail: e.galazzi@auxologico.it 


\section{ABSTRACT}

INTRODUCTION: Differential diagnosis between constitutional delay of growth and puberty (CDGP), partial growth hormone deficiency (pGHD), and congenital hypogonadotropic hypogonadism (cHH) may be difficult. All these conditions usually present with poor growth in preor peri-pubertal age and they may recur within one familial setting, constituting a highly variable, but somehow common, spectrum of pubertal delay.

EVIDENCE ACQUISITION: Narrative review of the most relevant English papers published between 1981 and march 2020 using the following search terms "constitutional delay of growth and puberty”, "central hypogonadism”, “priming”, "growth hormone deficiency", "pitritary”, "pituitary Magnetic Resonance Imaging", with a special regard to the latest scientific agquisitions.

EVIDENCE SYNTHESIS: CDGP is by far the most prevalent enitity in boys and recurs within families. pGHD is a rare, often idiopathic and transient condition, where hypostaturism presents more severely. Specificity of pGHD diagnosis is increased by priming children before growth hormone stimulation test (GHST); pituitary MRI and geneticanalysis are recommended to personalize future follow-up. Diagnosing chitrmay be obvious, when anosmia and eunuchoid proportions concomitate. However, cHH can either overlap withpe $\mathrm{HD}$ in forms of multiple pituitary hormone deficiencies (MPHD) or syndromic conditions either with CDGP in family pedigrees, so endocrine workup and genetic investigations are necessary. The use of growth charts, bone age, predictors of adult height, primed GHST and low dose sex steroids (LDSS) treatment are recommended.

CONCLUSIONS: Only a step-by-step diagnostic process based on appropriate endocrine and genetic markers together with LDSS treatment can help achieving the correct diagnosis and optimizing outcomes.

\section{Key words:}

puberty, short stature, central hypogonadism, growth retardation, pituitary 


\section{TEXT}

Growth hormone $(\mathrm{GH})$ is the most abundant hormone in the adult pituitary gland. Somatotrophs, located predominantly in the lateral wings of the anterior pituitary, represent the most abundant cell population in the pituitary (35-45\% of total). GH action is crucial in mediating growth and metabolic functions in human tissues and, for this reason, is finely regulated. Neuropeptides, neurotransmitters and opiates impinge on the hypothalamus modulating the release of either GHRH, which induces GH gene transcription and hormone release, or somatostatin (also called sontatotropin release-inhibiting factor, SRIF), which suppresses both basal and GHRH-stimulated GH pulse amplitude and frequency. Stimulating effects have been described from $\alpha$-adrenergic pathway (morepinephrine, insuline induced hypoglycemia, clonidine, arginine, and Ldopa, apomorphines, endorphins/enkephalins (released after physical stress and extreme excercise), from slow-wave sleep, orexigenic hormones (ghrelin and synthetic hexapeptides through-growth hormone secretagogue receptor), cholinergic and serotoninergic neurons, gut neuropeptides (neurotensin. VIP, motilin, cholecystokinin, glucagone), acute glucocorticoid administration and sex steroids. Inhibiting effects have instead been described from $\beta$-adrenergic pathway, anorexigenighormones (leptine), high circulating fat free acids levels, acute hyperglysemia, hypothyroidism, chronic glicocorticoid exposure, and IGF-1, this last one as part of the hypoynalanic-pituitary peripheral regulatory feedback system. The integrated interactions between these influences elicit the classical episodic GH peaks right inside a specific 24-h circadian rythm. (1)

Gonadotropins (LH and FSH) comprise only 10-15\% of the anterior pituitary cell population but their role is crucial for gonadal stimulation and reproduction. Hypothalamic GnRH pulse amplitude and frequency determines the physiologic pattern of LH and FSH secretion. Kisspeptin neurons undergo a dynamic process of prenatal-postnatal maturation that enables them to establish connections to GnRH neurons early in development. KNDy neurons located in the arcuate nucleus of the hypothalamus and co-expressing Kisspeptin, neurokinin B and dynorphin represent the GnRH pulse 
generator in both sexes, which then in turn stimulate gonadotroph cells in the pituitary, triggering puberty induction and progression. After a first period of action in utero and in the first months of life (the so-called mini-puberty), this axis is switched off during childhood and reawakens itself in the peripubertal period. Many neurotrasmitters from the limbic system, the brain stem and from other hypothalamic nuclei stimulate (glutammate, norepinephrine, kisspeptin) or inhibit (GABA, endogenous opioid, dynorphin) the hypothalamus-pituitary-gonadal (HPG) axis. Other influences may derive from glial cells, periferic steroids milieu and gonadic peripheric production of activin/inhibin. Leptin, a product of peripheral adipose tissue, is alse a positive regulator of the hypothalamic-pituitary-gonadal axis, signaling energy availability to the central nervous system. (2)

Gonadal steroids then reciprocally have a wide influence on GH secretion and action. Testosterone stimulates central GH secretion mainly through its aromatization to estrogen: in fact, anti-estrogen tamoxifen is able to significantly reduce in normal, and in hypogonadal men on testosterone replacement therapy, the 24-h mean serum GH concentrations, the mean GH pulse amplitudes, and the serum IGF-1 levels. (4) As further proof the administration of a non-aromatizable androgen (dihydrotestosterone) is not able to elicit GA secretion. (5) Testosterone additionally acts peripherally, amplifying GH-mediated secretion of GF-1, sodium retention, substrate metabolism and protein anabolism Exogenous estrogens are instead able to stimulate GH secretion when given orally, due to their first-pass hepathic inibition of IGF-1 production. This effect can be avoided using transdermal routes, at least if physiological doses of estrogens are given. (6)

Instead it is still unresolved whether, in females pituitaries, estrogens have a central direct stimulatory role on somatotrophs, since stimulated GH secretion proved to be similar between women with premature ovarian failure (either assuming or not hormonal replacement therapy) and aged-matched controls with normal ovarian cycles. (7)

Animal models studies proved the importance of the sex steroids impingement on fetal pituitary somato-mammotrophs cells store, which will subsequently determine the GH reserve in childhood 
and adulthood. (8) (9) Similarly, human studies have also demonstrated that, physiologically, during puberty the activation of the hypothalamic-pituitary-gonadal axis leads to a large increase in the circulating sex steroids concentration, which then enhance the pulse amplitude of GH secretion, increase IGF-I concentrations and the anterior pituitary size. (5) (10)

Many association studies in normal children have also proved a physiological threefold increase in GH secretion following the increase in gonadal steroid concentrations during puberty. (11)

GH secretion has also proved to be reduced in hypogonadal children (12) but increased in precocious puberty, whose successful therapy is able to normalize GH secretion. (13)

Because of these multiple interconnections between GH and HPG axis, it is not infrequent that a child in peripubertal age may present to a pediatric endocrinologist with short stature and/or reduced growth velocity with associated delayed puberty. (Table I). For the same reasons, subnormal GH peaks to physiological or pharmacological stimuli are frequently found in normal prepubertal children, but they have proven to fully normalize when they will achieve stages 4 or 5 of Tanner maturation or after estrogen administration. (14)

While constitutional delay of growth and pubexty (CDGP) may be the most probable diagnosis in a child presenting with shoit stature and pubertal delay, especially for males, growth hormone deficiency and congenital hypogonadotropic hypogonadism must at the same time be ruled out. Otherwise, in children with true GHD or cHH left untreated, adult height and pubertal maturation will lack to fully develop normally, resulting in important psycho-social discomfort as well as long term medical sequelae in these children (permanent short stature in GHD, cryptorchidism and risk of testicular cancers/lack of fertility in $\mathrm{cHH}$, osteoporosis and alteration of body composition in both conditions). As growth is a good indicator of a child's health, the increasing attention on children wellness and well-being especially in the more developed countries has been a matter of medical attention over years. Moreover, as the child grows into adulthood, fertility potential becomes an important issue, which is also a major concern for parents. 


\section{EVIDENCE ACQUISITION}

\section{Constitutional delay of growth and puberty (CDGP)}

\section{A Definition}

The term CDGP describes children who have a normal variant of maturation tempo characterized by short stature with relatively normal growth rate during infanky, but showing deceleration during peribubertal period possibly due to to the lack of growth spurt physiologicany driven by the sex hormones rise. According to the pubertal status, 3 different "categories? of CDGP children may be defined:

- CDGP type 1: Prepubertal children (Tanner stage G 1 for boys $\geq 14$ yo or B1 for girls $\geq 13$ yo), as reported by the $200 \%$ ESPE classification. (15) usually associated by slow growth rate, delayed bone age (delay of 1 year or more compared to chronological age) and a positive family history of delayed puberty

- CDGP type 2: Pubertal chituren but displaying slow or stuttering progression of sexual caracteristics, with a genital Tanner stage less than - 2 SDS compared to normal age-matched peers, defined by the use of puberty nomograms (16)

- Possible CDGP type 3, according to Stalman et al: if before 14 (for boys) or 13 (for girls) years old if, during his/her growth, three out of four conditions are met: i) Tanner stage $<-1$ SDS defined with the use of puberty nomograms; ii) bone age delay $>1$ year compared to chronological age; iii) being short for target height (TH); and iv) positive family history of pubertal delay (menarche in the mother > 15 yo; late paternal growth spurt and shaving). (17)

\section{B Prevalence}


CDGP is a relative common condition, affecting $2-2.5 \%$ of the population. (18) This alteration is extremely common in boys, and less in girls. It is estimated that up to $80 \%$ of boys and around $33 \%$ of girls displaying delayed puberty have a self-limited condition. (19) However, prevalence in CDGP females ranges widely : in a large Georgean cohort of female adolescents with delayed puberty, for example, the prevalence of CDGP in girls is accounted to be lower and around 10\%, against the great majority of the female cohort displaying organic diseases (premature ovarian failaretabsence of uterus or vagina). (20) Because in family series reports males and females are described to be equally affected (19), a gender selection bias seeking medical attention has been postulated. (21)

\section{C Clinical presentation}

Children displaying CDGP may frequentry seek for medical attention for short stature, which is usually not severe (>-2.5 SDS) and for reduced growth veloeity (<-2 SDS) together with a prepubertal stage of sex maturation. Although growth yelocity (sy) may be reduced compared to normal pubertal children, it is frequently found to be $>3.6 \mathrm{~cm} / \mathrm{year}$ in boys. On the other hand, GV seems not discriminative at best for different etiologies of delayed puberty in girls. (22)

Because CDGP patients are sometimes poor eaters (23) and need higher caloric intake compared to age-matched controls (24), BMI is often found to be at lower range, which is an important concern for parents and contributes possibly indipendently to the reduced growth. Of interest, nearly $25 \%$ of boys with CDGP come with the diagnosis of attention deficit with hyperactivity disorder (24). Even though adrenarche/pubarche derive from adrenal rather than HPG axis activation, delayed puberty in these patients consists of a delayed gonadarche together with absence of pubarche/adrenarche. (25)

Looking at growth charts may be useful. CDGP boys are born with normal length, have a decreased growth pattern compared to target percentile until 2 years old, then tend to level till 5 years old, 
starting from when a height SDS loss is already detectable, reaching its maximum at pubertal age. (26)

For a complete auxological workup, a sistematic assessment of bone age is warrented, either using Greulich-Pyle or Tanner Whitehouse methods (referring to its second edition of 1983 TW2, or its third revised edition of 2001 TW3) or informatic programs that are rising into attention for the more accurate bone age assessment in non-american non-caucasian etnicities. (27) In CDCP subjects bone age is frequently found to be delayed by at least 2 years compared to chronological age, even though it can range from 1 to 3 years less, so that if we bring the child back on his biological age the growth percentile may be adequate for the family target. (28)

The prediction of adult height based on bone age (PAH $=$ predicted adult height) may also be very useful because it frequently suggest that a child with CDGP willay within the lower range of his/her target height (29). To this regard it is worth explaining that different methods for final height prediction based on bone age exist, and according to the method used there may be some overestimations or undestimations of the predigted final height. (Table II) In the matter of question, the most used Bayley and Pinneaud system has been proved to overestimate boy's final height, raising doubts of the possibility of truly reîy on this method for adult height prediction. (29) For this reasons, new models of bøne age prediction in CDGP patients have been recently established. (30)

Clinical hystory and examination of the child should point out the so called "red flags" i.e. cues orienting the clinician towards specific diagnostic subgroups (Fig. 2). To this extent it is worth noticing that in CDGP patients cryptorchidism may be found in a low percentage of cases (2\%) mostly as a unilateral finding. (18) Up to $80 \%$ of children diagnosed as CDGPs have at least one family member in which self-limited delayed puberty has occured, which can be also taken as an important diagnostic tool; however, a family history of CDGP does not exclude cHH given the incomplete penetrance and variable expressivity of $\mathrm{cHH}$ phenotype within pedigrees (of which delayed puberty, 
subfertility and hypo-anosmia can also be enriched). (2) (3) A new observation of our group introduced into this complex clinical picture also TBX3 mutations accounting for Ulnar Mammary Syndrome (UMS), and several reports of UMS families describe the variable association of either CDGP, more frequently, either of true cHH defects and GHD, in a minority of cases (31). (Figure 2)

\section{D Endocrine workup and the role of sex steroid priming before growth hormone stimulation} tests

Priming refers to the administration of sex steroids to prepubertal or early puberal children prior to GHST. The evidence to support this practice is low, however suggested by the 2016 International Guidelines for growth hormone deficiency and idiopathic short statureAccording to these guidelines, priming is suggested for prepubertal boys older than 11 or prepubertal girls older than 10 years with adult height prognosis within -2 SD of the peference population mean in order to prevent unnecessary rhGH treatment of children with a more probable dragnosis of constitutional delay of growth and puberty. (32) (33)

The studies supporting this approach are however of limited evidence, considering the small group of patients of the studies analyzed, yet sometimes conflicting. Marin et al showed a 95\% rate of normalization in 11 normal children after administration of ethinylestradiol (EE) $40 \mu \mathrm{g} / \mathrm{m} 2$ in 3 divided doses with meals for 2 days and, compared to placebo, a rise in both GH peak from $7.6 \pm 4.4$ on placebo to $18.7 \pm 9.2 \mu \mathrm{g} / \mathrm{L}$ on $\mathrm{EE}$ and of the lower limit of the $95^{\circ}$ confidence interval from 1.7 to $7.2 \mu \mathrm{g} / \mathrm{L}$. (14) Martinez et al, similarly, showed in a randomized control study a significant increase in $\mathrm{GH}$ peaks under a sequential arginine-clonidine test when 44 short normal children were primed with estradiol valerate (E2) orally ( 1 or $2 \mathrm{mg}$ depending on the weight $<$ or $>$ of $20 \mathrm{~kg}$, respectively) in three consecutive days before testing, compared to placebo: in these children GH mean peak 
increased from $17.8 \pm 10.9$ on placebo to $27.9 \pm 14.5 \mu \mathrm{g} / \mathrm{L}$ on E2, increasing diagnostic accuracy of GHST form $90 \%$ to $95 \%$. (34) Analogously, Molina et al proved that 39 children primed with either $100 \mathrm{mg}$ i.m. of testosterone enanthate for 5-8 days (in boys) or with $1 \mathrm{mg}$ estradiol valerate daily for 3 days (in girls) were able to significantly increase GH mean peaks under clonidine stimulation test, either if diagnosed as CDGP (from $5.83 \pm 2.67$ to $17.42 \pm 8.46 \mathrm{ug} / \mathrm{l}$ ) or as GHD (from $3.68 \pm 2.34$ to $5.95 \pm 2.76 \mathrm{ug} / \mathrm{l}) .(35)$ Muller et al showed a normalization $(\mathrm{GH}$ peak $>10 \mathrm{ug} / \mathrm{l}$ ) after arginine test in $77 \%$ of 26 peripubertal boys primed with $100 \mathrm{mg}$ of testosterone enanthate $3-10$ days before the stimulation. (36) Taken together, these studies led to the suggestion that estrogen priming may reduce the number of false positive children (i.e. false non responders to a GHST) avoiding unnecessary rhGH treatment in a high proportion of children under assessment for short stature.

Other studies have however shown opposite results. Soliman et al proved that in children above 9 years of age under investigation for short stature with a clonidine stimulation test, the proportion of patients displaying GH peaks $>10 \mu \mathrm{g} / \mathrm{L}$ did not differ between the primed group (pre-treated with 25 $\mathrm{mg}$ of intramuscular testosterone depot $7-10$ days before the test for boys or with 1,25 $\mathrm{mg}$ of oral conjugated estrogens for 3 days before the test for girls) compared to the unprimed group (52\% vs 47\% respectively, N.S) (37) Most importantly, only one follow-up study on 50 boys was able to prove that avoiding treatment in children with subnormal unprimed but normal primed GH peaks under GHST does not result in an impaired final height compared to their midparental target (-1.27 vs -1.38 SDS, respectively). (38)

Larger follow-up studies considering both males and females and looking at final height of children undergoing primed GHST are lacking. However, taken together, these studies evoke the idea that priming before GHST may reduce the false positive diagnosis of growth hormone deficiency, avoiding unnecessary rhGH treatment in many children under investigation for short stature. It is however estimated that only $30-40 \%$ of pediatric endocrinologists prime peripubertal children prior to $\mathrm{GH}$ stimulation testing in routine clinical practice. The limited diagnostic application is justified 
Page 72 of 120

by some experts based on considerations of priming as an artificial stimulus generating false transient normal GH peaks under GHST. (39)

Beyond GHST, no endocrine marker can be fully reliable in the diagnosis of CDGP. Nevertheless, in males, measurable levels of Inhibin B (> $35 \mathrm{ng} / \mathrm{mL}$ ) have been proposed to fairly correlate with the maturation of Sertoli cells in the gonads, hence indirectly proving that, in the first months of life, mini-puberty has occurred, pointing out a CDGP rather than $\mathrm{cHH}$ diagnosis. (40) $\mathrm{AMH}$ has also proved to be slightly higher in prepubertal CDGP compared to $\mathrm{cHH}$, however not discriminative for peripubertal CDGP (Tanner stage 2) where it is found to be lower, thus not giving advantages compared to inhibin B alone. (40) (41) In prepubertal CDGP the combination OPrnhibin B at a cutoff $\geq 28.5 \mathrm{ng} / \mathrm{L}$ with $\mathrm{AMH}$ at a cut-off of $\geq 20 \mathrm{ng} / \mathrm{mL}$ has however proved to increase the specificity of CDGP diagnosis up to 83\%. (41) Other markers of testicular (INSL3), and adrenal (DHEAS) activity have not proved to be discriminative for the differential diagnosis between CDGP and $\mathrm{cHH}$.

The restriction of most of the studies to the malecohorts does not allow to use these endocrine markers for girls. At the same time, in females Inhibin B levels are less useful as they are lower and a less significant rise is seen at puberty. (42)

Basal gonadotropin levels are not discriminative as they are supposed to be low either in prepubertal CDGP or in $\mathrm{CHH}$ cohorts. If in CDGP children puberty is in a very initial stage, basal gonadotropins levels may be found to be more than $0.2 \mathrm{UI} / \mathrm{L}$ in both genders with the use of immunochemiluminometric assays, which could be a simple and useful marker against a severe $\mathrm{cHH}$ form. (43) Moreover, HPG axis stimulation upon GnRH test or following a GnRH agonist (GnRHa) has also been proposed (22) (42) (43), however up to $30 \%$ of children diagnosed as either CDGP or cHH overlap their LH peaks under stimulation. (44) Despite some promises for longer GnRH test protocols (up to 36 hours), these tests have suggested to be helpful only in a few studies but without 
high diagnostic accuracy. Similarly, the use of GnRHa (Naferelin, Leuprolide, Triptorelin, Buserelin) has proved to elicit higher LH peaks but the low sample size of these studies, the presence of overlapping results with $\mathrm{cHH}$ cohorts and the absence of a clear diagnostic threshold limit their diagnostic utility. (44)

HCG test has also been postulated as a useful diagnostic tool for the differential diagnosis between CDGP and cHH (see below section 3.D) (45) (46).

Kisspeptine boluses have also proved to heterogeneously increase LHiesponses in CDGP patients (47) in research settings, but this approach is not yet routinely performed in clinical practice.

Another important tool that can be taken into account to differentiate CDGPfrom other cohorts is the evidence of a self progressing pubertal development after a 3-6 months treatment trial with low dose sex steroids (LDSS). (3) (48) After LDSS withdra wal, an Inhisin B > $94.7 \mathrm{ng} / \mathrm{mL}$ and LH peak after GnRHa > 14.7 U/L have been also provein to discriminate at best CDGP upon cHH. (49)

\section{E GENETIC TESTS}

Genetic basis of CDGP are supposed to be different from those of $\mathrm{cHH}$. Even though, heterozygous variants in cHH putative genes have been found in up to $7 \%$ of the CDGP cohorts (18), the current scientific literature tends to consider the hereditary basis of CDGP as a different, yet mainly still unknown, genetic field. Observational studies have demonstrated that several different inheritance patterns can occur in CDGP, including autosomal dominant pattern (in the majority of the cases, with or without complete penetrance), autosomal recessive, bilinear (both parents affected) or X-linked. De novo mutations can also occur. (19) 
Page 74 of 120

\begin{abstract}
Four genes clusters have been demonstrated in CDGP cohorts by Howard et al. with exome sequencing in Finnish CDGP index patients: (3)
\end{abstract}

1) Fat Mass and Obesity-associated (FTO) gene (in three of 67 families)

2) Heparan Sulfate 6-O-Sulfotransferase 1 (HS6ST1) gene (in one in 67 families)

3) Enhanced At Puberty 1 (EAP1) gene (in two in 67 families)

4) IGSF10 rare sequence variants in up to $16.4 \%$ of the CDGP cohorts, a gene which encodes a protein that belongs to the immunoglobulin superfamily. However, the role of IGFS10 in delayed puberty remains open, as in a follow-up study, IGSF10 mutations were not reported to be enriched in CDGP patients when compared to controls.

Mutations in the pituitary trascription factor POLF1(PIT) involved mituitary thyrotrophs and lacto-somatotrophs cells development and hormonal expression may present with pubertal delay or with absent or delayed adrenarche, resembling delayed puberfy (50). Mutations in GHSR, a growth hormone secretagogue receptor gene whose endogenous ligand ghrelin produced from gastric cells increases GH pituitary secretion, have been formd to be mutated in both GHD and CDGP patients.

Some known syndromic conditions may present with either CDGP, GHD or cHH within family pedigrees. (Prader Willy Syndrome or CHARGE syndrome). Moreover, as already mentioned, TBX3 mutations accounting for Ulnar Mammary Syndrome (UMS) have been described in litterature also linked to all of these scenarios including CDGP in many family pedigrees. (31).

The genetic basis of CDGP and shared causes with GHD and cHH are illustrated in Figure 1.

\title{
1. F FINAL OUTCOMES AND THERAPEUTIC OPTIONS
}

Given that CDGP is a self-limiting condition, reassurance and watchful waiting are reasonable approaches to treatment. On the other hand, however, new evidences towards long-term sequelae 
associated with delayed puberty are rising into clinician's attention, from the possibility of early menopause and low bone density to a worse psychosocial well-being and peer's relationships (19). Moreover, association studies investigating earlier or later timing in puberty in both genders have been linked with a wide range of adverse health outcomes, including cancers, cardiometabolic, gastrointestinal, musculoskeletal and neurological pathologies. (52)

Additionally, because in CDGPs the magnitude of the growth spurt may be blunted as the child gets older, not infrequently these children will not be able to reach their full growth potential. (53) To this regard, final height in CDGP patients has been widely investigated in boys and many studies have proven that untreated CDGP patients are prone to become shorter either cornpared to their mid parental targets and/or their peers displaying normal timing of puberty, wereas if a treatment with LDSS is given to the child for a short period a time, FH has proved to become similar or better compared to those left untreated. (54) (55) (56) (57) (Table III) This effect may expire if higher doses of testosterone are used. (58) Testosterone therapy (in the form of testosterone esters/undecanoate, given either intramuscularly, transdermal gel, or orally) in this group of patients appears a safe and well tolerated approach thatcan favor a prompt recovery of hypothalamus-pituitary axis after discontinuation of treatment in vow doses are given. (59) The treatment schedules are quite variable, and the efficacy of the treatment is clearly an under-investigated area in adolescent medicine with very few randomised trials available. Letrozole treatment has also been proven to give benefits in CDGP boys compared to testosterone in terms of pubertal progression, even by eliciting different HPG axis responses (increasing gonadotropins and Inhibin B, leading to larger testis size). (22) Both therapies (testosterone $1 \mathrm{mg} / \mathrm{kg} / \mathrm{month}$ or letrozole $2.5 \mathrm{mg} /$ day) had anyway proven to elicit changes in Sertoli cells markers (i.e. decrease in AMH), reassuring about safety in developing mature seminiferous epithelium with both approaches. (60) Other therapies such as oxandrolone have also been suggested for treatment of CDGP, but long term data are lacking. (61) (62) 


\begin{abstract}
Very few follow-up studies are instead available for CDGP girls, and data on treatment with low dose estradiol are almost lacking. (57) (63) (Table III) This is possibly due to the lower rate of presentation to medical attention of girls with pubertal delay compared to boys (26). For girls, natural and transdermal estradiol preparations are preferred.
\end{abstract}

A reasonable therapeutic approach for CDGP children may be made either with $50 \mathrm{mg}$ testosterone enanthate intramuscolary monthly for 3-6 months either with $10 \mathrm{mg}$ testosterone gel $2 \%$ daily for 3 months for boys, or with $1 / 4$ of a $25 \mu \mathrm{g}$ patch of $17-\beta$ estradiol once or twice weekly for 6 months for girls. (3) (64) (65)

Taken together we believe that CDGPs should not be considered as a para-physiological variant of maturation-tempo but, perhaps more appropriately, as a condition charactented by a significant delay of pubertal timing needing treatment with LDSS for a short perigd of time in order to normalize their growth pattern and achieve full growth potential and limit psychosocial and medical issues associated with delayed puberty.

\title{
2. Idiopathic growth hormone deficiency
}

\section{A DEFINITION:}

Growth hormone deficiency is a complex yet rare diagnosis in a child, that should be based on the whole thing of auxological, anatomic and laboratory's findings. (33) This condition can be challenging to differentiate from CDGP as in both settings there is a height SDS deflection and relatively low height velocity compared with cross-sectional population references. Moreover, GHD may also overlap with $\mathrm{cHH}$ clinically, especially when multiple pituitary hormone deficiencies (MPHD) or shared genetic mutations with the condition occurs. 


\section{B PREVALENCE}

The prevalence of GHD is around 1 child every $4.000-10.000$. It is therefore a rare condition and mainly a diagnosis of exclusion upon other possible causes of poor growth (malnutrition, chronic liver and renal diseases, pulmonary diseases, syndromic conditions, iron overload, hypothyroidism, diabetes, skeletal dysplasias, inborn errors of metabolism, and CDGP).

Prevalence of GHD worldwide may ranges widely due to the lack of standard diagnostic criterias (for example, it has been overestimated as up as 1:1800 in Sri Lanka probably due to more liberal diagnostic standards) and also due to referral bias. Even thought there are no apparent racial differences in the incidence of GHD, The National Cooperative Growth Stridy (NCGS), Genentech's study on North American database, revealed that $85 \%$ of patients receiving GH treatment for idiopathic GHD were white, $6 \%$ were black, and $2 \%$ were Asian and Similar distributions were seen with patients with other forms of short stature. Additionarly, patients with GHD from organic causes such as tumors and radiation, may be nuch more prevalent in more industrialized countries, where medical intervention on population is deepened. (66).

\section{C CLINICAI PRESENTATIGN}

Children with GHD may display severe armonic short stature, a reduced height compared to the target height $(\mathrm{TH})$ and/or a poor growth rate. The past medical history may help the clinician if neonatal hypoglycemias, midline defects, prolonged jaundice or MPHDs are present. (67)

In growth charts of boys with congenital GHD a continuous decrease in height SDS from birth on occurs without any levelling (68). Moreover, an increase in fat mass has been described in patients left untreated giving them a "cherubic appearance", which can also be taken as an important diagnostic tool against a presumptive CDGP diagnosis, where BMI is classically found to be low. 
Page 78 of 120

Bone age, either assessed with Greulich \&Pyle or Tanner-Whitehouse methods, is again found to be delayed due to the low GH-IGF-1 levels modelling bone maturation. However, there may be three possible confounding scenarios in which bone age may not be delayed: (i) recently acquired GHD, (ii) obesity, which is tipically associated with advanced bone age, and (iii) concomitant precocious puberty, a scenario where sex hormones can trigger bone maturation. (33)

PAH based on bone age will clearly show an adult height well below the genetic potential of the child. As already mentioned, many methods for PAH preditions exist (Table II): target height, which is the most used method of height prediction in clinical practice, has anyway been associated with a higher prediction error compared to the less used Roche-Weiner-Thissen method (RPT) in a cohort of severe GHD. (69) Therefore, this method might be superior for the prediction of adult height in a child with short stature. It is however clear that CDGP can come into differential diagnosis mainly with cases of recently acquired GHD or, more frequently, partial idiopathic GHD (pGHD).

\section{D ENDOCRINE WORKUP, role of sex steroid priming before GHST and pituitary MRI}

Serum IGF-1 levels are fiequently low in GHD compared to pubertal aged-matched peers and its determination in peripubertal children should be assessed within adjusted reference ranges for actual pubertal status. (70) An IGF-1 level > 0 SDS for gender and age specific range makes the GHD diagnosis highly unlikely (71) and it can be used as a screening tool for GHD. However, when IGF1 is found to be low, a series of other conditions need to be excluded (such as malnutrition, chronic diseases, hepatic diseases).

However, IGF-1 levels may be influenced by a series of other conditions, therefore an evaluation of $\mathrm{GH}$ reserve in the majority of cases is warranted. 
Page 79 of 120

Regarding growth hormone stimulation tests, in the absence of a "gold standard", it is impossible to precisely define the sensitivity and the specificity of any test for GHD. Insulin tolerance test (ITT) may be considered the gold standard for the evaluation of GH reserve, but its intrinsic risks hamper the definition of normal responses thresholds. Some information in specificity can be learned by comparing the results obtained in normal children. It is well known that within normal children and/or children with idiopatic short stature 10 to $25 \%$ will show a GH peak $<7 \mu \mathrm{g} / \mathrm{L}$ and up to $23-49 \%$ will have a peak < $10 \mu \mathrm{g} / \mathrm{L}$. (72) This may suggest that every individual stimulus may incorrectly classify almost half of the children as false positive GHD, if higher cut-offs are assumed. To this regard, an attempt of progressively reducing the diagnostic cut-off of GH peak by $7 \mu \mathrm{g} / \mathrm{L}$ has been recently proposed by the latest Growth Hormone Research Society Guidelines (33), githough the previous cutoff (at $10 \mathrm{mcg} / \mathrm{dL}$ ) has not been revised yet. Also in Italy, the cut off of $8 \mathrm{mcg} / \mathrm{dL}$ has just been confirmed in the latest revision of nota AIFA 39.

Sensitivity of GHST, can hence be deduced by comparing@ne positive test to the positive response of another investigation, for example correlating 10 ifF-1 concentrations to the failed results on GHST. However sometimes the tests can be diserepant and in this scenario it is difficult to determine whether this is due to the por sensitivit get the IGF-1 test or to the poor specificity of the GHSTs themselves.

To increase GHST specificity, sex steroids priming preparation should be performed before testing. However, in contrast with CDGP cohorts, sex steroid priming before growth hormone stimulation testing has been associated with conflicting benefits in the GHD cohorts in litterature. Even though in the already cited study of Molina primed GHD children were able to significantly increase GH mean peaks under clonidine stimulation test from $3.68 \pm 2.34$ to $5.95 \pm 2.76 \mathrm{ug} / \mathrm{l}$. (35), in the study performed by Martinez et al, GHD children did not significantly increase GH mean peaks under sequential arginine-clonidine test after estrogen priming (GH peak $3.1 \pm 2.4$ on placebo and $4.5 \pm 2.7$ 
Page 80 of 120

$\mu \mathrm{g} / \mathrm{L}$ on E2, NS), suggesting that the effect of priming is irrelevant in those patients with more severe forms of GHD, thus displaying lower GH peaks under stimuli. (34)

Because of the poor specificity and the low reproducibility of the GHST, the cardinal tool for a correct diagnosis is again a pathological short stature and/or growth deceleration (i.e. height $t<-2$ SDS, difference from target height $<-1.5$ SDS, growth velocity $<-2$ SDS) highlighted by clinical examination, considered to be the undeniable starting point. Pathological auxological criterias are in fact thought to increase the pre-test probability of GHD in children under investigation, expecially in those without any other risk factor (i.e. pathology including ectopic posterior pituitary and/or abnormality of the pituitary stalk, irradiation, at least other pituitary hormone deficiency or carrying a pathogenic genetic mutation), and in these patients two abnomal tests are frequently needed before GHD is diagnosed. (32) Instead, in a patient with pathologic auxological criteria, a normal GH peak in one test rules out GHD in most of the cases. However, as in some conditions (cranial irradiation, optic nerve hypoplasia, traumatic brain injury, or known genetic conditions) GHD may evolve over time, a second GHST is frequenty suggested at a rertime point. (33)

A Magnetic Resonance Imaging (MRI) of the hypothalamus and pituitary glands should be performed in all patients diagnosed with GHAD in order to rule out anatomical defects of the hypothalamicpituitary region or tumoral brain lesions. This is important for predicting the likelihood of other pituitary deficiencies, the utility of genetic testing and the probability of persistent GHD after attainment of final height. (33) In around $15 \%$ of cases an anatomic malformation of the hypothalamus-pituitary axis is found, but in the majority of the children, no cause can be identified and this group of patients are often referred as having idiopathic growth hormone deficiency (IGHD). (73) These children diagnosed as IGHD frequently carry transient forms of growth hormone deficiency during childhood and the rate of normal retesting has been found to be as high as $80 \%$ in many papers (see later). (74) (75) (76) (77) 
Page 81 of 120

Major anatomical abnormalities (including thin or interrupted hypophyseal stalk, suprasellar or intrasellar tumors invading the hypothalamus-pituitary anatomy) are known risk factors for multiple pituitary hormonal deficiencies (MPHDs) and of persistent GHD in adulthood. (74) (75) (78) Ectopic posterior pituitary with an otherwise normal anterior pituitary gland is also consider to increase by $26 \%$ the probability of adult persistent GHD (79). A small anterior pituitary, defined as a gland $<-2$ SDS of normal size using the few available standards for normal population categorized for age and gender (80) (81) (82), may incidentally be found on MRI. A hypoplastic anterior pitaitary gland by itself is not sufficient to diagnose GHD, but may indicate the need for a rnore extensive evaluation of the anterior pituitary function. (33) Pituitary size should be interpreted in the context of pubertal status. It is in fact well established in normal subjects that the pituitary gland increases its size during puberty (a phenomenon even more pronounced in females), reaching a plateau at approximately 20 years old, and a physiologic decline thereafter. (83)

Many Authors studying pituitary MRI of IGHD children have indeed found a significantly low volume of the pituitary gland compared to age-matened peers, speculating that there could be an association between anatomic and functional abnormalities, meaning that those patients with smaller pituitary glands may have a smaller somatotrophs volume thus secreting less growth hormone. (84)

\section{E GENETC TESTS}

The majority of patients with growth hormone deficiency is considered of idiopathic origin. Some isolated growth hormone deficiency are secondary to a genetic mutation within the GH gene locus named GH1 (IGHD type IA or IB ) or in its introns (IGHD type II), or may be transmitted as an Xlinked trait together with hypogammaglobulinemia (IGHD type III) (73).

An exome or a genome wide approach is nowadays thought to be the best diagnostic option, yet sometimes not available in clinical settings. A panel-oriented gene analysis for the most frequent 
Page 82 of 120

genes associated with GHD could be a reasonable approach. Some features are associated with a high pre-test probability of a genetic mutation: severe short stature at presentation $(<-3$ SDS from population or from target height), multiple pituitary hormonal deficiencies, anatomic alteration of the CNS, familial segregation with an autosomal dominant or recessive pattern or with a history of consanguinity. (33) Genes associated with GHD and shared with CDGP and cHH are illustrated in

\section{Figure 2.}

\section{F FINAL OUTCOMES AND THERAPEUTIC OPTIONS}

Even though growth hormone therapy has been given since 1958, starting with extracted GH from human pituitary glands, and then from 1980s with the use of the reconginant human GH (rhGH) technology, little is still known about its effect on adult height and gonflicting data exist on long-term studies, with some showing failure to reach the genetic midi-parental target height but others, by contrary, showing successful target height achievements. It is clear from reports that individual height response may vary considerably even with individualized treatment regimens, mainly depending on the chronological age at the start of theraps, on the severity of the GH deficiency after stimulation tests and on the stage of pubertal deveiopment. (86) (87) (88) (89) (90) (Table IV)

In fact, as a result of the lack of a uniformed cut-off limit for GHD, of the heterogeneity of the GHST used, and the fact that sex steroid priming is frequently not performed, it is not infrequent that a lot of these studies on IGHD children erroneously include also CDGP patients, who may present with short stature and pubertal delay. For this reason, outcomes reported in papers on final height of patients receiving rhGH treatment may vary widely and in some cases an overlap in terms of $\mathrm{FH}$ outcomes is seen with CDGP cohorts, expecially for CDGP girls or for CDGP boys treated with LDSS. (Tables III and IV) If very low growth outcomes are achieved after treatment with rhGH (SDS FH-IH around +1.2 only), possible other causes of short stature should be considered. (91) 


\begin{abstract}
Roughly, a standard substitutive dose of rhGH should be $25-35 \mu \mathrm{g} / \mathrm{kg} / \mathrm{die}$ but the dose of rhGH should then be individualized according to $\mathrm{GH}$ responsiveness aiming for the lowest dose able to induce a response in height velocity, possibly using prediction models. (92)
\end{abstract}

Retesting GH status at end of growth is currently recommended by the European Society for Pediatric Endocrinology guidelines for all patients with GHD except for those children with multiple $(\geq 3)$ pituitary hormone deficiencies regardless of the etiology, for GHD with a documented causal genetic mutation or specific pituitary/ hypothalamic structural defect. (32) To this extent, small pituitary glands are not considered as anatomic defects, since a high proportion of normalization at retesting in children with this condition has been demonstrated (74)

Guidelines differ on suggested cut-offs for GHD diagngsis during ransition under ITT test, with American guidelines using lower cut-offs $(5 \mu \mathrm{g} / \mathrm{L})$ (93) European Society for Pediatric Endocrinology guidelines suggesting a cut off of $5.6 \mu \mathrm{g} / \mathrm{t}-\mathrm{g}$ ) for immunometric assays, and GH Research Society guidelines suggesting a cut-off of 6 mg $/ \mathrm{L}$. (33)

Studies using standard cut orfs have confirmed that around two thirds of patients diagnosed as GHD during childhood-puberty, proved to have transient form of GHD. Tauber et al reported a $67 \%$ rate of normalization at retesting in IGHP patients, which was increased up to $71 \%$ in children previously diagnoseer as partial GHD (GH peak at diagnosis between 5-10 $\mu \mathrm{g} / \mathrm{L}$ ). (76) Moreover, a proportion of normalization of GH secretion in adulthood has been demonstrated as high as $87 \%$ for children with isolated IGHD of childhood onset (75).

Additionally, early retesting of children diagnosed as idiopathic GHD with a normal MRI has turned out to normalize in up to $85 \%$ in 1-6 months after diagnosis (95), and has been recommended. (96)

The reasons for the high proportion of patients who are apparently increasing their GH secretion at retesting are however likely to be multifactorial. Long-term exposure to sex steroids may increase 
pituitary size and GH secretion, some children may have had a form of transient GHD and, eventually, some others may have been incorrectly diagnosed as GHD, given the problems associated with biochemical testing outlined previously.

\section{Congenital Hypogonadotropic Hypogonadism}

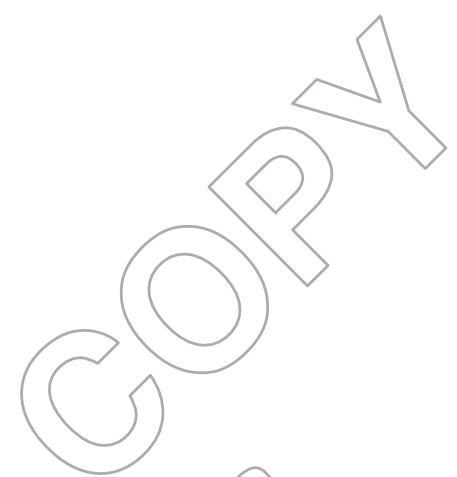

Congenital Hypogonadotropic Hypogonadism $(\mathrm{cHH})$ is an grganic and heterogenegus disease due to abnormal secretion or action of GnRH. It may be characteristically associated with an olfactory defect such as anosmia/hyposmia, the so called Kallmann syrirome (KS), or may occur in the context of normal olfaction, also known as normosmic $\mathrm{HH}(\mathrm{nHH})$. (2) The possible association with olfactory defects is related to the common embryonic grigins of the GnHR-secreting and olfactory neurons, which both migrate from the olfactory placode their final location in the brain through the cribriform plate of the ethmoid bone.

$\mathrm{cHH}$ is defined by the criteria of a prepubertal state at the age of $>14$ years and by a testicular volume not reaching a value of $\geq 5 \mathrm{~mL}$ during a 24-month follow-up despite a short trial with testosterone. A final differential diagnosis between CDGP is made if spontaneous puberty does not occur by the age of 18 years old. (44) However, the wait-and see approach is clearly not recommended because of the known psychosocial and medical issues associated with a pubertal delay already cited above.

\section{B PREVALENCE}

$\mathrm{cHH}$ is a rare disease with a frequency of 1:4000-6000 males with a 3-5:1 male:female sex ratio in tertiary centers. (97) The prevalence worldwide is difficult to determin, but it has been reported 
spanning from 1:10.000 to around 1: 86.0000, but when interpreting these findings methodological limitations of case ascertainment by medical record review should be kept in mind. (98) $\mathrm{cHH}$ may be familial or sporadic.

\section{C CLINICAL PRESENTATION}

A wide spectrum of phenotypes have been described.

- Complete cHH starting form foetal/neonatal life

- Complete $\mathrm{cHH}$ starting from the peripubertal period

- Partial cHH with an initial spontaneous drive of pubertal development but a subsequent sudden arrest (one third of the cases)

- Same as above with a reversal of GnRH secretion during adulthood famost $10 \%$ of the cases)

- Adult onset $\mathrm{cHH}$

The phenotype may vary accordingly in boys the presence of microphallus, mild hypospadias and/or (bilateral) cryptorchidism may indieate a complete defect of foetal/neonatal origin, whereas the absence of these signs but the lack of puberis to start or to progress till Tanner 5 may indicate either a complete peripuberatai form or a partial form of $\mathrm{cHH}$, respectively, which may be difficult to differentiate from self-liniting costitutional delay. In females the scenario is even less well-defined, since the foetal/neonatal phenotype of $\mathrm{cHH}$ females is still unknown and possibly indistinguishable from other phenotypes. Clinical features of $\mathrm{cHH}$ of peripubertal onset or of partial forms in females are again the absence/ the incomplete self progressing puberty and primary amenorrhea, both overlapping with CDGP females, and the presence of eunuchoid proportions. (97) Interestingly, in both sexes, gonadarche alone is found to be absent, whereas adrenarche and pubarche may be present. (25)

It is therefore clear that a complete physical examination considering limbs' asymmetry (ratio arm span/standing height $>1$, arm span $>6 \mathrm{~cm}$ of standing heightand for eunuchoid proportions, sitting 
height/leg lenght ratio $<0.8-1$ ) may orient clinicians towards $\mathrm{cHH}$ when disproportionateness is clinically detectable, taking available clinical chart for normal children as a reference. (99)

Short stature at pubertal age in $\mathrm{cHH}$ accounts for $40 \%$ of the cases, further rising complexity to the picture, however, an accurate analysis of the patient's growth chart may help in the diagnøsis. In boys with $\mathrm{cHH}$, in fact, height SDS does not differ to that of target potential till the first 5 years of life but a typical decreases at puberty occurs, with an inverse correlation with BMI, which is frequently found to be in the higher part of normal range. (30) Similar data on growth charts are however lacking in literature for $\mathrm{cHH}$ girls.

Apart from these specific endocrine phenotypes, other specific features, bothinearological and extraneurological, may be present. Associated neurologican phenotypes, include a defective smell sensation, sensorineural hearing loss, color blinaness (datonism), nystagmus and bimanual synkinesis (mirror movements). Hypo-Anosmia, that can be found in 50\% of the patients, is also a patognomonic sign of Kallman syndrome and may hetp in the diagnostic process. (2) The olfactory competence can be quantitatively tested with specific tests e.g. the University of Pennsylvania Smell Identification test (UPSIT) or the Brief-Smell Identification test (B-SIT). This evaluation is critical since many patients with es:H and hypo-anosmia are not aware of their defective sense of smell.

Other non-neurological signs are also described, such as midline defects (cleft lip/palate; arched palate), dentai abnormalities, renal agenesis/dysgenesis, syndactyly, polydactyly, camptodactyly, and metacarpal shortness. All of these features have to be carefully elicited during the physical examination of these patients and need to be considered all together because some of them can concomitate in GHD patients (Figure 2).

Moreover, a deep clinical examination must rule out syndromic conditions associated with hypogonadotropic hypogonadism. For example, the presence of morbid obesity and mental retardation should suggest Prader Willy Syndrome or Bardet-Biedl syndrome. The combination of 
coloboma, heart malformations, choanal atresia, growth retardation, genital anomalies should point out a diagnosis of CHARGE syndrome. The presence of $46 \mathrm{XY}$ sex reversal and primary adrenal insufficiency should suggest adrenal hypoplasia congenita secondary to NR0B1 mutation. The presence of other pituitary deficiencies and midline defects should suggest Septo Optic Dysplasia, or the rare Hartsfield syndrome or Gordon Holmes syndrome. (19) (97) The presence of ulnar forearm abnormalities, absence/hypoplasia of mammary and apocrine glands eventually associated with midline defects (i.e. hypoplastic anterior pituitary) or renal malformations in the proband or in a family member may suggest UMS. (31) (Figure 2)

\section{D ENDOCRINE WORKUP}

Basal gonadotropins levels are in the majority of the cases not diseriminative. For this reason, other basal endocrine markers had been investigated. Inhibin B, atprotein derived from gonadal tissues through FSH stimulation (seminiferous tabules of the testis or cortical layer of the ovaries), are thought to be lower in $\mathrm{cHH}$ than in other conditions secause of the absence of minipuberty in these patients able to trigger the differentiation either of Sertoli cells in males either of Granulosa cells in females. In males, a low inhibin B lever $s 35 \mathrm{pg} / \mathrm{mL}$ ) (40), or the combination of low Inhibin B levels $(10-49 \mathrm{pg} / \mathrm{mL})$ together with low testis volume $(<1 \mathrm{~mL})(22)$, seems to discriminate at best $(100 \%$ sensiti ity and specificity) $\mathrm{cHH}$ patients. Moreover, the combination of a low basal LH $(<0.3 \mathrm{IU} / \mathrm{L})$ and a low basal Inhibin $\mathrm{B}(<111 \mathrm{pg} / \mathrm{ml})$ has been proven to provide $100 \%$ sensitivity and $98 \%$ specificity for the $\mathrm{cHH}$ diagnosis, giving a valid and reliable alternative to dynamic and more invasive stimulations. (100) In females with $\mathrm{cHH}$, Inhibin B levels are however reported to be either low or normal compared to age-matched controls, therefore not discriminative. (42)

Stimulation test may also be helpful in the diagnostic process. GnRHa Triptorelin proved to have an excellent accuracy for the diagnosis of $\mathrm{cHH}$ if $\mathrm{LH}$ peaks prove to be lower than 5.3 U/L after 4 hours of pharmacological stimulation (100\% sensibility and specificity). (100) 
The hCG stimulation test has also been used for many years, primarily to assess the presence of functioning testicular tissue and to investigate defects of testosterone biosynthesis and action. It is based on the ability of hCG to increase androgen production in Leydig cells via stimulation of the LH receptor. Therefore, a blunted testosterone response to hCG stimulation test has been supposed as evidence towards a cHH diagnosis. However, many protocols have been used and large studies are lacking. Promising results have been assumed with longer protocols (19 days of stimulation proving to perform better than 3 days) (45) or higher doses (subsequent injections of 1500 UI of hCG in three consecutive days) (46). Combining the results of GnRH test stimulation and $\mathrm{hCG}$ test has also proved to differentiate $\mathrm{cHH}$ from CDGP with a sensibility and a specificity of $100 \%$ if $\mathrm{LH}$ peaks under LHRH test are $<2.8 \mathrm{U} / \mathrm{L}$, testosterone levels after 3 day hCG test are $\leqslant 3,6 \mathrm{nmol} / \mathrm{P}$ and testosterone levels after 19 days of hCG test are $<9.5 \mathrm{nmol} / \mathrm{L}$. (45)

\section{E GENETIC TESTING}

The pathogenesis of cHH, with or without hypo/anosmia, is a wide area of current research in endocrinology. A genetic basis of $\mathrm{cHH}$ arii be defined in almost 50\% of the cases. (97) The genetic heterogeneity of $\mathrm{cHH}$ is due to the fact that all modes of inheritance can occur: X-linked, autosomal recessive and autosomal dominant. Rising complexity to the picture, the traditional Mendelian view of inheritance has been revised following identification of oligogenic forms of $\mathrm{cHH}$ in at least $20 \%$ of the cases. (2) Moreover, a specific genotype-phenotype correlation is frequently lacking, as the penetrance is incomplete and the expressivity extremely variable, again possibly due to the oligogenic fashion of inheritance, although an involvement of environmental factors cannot be excluded. Many mutations in genes known to cause aberrations of the hypothalamic-pituitary-gonadal axis have been described. The mutations can be classified as either affecting GnRH action, GnRH secretion, GnRH neurons development and migration or GnRH neurons specification and/or activation, and many of them are shared with CDGP cohorts. Moreover, some mutation in genes responsible for hereditable 
Page 89 of 120

forms of MPHD or syndromic conditions have also been associated with both cHH and GHD. (97)

The genetic basis of $\mathrm{cHH}$ and shared causes with CDGP or GHD cohort are illustrated in Figure 1.

\section{F FINAL OUTCOMES}

For males, treatment is based on the use of testosterone esters given either by intramuscular or transdermal routes with subsequent gradual dose increase every 6 months until reaching, in around 36 months, the adult scheme. The use of testosterone, either injectable or transdermal, leads to good virilization but has little-no effect on testicular growth. Treatment for females with hypogonadism is based on the initial use of estrogens in the form of 173-estradio (preferable either trans dermally (fancied) or orally, or in the form of oral EE. Estrogen therapy must aiso be integrated with progestin therapy after at least 2 years (or earlier in the case of more tharpon significant bleeding episode) in order to avoid endometrial hypertrophy, The natural (i.e micronized) over the synthetic forms of progestins are preferred. A complete explanation of therapeutic protocols and doses is beyond the scope of this review but can be found in the recent review published by Raivio T. et al. (3) While testosterone replacement only causes virilization, treatment with recombinant FSH associated with hCG has been shown to induce testes growth, increase Inhibin B levels and stimulate spermatogenesis in adolescent males with $\mathrm{cHH}$. Moreover, an early treatment with gonadotropins has been suggested to have a positive effect on future fertility. (44) Also, as already mentioned, the observation of a self limiting pubertal progression at discontinuation of sex steroids therapy may point out a cHH rather than CDGP diagnosis. (3)

\section{EVIDENCE SYNTHESIS}

In every child referred for a suspected growth disorder, anthropometric measurements, medical history (with special attention to the so called "red flag", see Figure 2), full physical examination 
with special attention to dysmorphisms and disproportions, pubertal development and bone age assessment must be evaluated by the pediatric endocrinologist.

Regarding auxological measurements standing height, arm span, sitting height and leg length must be measured at every examination, with the use of a proper stadiometer and a tape-measure. At the same time pubertal stage must be evaluated by the use of Tanner charts, with the use of a proper orchidometer for boys. At this regard it is worth remembering that, even though in both sexes hair growth in the pubic area depends on adrenal secretion, clinically, a delayed gonadarche together with a delayed adrenarche and pubarche orients towards a CDGP diagnosis, whereas delayed gonadal development alone is a more peculiar presentation of $\mathrm{cHH}$ patients. (25)

Bone age is another important diagnostic tool. To this extent it is worth fiemembering that in every child, TW3 method and G\&P method may overestimate and unaerestimate bone age, respectively. (28) Moreover, because G\&P standards and TW standards were derived from white children living in the United States and predominantly of North European ancestry, the use of new automated methods is recommended for the assessment of children of other ethnicity groups. (27) Bone age is usually found to be delayed in relation to chronological age in all three CDGP, GHD and cHH patients. Even if many endocrine (hypothyroidism, rickets, Cushing disease, panhypopituitarism) and non-endocrine conditions (malnutrition, prematurity, cardiac, liver or kidney diseases, systemic inflammations or infections) may present with a delayed bone age, this assessment is considered a non-invasive and cost-effective method able to select those patients in which further testing are recommended. In fact, a great proportion of patients with non-endocrine short stature (familial short stature, skeletal dysplasia, idiopathic short stature) may be excluded from further testing because displaying a bone age equal or sometimes advanced compared to chronological age, or because manifesting straightforward signs of skeletal dysplasia on X-rays. Moreover, usually, a failure of spontaneous pubertal development at the bone age maturation of 12 and 13 years, in females and males respectively, may be indicative of an organic cause rather than CDGP. (28) 
Bone age is also a useful starting point to predict FH outcomes. (Table II) PAH may be helpful for the differential diagnosis, as it will end up laying in the lower end of target height for CDGP patients, be far way lower than TH in GHD children, hence higher than TH in cHH patients. (Table I).

Taken as a whole, self-limited delayed puberty is the most common cause of short stature and delayed puberty in both sexes in clinical practice, and the higher number of males that present to medical attention is thought to be a consequence of referral bias. According to the literature, we can expect to find an underlying secondary medical cause of poor growth/delayed puberty in up to $27 \%$ of boys and $57 \%$ of girls presenting to medical attention. (3) Chronic systemic illnesses and malnutrition (the so called "functional causes" of delayed puberty) and other causes of poor growipinust be ruled out by baseline blood exams including full blood count, liver function test, creatinine, celiac screen, thyroid function tests, IGF-1, PRL, LH/FSH, testosterone/estradiol levels. (25) At the same time, the evidence of syndromic stigmata may evoke a specific syndrônie phenotype or a contiguous gene syndrome. The targeted genome analysis and/or a standard karyotype together with an array-CGH may be useful investigations in these situations. Whan all these confounding phenotypes are ruled out, the diagnosis must be garried out through a step-by-step approach (Figure 3).

Useful information can firstly be taken from growth charts from infancy, at least in boys. CDGP boys soon after birth are known to display poor growth until 2 years old, then tend to level till 5 years old, starting from when a height SDS loss starts to be detectable reaching their nadir at puberty (26) and BMI is found to be concordantly low. (30) By contrast, in boys with GHD a continuous decrease in height SDS without any levelling is found from birth on and a severe short stature is frequently detected (68), together with an increase in fat mass (in patients left untreated). (30) In boys with cHH, instead, height SDS does not differ to that of target potential in the first 5 years of life but a typical decreases at puberty occurs, with an inverse correlation with BMI. (30) Special considerations must then be taken for girls, in which GV does not discriminate at best the different etiologies of delayed puberty. (22) 


\begin{abstract}
If cHH presents with pathognomonic "red flags" (e.g. anosmia, eunuchoid habitus, pituitary lesions, ulnar-mammary malformations) this should help in the diagnostic process, however many features seem to overlap with GHD cohorts, further mistakening the diagnosis (Figure 2) .
\end{abstract}

Anyway, not all peripubertal children with pathological causes of growth failure present to medical attention with short stature. If insufficient clues for a disturbed growth are found at the first screening, the patient can be put on watchful waiting. If clues for disturbed growth are highilghted, additional further investigations must be performed. A combination of short stature ( SDS $\mathrm{H}<-2.5)$, severe distance to target height $(\triangle \mathrm{SDS} H-\mathrm{TH}>-1.6)$ and growth deflection $(>0.5$ SDS/year or $>0.7 \mathrm{SDS} / 2$ years or $>1$ SDS/undefined time) should be used as practical guideline to decideshich child should be screened with a GHST. (17)

An important consideration must be taken for those children in which puberty may be anticipated: in this scenario growth velocity may be falsely reassuring because driven by pubertal hormones, but then a severe deviation from target height becomes evident after puberty completion if growth hormone deficiency concomits. For this reason patients at risk of having GHD (i.e. Cancer Survivors treated with surgery and/or total body radiation and/or chemotherapy) must be investigated with a growth hormonestimulation test regardless of height SDS and GV SDS. (33)

In terms of GHST, hypothalamic stimulation (hypoglycemia tolerance test, clonidine test, arginine test, glucagon test) are preferred rather than combined stimuli (i.e. GHRH+ arginine) in order to rule out possible hypothalamic causes of growth hormone deficiency. Moreover, priming with sex steroids before GHST is useful in order to increase diagnostic accuracy of the stimulation and reduce the false positive diagnosis of presumed peripubertal idiopathic GHD, at least for boys > 11 years old and for girls > 10 years old. (32) To this extent many protocols exist within different centers (39): the use of $100 \mathrm{mg}$ of testosterone enanthate intamuscolary 1 week before the test for boys, and $1-2 \mathrm{mg}(<20 \mathrm{~kg}$ or $>20 \mathrm{~kg}$ respectively) of valerate estradiol orally for girls for the three nights before the test may 
be considerered a reasonable scheme, even though oral estradiol preparations can also be used for boys if a less invasive route of administration is preferred. If GH peak under GHST is less than 7-8 $\mu \mathrm{g} / \mathrm{L}$ (with immunometric assays), especially under 2 different stimulations, the child is considered as having GHD and a pituitary MRI is warranted. If no tumoral lesions in the brain are found, rhGH therapy can be started at substitutive doses $(25-35 \mu \mathrm{g} / \mathrm{kg} / \mathrm{die})$ and the child must be followed up periodically in order to verify appropriate catch-up growth after rhGH is commenced. According to the severity of GHD and to the underlying cause, early retesting of GH secretion may be considered. (95) (96)

It is also worth mentioning that in terms of final height outcomes a lot of different ferults are described in literature for treated GHD patients, showing a FH SDS spanning betweeny -1.1 to -0.5 and $\triangle \mathrm{SDS}$ FH - TH concordantly ranging between -0.6 to +1.08 . For this. reason, itjs also very difficult to confirm the diagnosis backwards, as these results overlap mostly with those described in some CDGP cohorts (Tables III and IV). This is possibly due to the low specificity of GHST per se together with the fact that most of these studies were performed without ary priming preparation before stimulation, and as a result they might include also some false positive patients that could have possibly displayed normal GH peaks if sex steroids priming would had been performed.

If GH peaks prove instead to be higher than 7-8 $\mu \mathrm{g} / \mathrm{L}$ in at least one GHST, a diagnosis of CDGP or cHH may be expected. The differential diagnosis between these two conditions is however far from being straightforward, especially in the peripubertal age given the heterogeneity of these diseases and the tendency to overlap of one into another clinically, hormonally and genetically. (Figures $\mathbf{1}$ and 2).

Basal gonadotropin levels have limited diagnostic specificity as they tend to be low both in CDGP and $\mathrm{cHH}$ cohorts. Even if in some CDGP patients at the very beginning of puberty gonadotropins may be detectable $(\mathrm{LH}>0.2-0.3 \mathrm{U} / \mathrm{L}$ ), this picture again tends to overlap at least with partial forms of cHH. (43) 
Page 94 of 120

Galazzi \& Persani, 33

For this reason, dynamic stimulation of HPG axis has been proposed. A combination of LHRH test and hCG test (3days \& 19 days stimulation) has been proposed in order to increase sensitivity and specificity of cHH diagnosis by $100 \%$. (45)

At least in boys, Sertoli cell markers but not Leydig cells, growth or adrenal markers are $/$ considered helpful in establishing whether a boy with delayed puberty will progress spontaneously. (41) Inhibin B may provide a simple first-line test capable of identifying a subset of patients with delayed puberty who are highly likely to have $\mathrm{cHH}$. These test may be performed before a short period of treatment with LDSS, which is considered more indicative and helpful. In fact, an increase in growth velocity and in gonadal and breast development after a short course of 3-6 months of b895 can be taken as evidence against the presence of GHD or cHH. (3) (64) This treatment may at the same time be helpful for CDGP children in sensibilizating their anterior pituitary glands tosex steroids in order to allow puberty to trigger spontaneously, minimizing psychosocial distress of these patients compared to peers and avoiding the known long term metabolic and bone sequelae associated with delayed puberty. (2)

Finally, it is worth mentioning that as these conditions may overlap mostly in terms of genetic causes, this is not yet a field able th differentiate these conditions, even though some promising studies on specific genes selectively discovered in CDGP families have been recently published. (19) 
Page 95 of 120

Galazzi \& Persani, 34

\section{CONCLUSIONS}

After systemic chronic illnesses or other causes of "functional" delayed growth have been ruled out, CDGP may be the most probable cause of poor growth in a child presenting with short stature and delayed puberty, especially for boys. However the differential diagnosis between CDGP GHD and $\mathrm{cHH}$ is a challenging one for the clinician at the beginning of clinical examination, for many reasons. First, as already mentioned, children may present with the same auxological features (short stature, low growth velocity, delayed puberty, delayed bone age). Secondary, even if PAH may help, it is difficult to reliably trust the predicted adult height given the low aceuracy of different methods, especially if bone age is extremely delayed. Third, although the presence of a positive familial history of delayed puberty may give a cue towards a presumptive CDGP diagnosis, $\mathrm{cHH}$ cannot be excluded giving the high hetherogenity of $\mathrm{cHH}$ presentation within pedigrees. Fourth, because of the lack of sensibilization of the pituitary gland of thesechildren to detectable levels of sex steroids, peripubertal CDGP can display decresed GH/stimulation peaks ander GHST and lower IGF-1 levels compared with their pubertal, age-matched peers pointingout the need of further investigations in order to rule out a low pituitary growth hormene resere. For this reason we recommend the use of priming before GHST in every patient tested for Gith at least from the age of 10 years old (girls) or 11 years old (boys). A. treatment hormonal approach is also recommended afterwords for those patients with normal GH peaks under GHST in order to allow a correct differential diagnosis between CDGP and $\mathrm{cHH}$, being beneficial at the same time for psychosocial wellness, final height outcomes, sexual, bone and metabolic health. 


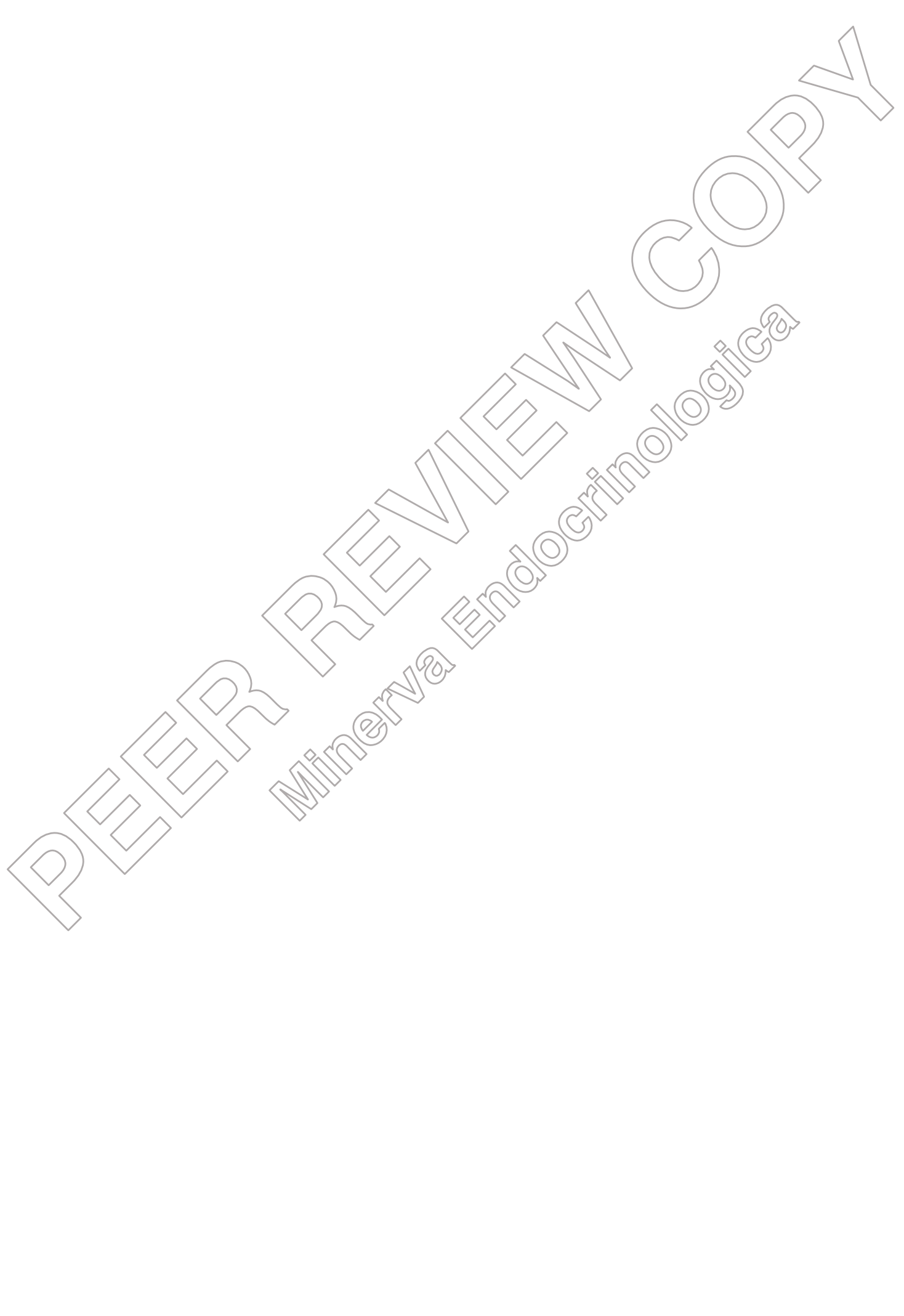




\section{REFERENCES}

1. Barinaga M, Yamonoto G, Rivier C, Vale W, Evans R, Rosenfeld MG. Transcriptional regulation of growth hormone gene expression by growth hormonereleasing factor. Nature 1983; 306(5938): 84-5.

2. Boehm U, Bouloux P-M, Dattani MT, de Roux N, Dodé C, Dunkel L, et al. Expert consensus document: European Consensus Statement on congerital hypogonadotropic hypogonadism--pathogenesis, diagnosis and treatment. Nat Rev Endocrinol 2015;11(9):547-64.

3. Raivio T, Miettinen PJ. Constitutional delay of puberty versus congenital hypogonadotropic hypogonadism. Genetics, managernent and updates. Best Pract Res Clin Endocrinol Metab 2019;33(3):1013-16.

4. Weissberger AJ, Ho KK. Activation of the somatotropic axis by testosterone in adult males: evidence for the role of aromatization. J Clin Endocrinol Metab 1993;76(6):1407-12.

5. Yeidinuis JD, Metzger DL, Martha PM, Mauras N, Kerrigan JR, Keenan B, et al. Estrogen and testosterone, but not a nonaromatizable androgen, direct network integration of the hypothalamo-somatotrope (growth hormone)-insulin-like growth factor I axis in the human: evidence from pubertal pathophysiology and sex-steroid hormone replacement. J Clin Endocrinol Metab 1997;3414-20.

6. Meinhardt UJ, Ho KKY. Modulation of growth hormone action by sex steroids. Clin Endocrinol (Oxf) 2006; 65(4):413-22.

7. Hartmann BW, Huber JC, Kirchengast S, Söregi, M.D. G, Albrecht AE. Effect of 
hormone replacement therapy on growth hormone stimulation in women with premature ovarian failure. Fertil Steril 1997; 68(1):103-7.

8. González-Parra S, Argente J, García-Segura LM, Chowen JA. Cellular Composition of the Adult Rat Anterior Pituitary Is Influenced by the Neonatal Sex Steroid Environment. Neuroendocrinology 1998;68(3):152-62.

9. Yan M, Jones MEE, Hernandez M, Liu D, Simpson ER, Chen C. Oestrogen Replacement in vivo Rescues the Dysfunction of Pituitary Somatotiopes in Ovariectomised Aromatase Knockout Mice. Neuroendocrinology 2005;81(3):158-66.

10. Mauras N, Rogol AD, Haymond MW, Veldínils JD. Sex steroides growth hormone, insulin-like growth factor-1: neuroendocrine and metabolic regulation in puberty. Horm Res 1996;45(1-2):74-80.

11. Albertsson-Wikland K, Rosberg S, Libre F, Lundberg LO, Groth T. Growth hormone secretory rates in children as estimated by deconvolution analysis of 24-h plasma concentration profiles. Am J Physior Metab. 1989;257(6):E809-14.

12. Giustina A, Scalvini T, Tassi C, Desenzani P, Poiesi C, Wehrenberg WB, et al. Maturation of the regulation of growth hormone secretion in young males with hypogonadotropic hypogonadism pharmacologically exposed to progressive increments in serum testosterone. J Clin Endocrinol Metab.1997;82(4):1210-9.

13. Mansfield MJ, Rudlin cCR, Crigler JF, Karol KA, Crawford JD, Boepple PA, et al. Changes in Growth and Serum Growth Hormone and Plasma Soipatomedin-C Levels During Suppression of Gonadal Sex Steroid Secretion in Girls with Central Precocious Puberty. J Clin Endocrinol Metab1988;66(1):3-9.

14. Marin G, Domené HM, Barnes KM, Blackwell BJ, Cassorla FG, Cutler GB. The 
effects of estrogen priming and puberty on the growth hormone response to standardized treadmill exercise and arginine-insulin in normal girls and boys. J Clin Endocrinol Metab 1994;79(2):537-41.

15. Wit JM, Ranke MB KC. International Classification of Paediatric Endocrine Diagnoses. Hormon Res. Pediatr. 2016; 86(3): 212-214.

16. Lawaetz JG, Hagen CP, Mieritz MG, Jensen MB, Petersen JH, Juul A. Evaluation of 451 Danish boys with delayed puberty: Diagnostic use of a new puberty nomogram and effects of oral testosterone therapy. J Clin Endocrinol Metab. 2015;100(4):137685.

17. Stalman SE, Hellinga I, Wit JM, Hennekam REM, Kamp GA, Plötz FB. Growth failure in adolescents: etiology, the role of pubertal iming and most useful criteria for diagnostic workup. J Pediatr Endecrino! Metab 2016;29(4):465-73.

18. Cassatella D, Howard SR, Acierno JS, XU C, Papadakis GE, Santoni FA, et al. Congenital hypogonadiotropic hypogonadism and constitutional delay of growth and puberty have distinci genetic.architectures. Eur J Endocrinol 2018;178(4):377-88.

19. Howard SR. The genetic basis of delayed puberty, Frontiers in Endocrinology. Frontiers Media S.A. 2019; (10): 423.

20. Reindollar RH, Rogers Byrd J, McDonough PG. Delayed sexual development: A study of 252 patients. Am J Obstet Gynecol 1981;140(4):371-80.

21. Grimberg A, Feemster KA, Pati S, Ramos M, Grundmeier R, Cucchiara AJ, et al. Medically underserved girls receive less evaluation for short stature. Pediatrics. 2011;127(4):696-702. 
22. Varimo T, Miettinen PJ, Känsäkoski J, Raivio T HM. Congenital hypogonadotropic hypogonadism, functional hypogonadotropism or constitutional delay of growth and puberty? An analysis of a large patient series from a single tertiary center. Hum Reprod 2017;32(1):147-53.

23. Wudy SA, Hagemann S, Dempfle A, Ringler G, Blum WF, Berthold LD, et al. Children with idiopathic short stature are poor eaters and have decreased body mass index. Pediatrics 2005; 116(1):52-7.

24. Han JC, Balagopal P, Sweeten S, Darmaun D, Mauras N. ㄷvidence for hypermetabolism in boys with constitutional delay of growth and maturation. J Clin Endocrinol Metab. 2006;91(6):2081-6.

25. Howard SR, Dunkel L. Delayed Puberty-Phenotypic Diversity, Molecular Genetic Mechanisms, and Recent Discoveries. Endocr Rev. 2019;40(5):1285-317.

26. Sedlmeyer IL, Palmert MR. Delayed guberty: analysis of a large case series from an academic center. J Clin Endocrino Metab 2002;87(4):1613-20.

27. Ren X, Li Y, Yang X, Wang S, Ahmad S, Xiang L, et al. Regression Convolutional Neural Network for Automated Pediatric Bone Age Assessment from Hand Radiograph. IEEE J Biomed Heal Informatics 2019;23(5):2030-8.

28. Creo AL, Schwenk WF. Bone age: A handy tool for pediatric providers Pediatrics. American Academy of Pediatrics 2017; 140(6):e20171486

29. Brämswig JH, Fasse M, Holthoff M-L, von Lengerke HJ, von Petrykowski W, Schellong G. Adult height in boys and girls with untreated short stature and constitutional delay of growth and puberty: Accuracy of five different methods of height prediction. J Pediatr 1990;117(6):886-91. 
30. Reinehr T, Hoffmann E, Rothermel J, Lehrian TJ, Brämswig J, Binder G. A New Model of Adult Height Prediction Validated in Boys with Constitutional Delay of Growth and Puberty. Horm Res Paediatr 2019;91(3):186-94.

31. Galazzi E, Duminuco P, Moro M, Guizzardi F, Marazzi N, Sartorio A, et al Hypogonadotropic hypogonadism and pituitary hypoplasia as recurrent features in ulnar-mammary syndrome. Endocr Connect. 2018;7(12) 1432-1441

32. Grimberg A, DiVall SA, Polychronakos C, Allen DB, Cohen LE, Quintos JB, et al. Guidelines for Growth Hormone and Insulin-Like Growth Factor-I Treatment in Children and Adolescents: Growth Hormone Deficiency, Idiopathio Short Stature, and Primary Insulin-Like Growth Factor-I Deficiency. Horm Res, Paediatr. 2017;86(6) 361-97.

33. Collett-Solberg PF, Ambler G, Backeljauw PF, Bijilingmaier M, Biller BMK, Boguszewski MCS, et al. Diagnosis, Genetics, and Therapy of Short Stature in Children: A Growth Hormone Research Society International Perspective. Horm Res Paediatr. 2019;92(1):1-14.

34. MartínezAS, Bomené tMM, Ropelato MG, Jasper HG, Pennisi PA, Escobar ME, et al. Estrogen Priming Effect on Growth Hormone (GH) Provocative Test: A Useful Too! for the Diagnosis of GH Deficiency. J Clin Endocrinol Metab. 2000:85(11):4168-72.

35. Molina S, Paoli M, Camacho N, Arata-Bellabarba G, Lanes R. Is Testosterone and Estrogen Priming Prior to Clonidine Useful in the Evaluation of the Growth Hormone Status of Short Peripubertal Children? J Pediatr Endocrinol Metab. 2008;21(3) 25766.

36. Müller G, Keller A, Reich A, Hoepffner W, Kratzsch J, Buckler JM, et al. Priming with 
Page 102 of 120

Testosterone Enhances Stimulated Growth Hormone Secretion in Boys with Delayed Puberty. J Pediatr Endocrinol Metab 2004;17(1) 77-83.

37. Soliman A, Adel A, Sabt A, Elbukhari E, Ahmed H, Sanctis V. Does priming with sex steroids improve the diagnosis of normal growth hormone secretion in short. children? Indian J Endocrinol Metab 2014;18(7):80-3.

38. Gonc EN, Kandemir N, Ozon A, Alikasifoglu A. Final heights of boys with normal growth hormone responses to provocative tests following priming. J Pediatr Endocrinol Metab 2008;21(10):963-71.

39. Murray PG, Dattani MT, Clayton PE. Controversies in the diagnosis and management of growth hormone deficiency in childhood and adolescence Archives of Disease in Childhood. 2016;101.96-100.

40. Coutant R, Biette-Demeneix E, Bouvattier $Q$, Bouhours-Nouet N, Gatelais F, Dufresne $S$, et al. Baseline inhibin B and anti-Mullerian hormone measurements for diagnosis of hyoggnadotropic hypogonadism $(\mathrm{HH})$ in boys with delayed puberty. J Clin Endocrinol Metáb 2010:95(12):5225-32.

41. Rohayern J, Nieschlag E, Kliesch S, Zitzmann M. Inhibin B, AMH, but not INSL3, IGF1 or DHEAS support differentiation between constitutional delay of growth and puberty and hypogonadotropic hypogonadism. Andrology 2015;3(5):882-7.

42. Li HWR, Anderson RA, Yeung WSB, Ho PC, Ng EHY. Evaluation of serum antimullerian hormone and inhibin B concentrations in the differential diagnosis of secondary oligoamenorrhea. Fertil Steril 2011;96(3):774-9.

43. Resende EAMR, Lara BHJ, Reis JD, Ferreira BP, Pereira GA, Borges MF. Assessment of Basal and Gonadotropin-Releasing Hormone-Stimulated 
Gonadotropins by Immunochemiluminometric and Immunofluorometric Assays in Normal Children. J Clin Endocrinol Metab 2007;92(4):1424-9.

44. Harrington J, Palmert MR. Clinical review: Distinguishing constitutional delay of growth and puberty from isolated hypogonadotropic hypogonadism: criticail appraisal of available diagnostic tests. J Clin Endocrinol Metab 2012;97(9):3056-67.

45. Segal TY, Mehta A, Anazodo A, Hindmarsh PC, Dattani MT. Role of GonadotropinReleasing hormone and human chorionic gonadotropin stimulation tests in differentiating patients with hypogonadotropic hypogonadism from those with constitutional delay of growth and puberty. J Clin Endocrinol Metab2009;94(3):7805.

46. Kauschansky A, Dickerman Z, Phillip M, Weintrob N, Strich D. Use of GnRH agonist and human chorionic gonadotrophin tests for differentiating constitutional delayed puberty from gonadotrophim deficiency in bove Clin Endocrinol (Oxf) 2002; 56(5) 603-7.

47. Chan YM, LippincottMF, Kusa fo, Seminara SB. Divergent responses to kisspeptin in children with delayed puberty. JCl insight. 2018;3(8) e99109.

48. Dunkel L, Quinton R. Transition in endocrinology: Induction of puberty. Vol. 170, European Journal of Endocrinology. BioScientifica Ltd. 2014; R229-39.

49. Sukumar SP, Bhansali A, Sachdeva N, Ahuja CK, Gorsi U, Jarial KDS, et al. Diagnostic utility of testosterone priming prior to dynamic tests to differentiate constitutional delay in puberty from isolated hypogonadotropic hypogonadism. Clin Endocrinol (Oxf) 2017;86(5):717-24.

50. Taha D, Mullis PE, Ibáñez L, De Zegher F. Absent or delayed adrenarche in Pit1/ 
POU1F1 deficiency. Horm Res 2005; 64(4):175-9.

51. Pugliese-Pires PN, Fortin JP, Arthur T, Latronico AC, Mendonca BB, Villares SMF, et al. Novel inactivating mutations in the $\mathrm{GH}$ secretagogue receptor gene in patients with constitutional delay of growth and puberty. Eur J Endocrinol 2011;165(2):23341.

52. Day FR, Elks CE, Murray A, Ong KK, Perry JRB. Puberty timing associated with diabetes, cardiovascular disease and also diverse health outcomes in men and women: The UK Biobank study. Sci Rep. 2015;(5):11208.

53. Bourguignon JP. Variations in duration of pubertal growth: aneechanism compensating for differences in timing of puberty and minimizing their effects on final height. Belgian Study Group for Paediatric Endocrinoiogy. Acta Paediatr Scand Suppl 1988;347:16-24.

54. Crowne EC, Shalet SM, Wallace WHEminson DM, Price DA. Final height in boys with untreated constitutional delay in growth and puberty. Arch Dis Child [Internet]. 1990;65(10):1 109-12.

55. Poyražoğluș, Günöz H, Darendeliler F, Saka N, Bundak R, Baș F. Constitutional delay of growth and puberty: From presentation to final height. J Pediatr Endocrinol Metab. 2005;18(2):171-9.

56. Couto-Silva AC, Trivin C, Adan L, Lawson-Body E, Souberbielle JC, Brauner R. Management of boys with short stature and delayed puberty. J Pediatr Endocrinol Metab 2005;18(8):807-13.

57. Zucchini S, Wasniewska M, Cisternino M, Salerno M, lughetti L, Maghnie M, et al. Adult height in children with short stature and idiopathic delayed puberty after 
different management. Eur J Pediatr 2008 Jun 24;167(6):677-81.

58. Martin MM, Martin ALA, Mossman KL. Testosterone treatment of constitutional delay in growth and development: effect of dose on predicted versus definitive height. Acta Endocrinol (Copenh) 1986;113(4_Suppl):S147-52.

59. Uruena M, Pantsiotou S, Preece MA, Stanhope R. Is testosterone therapy for boys with constitutional delay of growth and puberty associated with impaired final height and suppression of the hypothalamo-pituitary-gonadal axis? Eur J Pediatr 1992;151(1):15-8.

60. Kohva E, Varimo T, Huopio H, Tenhola S, Youtilainen R, Toppari J, et al. AntiMüllerian hormone and letrozole levels in boys yith constitutional delay of growth and puberty treated with letrozole or testosterone. fun Reprod 2020;35(2):257-64.

61. Stanhope R, Buchanan GR, Fenn GC, Preece MA. Double blind placebo controlled trial of low dose oxandrolone in the treatment of boys with constitutional delay of growth and puberty. Arch Dis Chiid 1988;63(5):501-5.

62. De Luca F Argente J, Cavallo L, Crowne E, Delemarre-Van de Waal HA, De Sanctis C, ei al. Management of Puberty in Constitutional Delay of Growth and Puberty. J Pediatr Endocrinol Metab 2001;14(s2):953-7.

63. Crowne EC, Shalet SM, Wallace WH, Eminson DM, Price DA. Final height in girls with untreated constitutional delay in growth and puberty. Eur J Pediatr 1991;150(10):708-12.

64. Kaplowitz PB. Diagnostic value of testosterone therapy in boys with delayed puberty. Am J Dis Child 1989;143(1):116-20. 
65. Chioma L, Papucci G, Fintini D, Cappa M. Use of testosterone gel compared to intramuscular formulation for puberty induction in males with constitutional delay of growth and puberty: a preliminary study. J Endocrinol Invest. 2018 Feb 1;41(2):259_ 63.

66. Overview | Human growth hormone (somatropin) for the treatment of growth failure in children | Guidance | NICE. [Internet]. Available from https://www.nice.org.uk/guidance/TA188 [cited 2020 January/29]

67. Murray PG, Clayton PE. Disorders of Growth Hormone in Childhood. In: Feingold KR, Anawalt B, Boyce A, et al., (Editors) Endotext. South Dartmoothe (MA): MDText.com, Inc.; 2000. Available from: https://www.ncbi.nlm.nih.gov/books/NBK278971

68. Rothermel J, Lass N, Toschke C, Reinehr T, Progressive decline in height standard deviation scores in the first 5 years of ife distinguished idiopathic growth hormone deficiency from familial short stature and constitutional delay of growth. Horm Res Paediatr. 2016;86(2):117-25.

69. Biczysko-Mokosa A, Petriczko E, Horodnicka-Józwa A, Dawid G, Kedzia A, Lewiński $A$, et al Evaluation of final height prediction and selected parameters in Polish patients with severe and partial growth hormone deficiency. Neuro Endocrinol Lett. $2014 ; 35(3): 242-7$.

70. Inoue-Lima TH, Vasques GA, Scalco RC, Nakaguma M, Mendonca BB, Arnhold IJP, et al. IGF-1 assessed by pubertal status has the best positive predictive power for GH deficiency diagnosis in peripubertal children. J Pediatr Endocrinol Metab. 2019 Feb 1;32(2):173-9.

71. Blum WF, Alherbish A, Alsagheir A, El Awwa A, Kaplan W, Koledova E, et al. The 
growth hormone-insulin-like growth factor-I axis in the diagnosis and treatment of growth disorders. Endocrine Connections. BioScientifica Ltd. 2018;(7):R212-22.

72. Ghigo E, Bellone J, Aimaretti G, Bellone S, Loche S, Cappa M, et al. Reliability of provocative tests to assess growth hormone secretory status. Study in 472 normally growing children. J Clin Endocrinol Metab 1996;81(9):3323-7.

73. Giordano M. Genetic causes of isolated and combined pituitary hormone deficiency. Best Pract Res Clin Endocrinol Metab2016;30(6):679-91.

74. Léger J, Danner S, Simon D, Garel C, Czernichow D. Do all patients with childhoodonset growth hormone deficiency (GHD) and ectopic neuroriypophysis have persistent GHD in adulthood? J Clin Endocringl Metab 2005;90(2):650-6.

75. Quigley CA, Zagar AJ, Liu CC, Brown DM, Husernan C, Levitsky L, et al. United States multicenter study of factors predicting the persistence of $\mathrm{GH}$ deficiency during the transition period between childhood and adulthood. Int J Pediatr Endocrinol 2013;(1):6.

76. Tauber M, Moulin P, Pienkowski C, Jouret B, Rochiccioli P. Growth hormone (GH) retesting and auxological data in $131 \mathrm{GH}$-deficient patients after completion of treatment. J Clin Endocrinol Metab 1997;82(2):352-6.

77. Toogood A, Shalet S. Diagnosis of severe growth hormone (GH) deficiency in young adults who received $\mathrm{GH}$ replacement therapy during childhood. Acta Paediatr 1997;86(S423):117-20.

78. Donaubauer J, Kiess W, Kratzsch J, Nowak T, Steinkamp H, Willgerodt H, et al. Reassessment of growth hormone secretion in young adult patients with childhoodonset growth hormone deficiency. Clin Endocrinol (Oxf) 2003;58(4):456-63. 
79. Murray PG, Hague C, Fafoula O, Gleeson H, Patel L, Banerjee I, et al. Likelihood of persistent $\mathrm{GH}$ deficiency into late adolescence: relationship to the presence of an ectopic or normally sited posterior pituitary gland. Clin Endocrinol (Oxf) 2009;71(2):215-9.

80. Yadav P, Singhal S, Chauhan S, Harit S. MRI evaluation of size and shape of normal pituitary gland: age and sex related changes." J Clin Diagn Res 2017 TC01TC04.

81. Argyropoulou M, Perignon F, Brunelle F, Brauner R, Rappaport R. Height of normal pituitary gland as a function of age evaluated by magnetic resonance imaging in children. Pediatr Radiol 1991;21(4):247-9.

82. Han X, Xiu J, Huang Z, Zhang J, Zhang Z, Dong Y, êl al. Three-dimensional magnetic resonance volumetry of the pituitary gland is effective in detecting short stature in children. Exp Ther Med 2014;8(2):551-6.

83. Doraiswamy PM, Potts JM, Axelson DA, Husain MM, Lurie SN, Na C, et al. MR assessment of pituitary gland morphology in healthy volunteers: age- and genderrelated differences. AJNR Am J Neuroradiol;13(5):1295-9.

84. Kessler M, Tenner M, Frey M, Noto R. Pituitary volume in children with growth hormone deficiency, idiopathic short stature and controls. J Pediatr Endocrinol Metab 2016;29(10):1195-200.

85. Maghnie M, Lindberg A, Koltowska-Häggström M, Ranke MB. Magnetic resonance imaging of CNS in 15043 children with GH deficiency in KIGS (Pfizer International Growth Database). Eur J Endocrinol 2013;168(2):211-7.

86. Kriström B, Aronson AS, Dahlgren J, Gustafsson J, Halldin M, Ivarsson SA, et al. 
Growth Hormone (GH) Dosing during Catch-Up Growth Guided by Individual Responsiveness Decreases Growth Response Variability in Prepubertal Children with GH Deficiency or Idiopathic Short Stature. J Clin Endocrinol Metab 2009;94(2):483-90.

87. Reiter EO, Price DA, Wilton P, Albertsson-Wikland K, Ranke MB. Effeet of growth hormone $(\mathrm{GH})$ treatment on the near-final height of 1258 patients with iciopathic $\mathrm{GH}$ deficiency: analysis of a large international database. J Clin E.ndocrino Metab 2006;91(6):2047-54.

88. Cutfield W, Lindberg A, Wikland KA, Chatelain P, Ranke M, Wilton Final height in idiopathic growth hormone deficiency: the KIGS experience. Acia Paediatr 1999;88(s428):72-5.

89. Blethen SL, Baptista J, Kuntze J, Foley T, LaFranchi S, Johanson A. Adult Height in Growth Hormone (GH)-Deficient Children Treated with Biosynthetic GH. J Clin Endocrinol Metab 1997;82(2):418-20.

90. Pozzobon G, Partenope C, Mora S, Garbetta G, Weber G, Barera G. Growth hormone therapy in children predictive factors and short-term and long-term response criteria. Endocrine 2019; 66(3):614-621

91. Deodati A, Cianfarani S. Impact of growth hormone therapy on adult height of children with idiopathic short stature: systematic review. BMJ 2011;(342):c7157.

92. Wit JM, Ranke MB, Albertsson-Wikland K, Carrascosa A, Rosenfeld RG, Van Buuren S, et al. Personalized approach to growth hormone treatment: Clinical use of growth prediction models. Vol. 79, Hormone Research in Paediatrics. Horm Res Paediatr; 2013; 257-70. 
93. Yuen KCJ, Biller BMK, Radovick S, Carmichael JD, Jasim S, Pantalone KM, et al. American association of clinical endocrinologists and american college of endocrinology guidelines for management of growth hormone deficiency in adults and patients transitioning from pediatric to adult care. Endocr Pract 2019;25(11):1191-232.

94. Grimberg A, DiVall SA, Polychronakos C, Allen DB, Cohen LE, Quirasos JB, et al. Guidelines for Growth Hormone and Insulin-Like Growth Factor-I Treatment in Children and Adolescents: Growth Hormone Deficiency, Idiopathic Short Stature, and Primary Insulin-Like Growth Factor-I Deficiency. Horm Rês Paediatr 2016;86(6):361-97.

95. Loche S, Bizzarri C, Maghnie M, Faedda A, Tzialla C, Auteili M, et al. Results of early reevaluation of growth hormone secretion in short children with apparent growth hormone deficiency. J Pediati 2002;140(4) 44 5-9.

96. Vuralli D, Gonc EN, Ozon ZA, Alikasifogiu A, Kandemir N. Clinical and laboratory parameters predicting a requiremen for the reevaluation of growth hormone status during growth hormone treatmen: Retesting early in the course of $\mathrm{GH}$ treatment. Growth HormigF Res 20 17:34.31-7.

97. Cangiano B, Swee DS, Quinton R, Bonomi M. Genetics of congenital hypogonadotropic hypogonadism: peculiarities and phenotype of an oligogenic disease. Hum Genet 2020 [Epub ahead of print].

98. Fraietta R, Zylberstejn DS, Esteves SC. Hypogonadotropic Hypogonadism Revisited. Clinics 2013;68(Suppl 1):81.

99. Fredriks AM, Van Buuren S, Van Heel WJM, Dijkman-Neerincx RHM, Verloove- 
Vanhorick SP, Wit JM. Nationwide age references for sitting height, leg length, and sitting height/height ratio, and their diagnostic value for disproportionate growth disorders. Arch Dis Child. 2005;90(8):807-12.

100. Binder G, Schweizer R, Blumenstock G, Braun R. Inhibin B plus LH vs GriRH agonist test for distinguishing constitutional delay of growth and puberiy from isolated hypogonadotropic hypogonadism in boys. Clin Endocrino ( $(0 \times f) 2015$ ;82(1):100-5. 
Page 112 of 120

\section{NOTES}

Conflicts of interest- The Authors certify that there is no conflict of interest with any financial organization regarding the material discussed in the manuscript.

Funding-This work was supported by Ricerca Corrente funds of Istituto Auxologico Italiano (codes: 05F401_2014 and 02C502_2005).

Authors' contributions. - E.G. conducted the literature review and prepared the manuscript. L.P. performed the critical revision of the manuscript. All authors read and approved the submitted version. 
Page 113 of 120

\section{TABLES}

Table I - Clinical differences between CDGP, GHD and cHH at presentation (2) (3) (15) (16) (17) (18) (25) (26) (29) (30) (33) (44) (67) (68) (97) (99)

\begin{tabular}{|c|c|c|c|}
\hline & CDGP & GHD & cHH \\
\hline $\begin{array}{l}\text { Initial Height } \\
\text { (SDS) }\end{array}$ & $>-2.5$ & any & $\begin{array}{l}>-2.5 ; 60 \% \text { of the } \\
\text { cases has normal } \\
\text { height }\end{array}$ \\
\hline Growth velocity & $\begin{array}{l}\text { Prepubertal, } \\
\text { concordant with } \\
\text { bone age }\end{array}$ & $\begin{array}{l}\text { Extremely } \\
\text { reduced }\end{array}$ & Prepubertal \\
\hline BMI & Reduced & Increased & $\begin{array}{l}\text { Normalor } \\
\text { increased }\end{array}$ \\
\hline Bone Age (BA) & $\begin{array}{l}\text { Delayed by 1-3 } \\
\text { years }\end{array}$ & $\begin{array}{l}\text { Frequently } \\
\text { delayed; possible } \\
\text { rare cases of } \\
\text { normak'advarced } \\
\text { BA for CA if } \\
\text { sudden GHD } \\
\text { onset occurs or } \\
\text { precocious } \\
\text { puberty coexists }\end{array}$ & \\
\hline $\begin{array}{l}\text { Predicted Adult } \\
\text { Height (PAH) }\end{array}$ & $\begin{array}{l}\text { Lower limit } \\
\text { TH }\end{array}$ & $<\mathrm{TH} \ll$ & $>\mathrm{TH}$ \\
\hline $\begin{array}{l}\text { Past history } \\
\text { illness }\end{array}$ & $\begin{array}{l}\text { Sometimes } \\
\text { cryptorchidism } \\
\text { (unilateral) or } \\
\text { phimosis }\end{array}$ & $\begin{array}{l}\text { Neonatal } \\
\text { aypoglycemia, } \\
\text { prolonged } \\
\text { jaundice, } \\
\text { micropenis, } \\
\text { midline defects }\end{array}$ & $\begin{array}{l}\text { "Red flags": } \\
\text { cryptorchidism } \\
\text { (bilateral), } \\
\text { micropenis, } \\
\text { hypospadias, } \\
\text { renal anomalies, } \\
\text { midline defects, } \\
\text { hypo/anosmia }\end{array}$ \\
\hline Family history & $\begin{array}{l}\text { positive for } \\
\text { CDGP in } 80 \% \text { of } \\
\text { the cases }\end{array}$ & $\begin{array}{l}\text { Parent's } \\
\text { consanguinity; } \\
\text { one family } \\
\text { member affected } \\
\text { if secondary to a } \\
\text { specific mutation }\end{array}$ & $\begin{array}{l}\text { One family } \\
\text { member affected } \\
\text { or presenting } \\
\text { hypo/anosmia or } \\
\text { neurologic } \\
\text { diseases or } \\
\text { history of CDGP }\end{array}$ \\
\hline
\end{tabular}

Table note:

$B M I=$ body mass index,$P A H=$ predicted adult height, $B A=$ bone age, $C A=$ chronological age, $T H=$ target height . 
1 Table II - Differences of five methods of adult height prediction (PAH) in terms of over-

5

6

\begin{tabular}{|c|c|c|}
\hline Method of PAH & boys & girls \\
\hline Bayley and Pinneau & $+3.1 \mathrm{~cm}$ & $-0.8 \mathrm{~cm}$ \\
\hline $\begin{array}{l}\text { Roche-Weiner-Thissen } \\
\text { (RWT) }\end{array}$ & $-0.6 \mathrm{~cm}$ & $+2.3 \mathrm{~cm}$ \\
\hline $\mathrm{TH}$ & $+1.7 \mathrm{~cm}$ & $+1.2 \mathrm{~cm}$ \\
\hline $\begin{array}{l}\text { Tanner-Whitehouse Mark I } \\
\text { (TW-MI) }\end{array}$ & $-7.3 \mathrm{~cm}$ & $-2.1 \mathrm{~cm}$ \\
\hline $\begin{array}{l}\text { Tanner-Whitehouse Mark II } \\
\text { (TW-MII) }\end{array}$ & $-4.2 \mathrm{~cm}$ & $-1.8 \mathrm{~cm}$ \\
\hline
\end{tabular}


Page 115 of 120

Galazzi \& Persani, 54

Table III-Final height (FH) in CDGP boys and girls considering their possible treatment with low dose sex steroids (54) (55) (56) (57) (63)

\begin{tabular}{|c|c|c|c|c|c|}
\hline & $\begin{array}{l}\text { SDS FH } \\
\text { untreated } \\
\text { patients }\end{array}$ & $\begin{array}{l}\text { SDS FH } \\
\text { treated } \\
\text { patients }\end{array}$ & SDS TH & $\begin{array}{l}\Delta \text { SDS } \\
\text { FH -TH }\end{array}$ & $\begin{array}{l}\text { SDS FH } \\
\text { reference } \\
\text { population }\end{array}$ \\
\hline \multicolumn{6}{|c|}{ BOYS } \\
\hline $\begin{array}{l}\text { Crowne et al, } \\
\text { EJP, } 1991 \\
(n=43)\end{array}$ & -1.6 & n. $r$. & -0.6 & -1 & n. $r$ \\
\hline $\begin{array}{l}\text { Poyrazoglu et } \\
\text { al, JPEM } 2005 \\
(\mathrm{n}=30)\end{array}$ & -2.3 & n. $r$. & n. $r$. & & +0.12 \\
\hline $\begin{array}{l}\text { Couto-Silva et } \\
\text { al, JPEM } 2005 \\
(\mathrm{n}=70)\end{array}$ & -0.7 & -1.2 & n. $r$ & n. $r$. & n. $r$. \\
\hline $\begin{array}{l}\text { Zucchini et al, } \\
\text { EJP } 2008 \\
(\mathrm{n}=29)\end{array}$ & -1.02 & -1.39 & $\begin{array}{l}-1.12 \\
\text { untreated } \\
\text { patients; } \\
-1.45 \text { trea } \\
\text { patients }\end{array}$ & $\begin{array}{l}+0.1 \\
\text { patients; } \\
+0.43 \\
\text { treated } \\
\text { patients }\end{array}$ & n. $r$. \\
\hline \multicolumn{6}{|c|}{ GIKLS } \\
\hline $\begin{array}{l}\text { Crowne et al, } \\
\text { EJP, } 1991 \\
(n=15)\end{array}$ & -1.5 & $n \cdot r$ & -0.8 & -0.7 & n. $r$. \\
\hline $\begin{array}{l}\text { Zucchini et al, } \\
\text { EJP } 2008 \\
(n=16)\end{array}$ & -0 & 12. $r$. & -0.88 & +0.1 & n. $r$. \\
\hline
\end{tabular}

Table note: n.r. $=$ not reported 
Table IV - Final height (FH) in GHD boys and girls treated with rhGH at substitutive doses. (86) (87) (88) (89) (90)

\begin{tabular}{|l|l|l|l|}
\hline & FH SDS & $\Delta$ SDS FH -IH & $\Delta$ SDS FH -TH \\
\hline $\begin{array}{l}\text { Reiter E.O. et al } \\
(\mathrm{n}=1258)\end{array}$ & $-0.8\left(\mathrm{O}^{\Uparrow}\right) ;-1(+)$ & n.r. & From -0.6 to +0.2 \\
\hline $\begin{array}{l}\text { Cutfield et al } \\
(\mathrm{n}=369)\end{array}$ & -1.5 & +1.7 & -0.5 \\
\hline $\begin{array}{l}\text { Genentech American } \\
\text { group } \\
(\mathrm{n}=121)\end{array}$ & $-0.7 \pm 1.2$ & n.r. & \\
\hline $\begin{array}{l}\text { Pozzobon et al } \\
(\mathrm{n}=94)\end{array}$ & -1.11 & From +1.85 to +1.39 & $\begin{array}{l}\text { From }+0.11 \pm 0.80 \text { to } \\
+0.26 \pm 0.82\end{array}$ \\
\hline
\end{tabular}

Table note: $n . r .=$ not reported 
Page 117 of 120

Galazzi \& Persani, 56

\section{TITLES OF FIGURES}

Figure 1. - Genetic bases of CDGP, GHD and cHH and shared causes.

Figure 2. - Red Flags for cHH. Note that most of these features are shared with GHD and, in a minority of cases, with CDGP.

Figure legend:

ONH = Optic nerve hypoplasia

SOD = Septo optic dysplasia

$H P E=$ holoprosencephaly

$E P P G=$ ectopic posterior pituitary gland

PSIS = pituitary stalk interruption syndrome

MPHD = multiple pituitary hormonal deficiencies

CHARGE = Coloboma, Heart defects, Atresia of choanae, Retasdation of growth, Ear abnormalities

Figure 3. - Diagnostic algorith nor the differential diagnosis between CDGP, GHD and cHH

Figure legend

- GHST = growth hormone stimulation test; Criteria for GHST: SDS H<-3 or $\triangle S D S T H-I H$ $<1.5 \& G V<1$

- LDSS = low dose sex steroids yor example testosterone enanthate im 25-50 mg/monthly for boys for 6 months or oestrudiol patches $12.5 \mu \mathrm{g}$ twice weekly for girls for 6 months

*Exampie of priming protocol before GHST: Testosterone enanthate $100 \mathrm{mg}$ im 7 days before the test for boys; E2 Valerate 1-2 mg orally (if <20 kg or > $20 \mathrm{~kg}$ respectively) 3 days before the test for girls.

** Supportive endocrine markers (for boys):

- Inhibin B $<35$ ng/L for Tanner stage 1; < $65 \mathrm{ng} / \mathrm{L}$ for Tanner stage 2

- $A M H<20 \mathrm{ng} / \mathrm{mL}$

- LH peak under GnRH test or GnRHa < 4-5 UI/L

- Testosterone levels $<3.6 \mathrm{nmol} / \mathrm{L}$ after 3 days or $<9.5 \mathrm{nmol} / \mathrm{L}$ after 19 days of hCG test 
Page 118 of 120

1

2

3

4

5

6

7

8

9

10

11

12

13

14

15

16

17

18

19

20

21

22

23

24

25

26

27

28

29

30

31

32

33

34

35

36

37

38

39

40

41

42

43

44

45

46

47

48

49

50

51

52

53

54

55

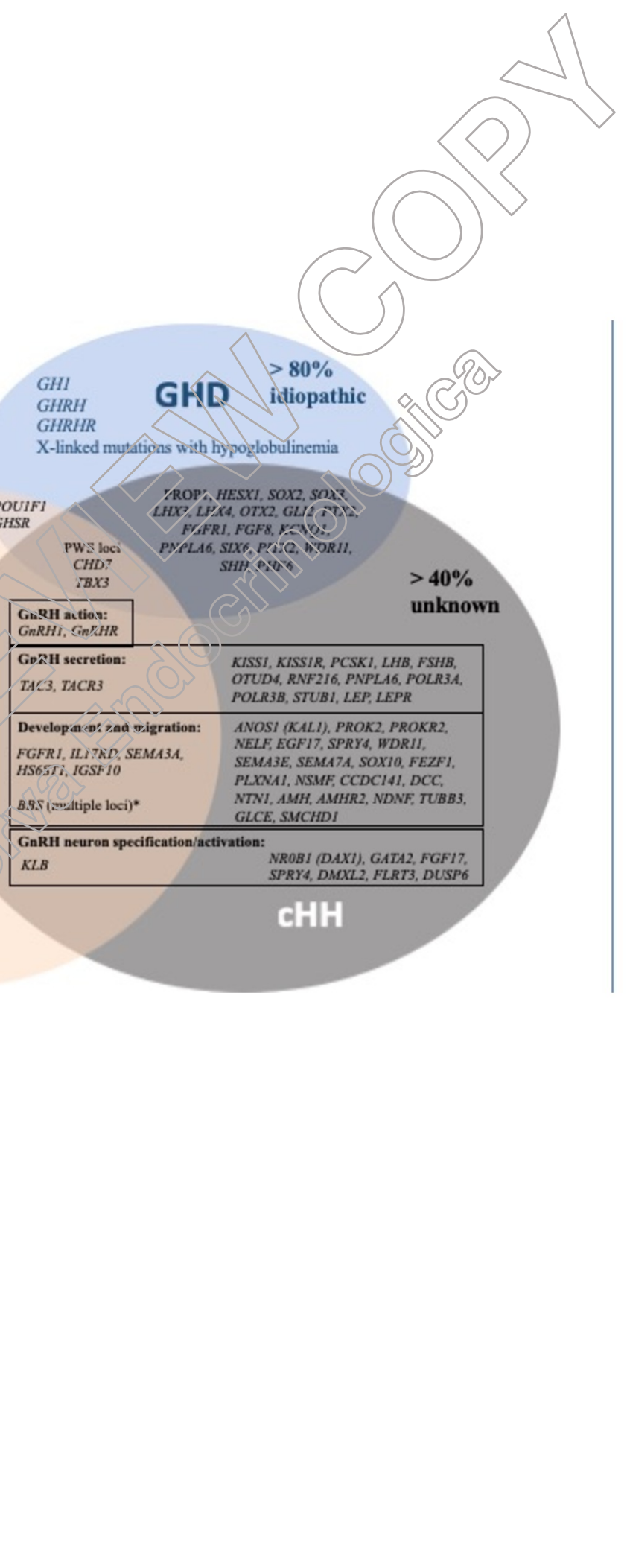


Page 119 of 120 
Page 120 of 120

1

2

3

4

5

6

7

8

9

10

11

12

13

14

15

16

17

18

19

20

21

22

23

24

25

26

27

28

29

30

31

32

33

34

35

36

37

38

39

40

41

42

43

44

45

46

47

48

49

50

51

52

53

54

55

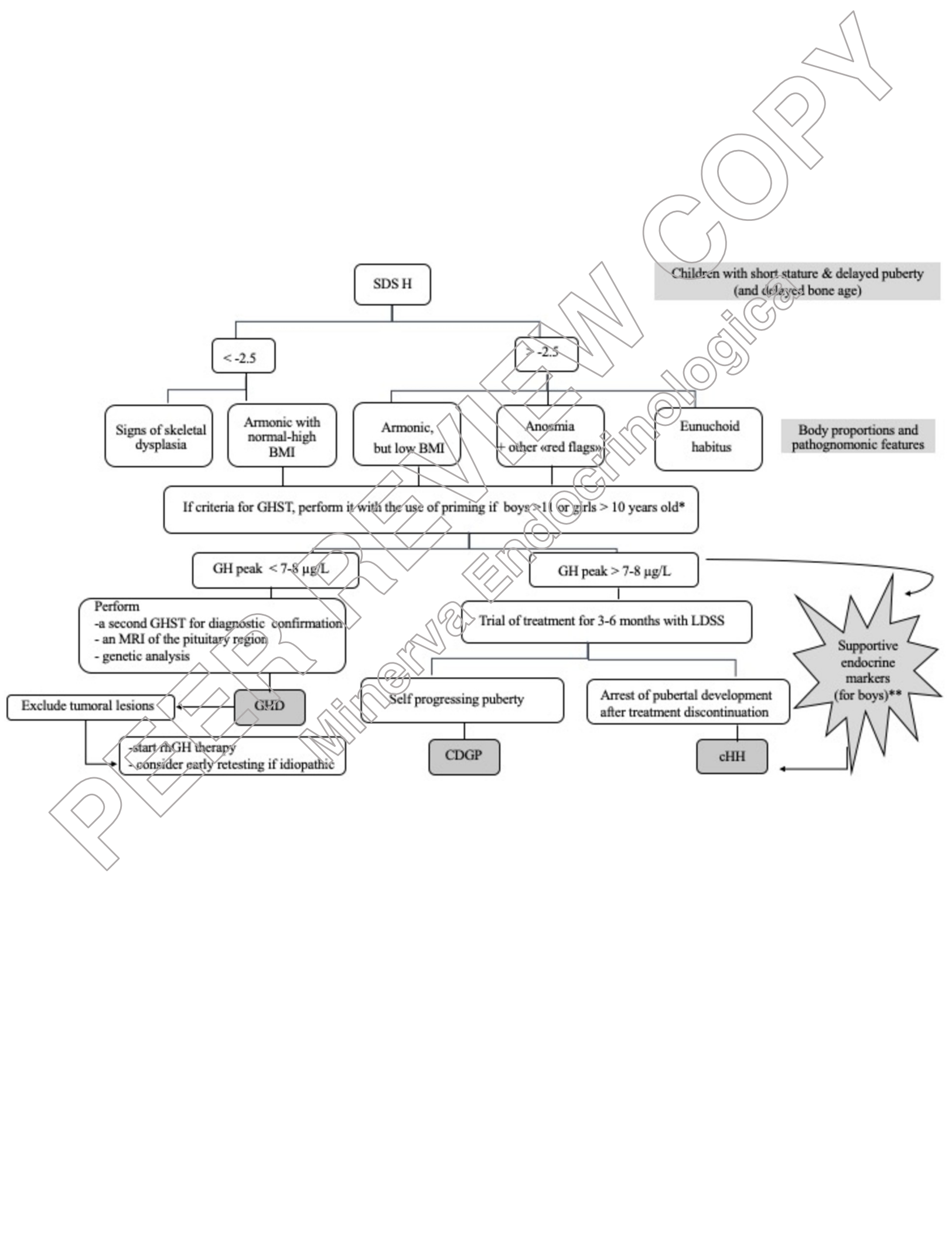

